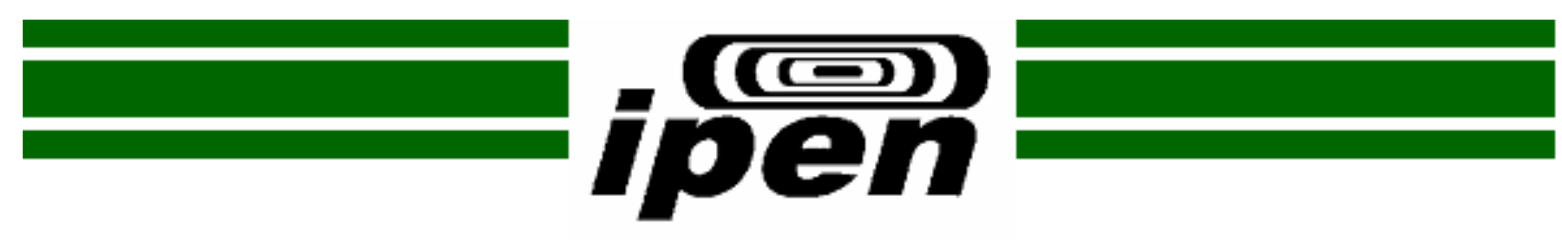

AUTARQUIA ASSOCIADA À UNIVERSIDADE DE SÃO PAULO

\title{
DESENVOLVIMENTO DE UM GUIA ORIENTATIVO PARA DOSIMETRIA EM TOMOGRAFIA COMPUTADORIZADA
}

\author{
Ladyjane Pereira Fontes
}
Dissertação apresentada como parte dos requisitos para obtenção do Grau de Mestre em Ciências na Área de Tecnologia Nuclear - Aplicações.

Orientadora:

Dra. Maria da Penha A. Potiens

\section{SÃO PAULO}

2016 
INSTITUTO DE PESQUISAS ENERGÉTICAS E NUCLEARES

AUTARQUIA ASSOCIADA À UNIVERSIDADE DE SÃO PAULO

\title{
DESENVOLVIMENTO DE UM GUIA ORIENTATIVO PARA DOSIMETRIA EM TOMOGRAFIA COMPUTADORIZADA
}

\author{
Ladyjane Pereira Fontes
}

Dissertação apresentada como parte dos requisitos para obtenção do Grau de Mestre em Ciências na Área de Tecnologia Nuclear - Aplicações.

Orientadora:

Dra. Maria da Penha A. Potiens

SÃO PAULO

2016 
À Deus, meu refúgio e fortaleza e aos meus pais, Ulisses e Jeane, por sempre apoiar e incentivar os meus projetos. Amo vocês. 
"Não te mandei eu? Esforça-te, e tem bom ânimo; não temas, nem te espantes; porque o Senhor teu Deus é contigo, por onde quer que andares"

Josué 1.9 


\section{AGRADECIMENTOS}

À Deus que me concedeu a graça de chegar até aqui e realizar mais um sonho.

À Dra. Maria da Penha A. Potiens, pela paciência, dedicação e carinho durante a orientação deste trabalho.

Ao Dr. Vitor Vivolo, pela disposição em contribuir com seu conhecimento para a execução deste trabalho.

À Dra. Denise Yanikian Nersissian, pela oportunidade de aprender sobre Dosimetria em Tomografia Computadorizada e realização de trabalho de campo.

À Dra. Ana Figueiredo Maia pelo apoio e disponibilidade em contribuir na execução deste trabalho.

À Marcela Alcântara, sempre prestativa e atenciosa, contribuindo no aprendizado e realização do trabalho de campo.

Ao Físico Luís Eduardo Andrade Macedo, pela grande contribuição em conhecimento, apoio e oportunidade de estágio que me proporcionou o ingresso no mestrado.

Ao Dr. Cássio Costa Ferreira, pela disposição em contribuir para a execução deste trabalho.

Ao IPEN-CNEN/SP, pela infraestrutura para execução deste trabalho e apoio financeiro.

À Empresa MRA pelo empréstimo da câmara de ionização do tipo lápis utilizada neste trabalho.

Aos funcionários da Oficina do IPEN, em especial ao senhor Sérgio Sá.

Aos colegas do IPEN: em especial a Nathalia, Daniela, Fábio, Shirlane, Lílian, Daniel, Maria e todos os alunos e funcionários do GMR, que de maneira direta ou indireta contribuíram para a realização deste trabalho.

À amiga Jamille Almeida, pela parceria e apoio durante o mestrado e na vida.

À Joseane Pereira, pela acolhida e apoio fundamental durante a minha mudança para São Paulo. Não tenho palavras para agradecer.

À toda minha família, em especial aos meus pais e meu irmão, que sempre me apoiaram e não mediram esforços para me ajudar a cumprir mais essa etapa.

Ao meu querido Guilherme Assemany pela compreensão, apoio e paciência. 


\title{
DESENVOLVIMENTO DE UM GUIA OPRIENTATIVO PARA DOSIMETRIA EM TOMOGRAFIA COMPUTADORIZADA
}

\author{
Ladyjane Pereira Fontes
}

\section{RESUMO}

Devido as frequentes dúvidas dos usuários das câmaras de ionização do tipo lápis calibradas no Laboratório de Calibração de Instrumentos do IPEN (LCI IPEN), em como aplicar corretamente os fatores indicados em seus certificados de calibração, foi elaborado um guia orientativo para dosimetria em tomografia computadorizada. O guia orientativo inclui 0 conhecimento prévio da Camada Semirredutora (CSR), já que é necessário conhecer a energia efetiva do feixe para aplicação do fator de correção para qualidade $\left(\mathrm{k}_{\mathrm{q}}\right)$. A avaliação da CSR em tomógrafos torna-se uma difícil tarefa devido à geometria do sistema e por essa razão foi realizado um levantamento das metodologias existentes para a determinação da CSR em feixes clínicos de Tomografia Computadorizada (TC), levando em consideração fatores técnicos, práticos e econômicos. Neste trabalho, optouse em testar um Sistema Tandem composto por capas absorvedoras confeccionado na oficina do IPEN, baseado em estudos preliminares devido ao baixo custo e boa reposta. O Sistema Tandem é composto por 5 capas absorvedoras cilíndricas de $1 \mathrm{~mm}, 3 \mathrm{~mm}, 5 \mathrm{~mm}, 7 \mathrm{~mm}$, e $10 \mathrm{~mm}$ de alumínio e por 3 capas absorvedoras cilíndricas de $15 \mathrm{~mm}, 25 \mathrm{~mm}$ e $35 \mathrm{~mm}$ de acrílico (PMMA) acopladas à câmara de ionização do tipo lápis comercial amplamente utilizada em testes de controle de qualidade na dosimetria em feixes clínicos de Tomografia Computadorizada. Através das curvas Tandem, foi possível avaliar os valores de CSR e, através da curva de calibração da câmara de ionização do tipo lápis, encontrar o $K_{q}$ adequado ao feixe. O Guia elaborado traz informações de como construir a curva de calibração em função da CSR, para encontrar o $K_{q}$, bem como informações para construção da curva Tandem, para encontrar valores próximos de CSR. 


\title{
Ladyjane Pereira Fontes
}

\begin{abstract}
Due to frequent questions from users of ionization chambers pencil type calibrated in the Instrument Calibration Laboratory of the Institute of Energy and Nuclear Research (LCI - IPEN), on how to properly apply the factors indicated in their calibration certificates, a guide was prepared guidance for dosimetry in computed tomography. The guide includes guidance prior knowledge of half value layer (HVL), as it is necessary to know the effective beam energy for application quality for correction factor (kq). The evaluation of HVL in TC scanners becomes a difficult task due to system geometry and therefore a survey was conducted of existing methodologies for the determination of HVL in clinical beams Computed Tomography, taking into account technical, practical and economic factors. In this work it was decided to test a Tandem System consists of absorbing covers made in the workshop of IPEN, based on preliminary studies due to low cost and good response. The Tandem system consists of five cylindrical absorbing layers of $1 \mathrm{~mm}$, $3 \mathrm{~mm}, 5 \mathrm{~mm}, 7 \mathrm{~mm}$ and $10 \mathrm{~mm}$ aluminum and 3 cylindrical absorbing covers $15 \mathrm{~mm}, 25 \mathrm{~mm}$ and acrylic $35 \mathrm{~mm}$ (PMMA) coupled to the ionization chamber of commercial pencil type widely used in quality control tests in dosimetry in clinical beams Computed tomography. Through Tandem curves it was possible to assess HVL values and from the standard curve pencil-type ionization chamber, $\mathrm{Kq}$ find the appropriate beam. The elaborate Guide provides information on how to build the calibration curve on the basis of CSR, to find the $\mathrm{Kq}$ and information for construction Tandem curve, to find values close to CSR.
\end{abstract}




\section{Sumário}

1. INTRODUÇÃO

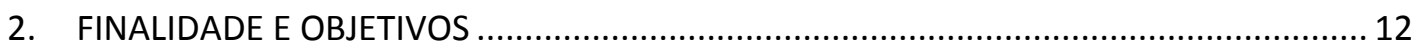

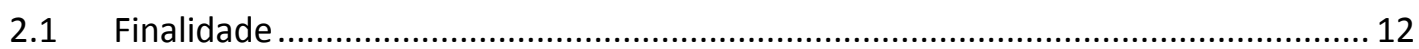

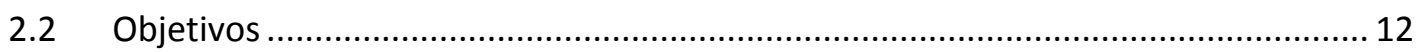

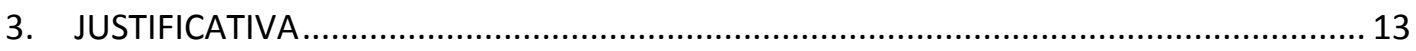

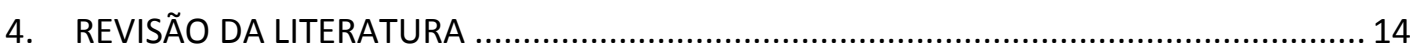

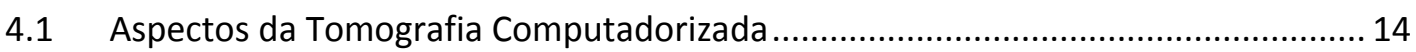

4.2 Evolução do Equipamento de Tomografia Computadorizada .................................. 15

4.3 Componentes do Equipamento de Tomografia Computadorizada .......................... 20

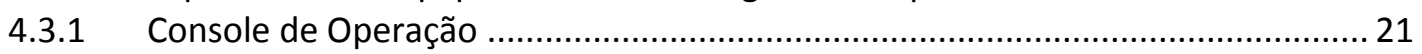

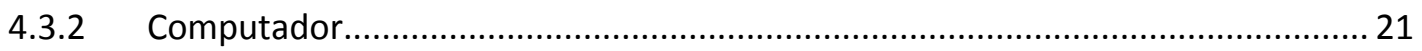

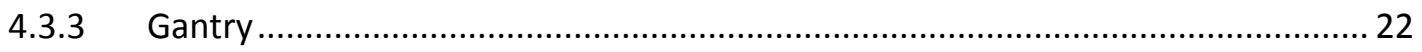

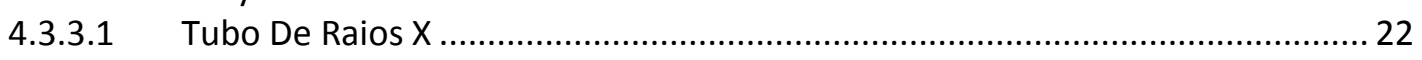

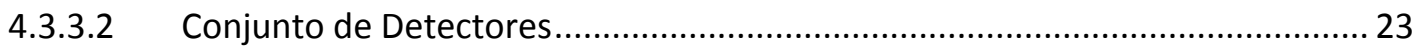

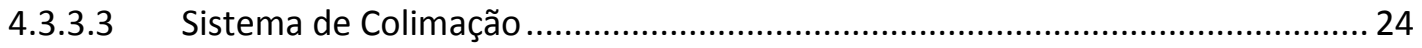

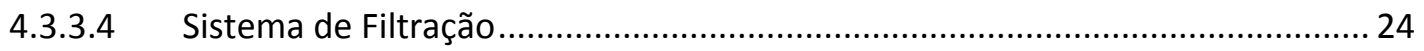

4.4 A Imagem de Tomografia Computadorizada ....................................................... 24

4.5 Controle de Qualidade em Equipamentos de Tomografia Computadorizada.......... 25

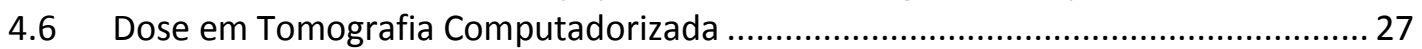

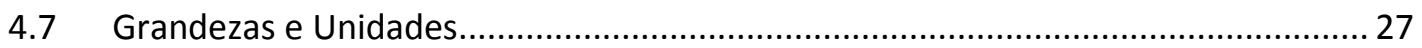

4.7.1 Grandezas Dosimétricas Básicas .......................................................................... 28

4.7.2 Grandezas Dosimétricas em Tomografia Computadorizada ................................. 29

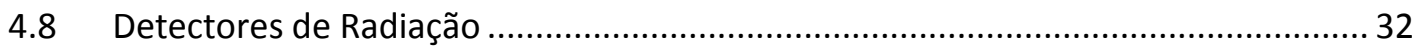

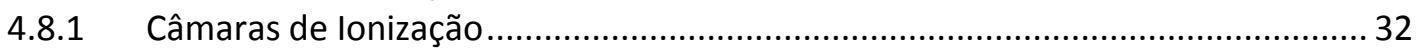

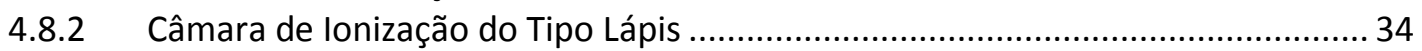

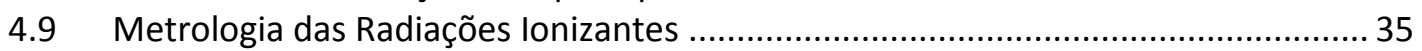

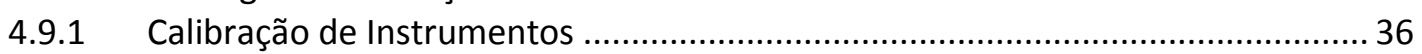

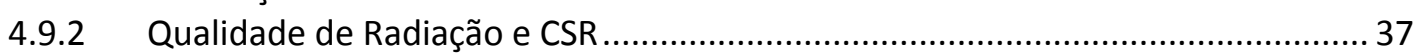

4.9.3 Laboratório de Calibração de Instrumentos do IPEN (LCI-IPEN) ........................... 39

4.9.4 Calibração da Câmara de lonização do Tipo Lápis .............................................. 40

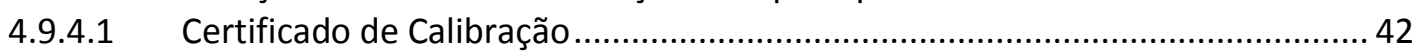

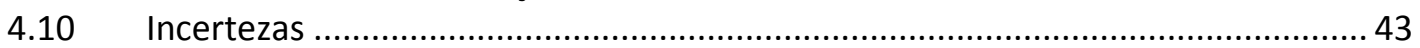

4.10.1 Incertezas nas Medidas com Dosímetros em Radiodiagnóstico ........................... 44

4.11 Dosimetria Clínica em TC e Protocolos Disponíveis .............................................. 48

4.11.1 Medidas Da Taxa De Kerma No Ar E Medidas Com Simuladores ......................... 49

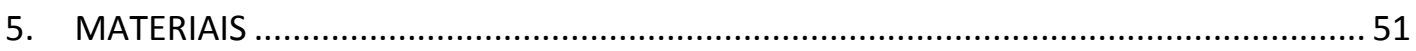

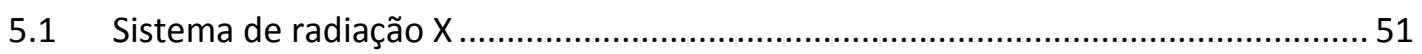

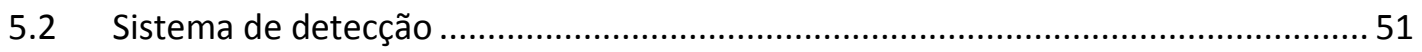

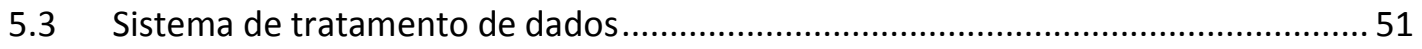

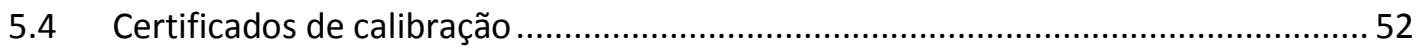

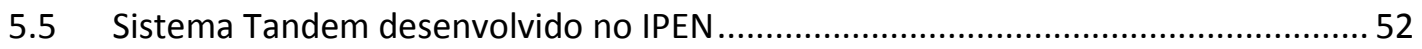

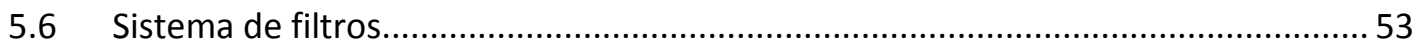

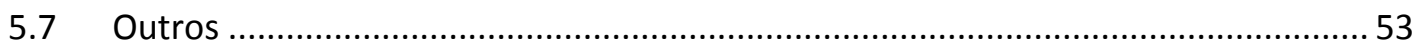

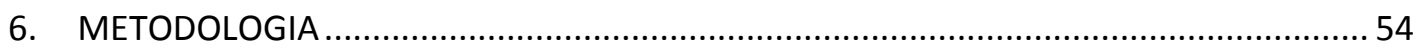

6.1 Avaliação da Dependência Energética de Diferentes Câmaras de lonização do Tipo Lápis de Mesmo Modelo e Fabricante........................................................................... 54 
6.2 Estudo das Metodologias Utilizadas para Avaliação da CSR em Tomografia

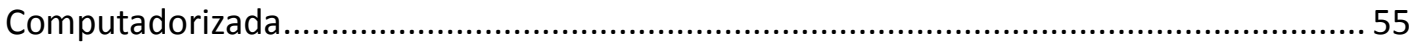

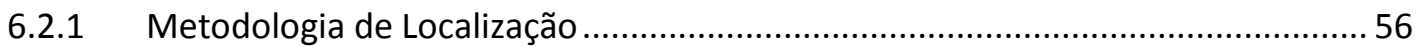

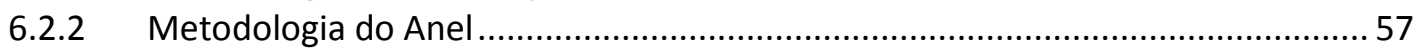

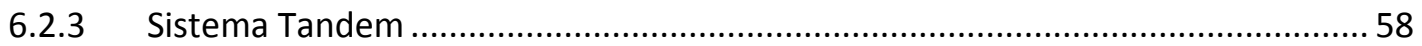

6.3 Calibração das Câmaras de Ionização do Tipo Lápis ................................................ 59

6.3.1 Procedimento de Calibração das Câmaras De Ionização do Tipo Lápis ................. 61

6.3.1.1 Determinação das Taxas de Kerma no Ar com a Câmara Padrão........................ 61

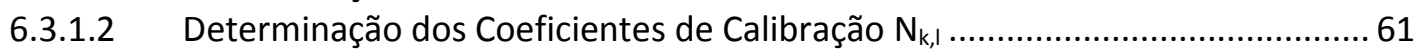

6.3.1.3 Determinação do Fator de Correção para Qualidade $K_{\mathrm{q}}$...................................62 62

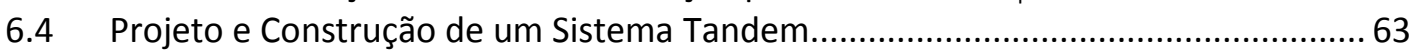

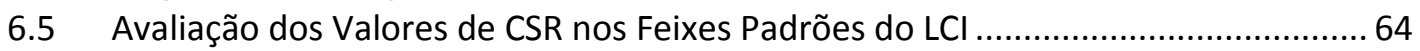

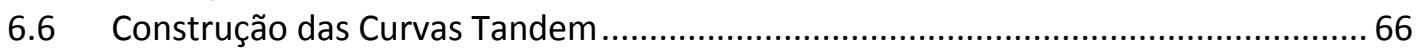

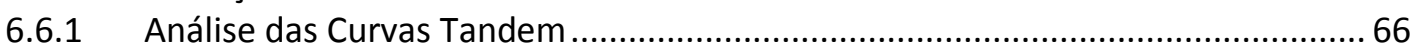

6.7 Testes Realizados com o Sistema Tandem no Hospital A ......................................67 67

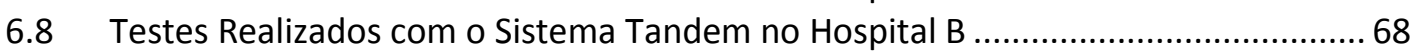

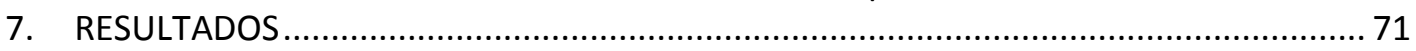

7.1 Avaliação da Dependência Energética de Diferentes Câmaras de lonização do Tipo

Lápis de Mesmo Modelo e Fabricante........................................................................... 71

7.2 Calibração da Câmara de Ionização do Tipo Lápis Utilizada que Compõe o Conjunto

Um. 72

7.2.1 Determinação da Curva de Calibração da Câmara de Ionização do Tipo Lápis que Compõe o Conjunto Um.

7.2.2 Calibração da Câmara de Ionização do Tipo Lápis Utilizada que Compõe o

Conjunto Dois.

7.2.3 Determinação da Curva de Calibração da Câmara de Ionização do Tipo Lápis que

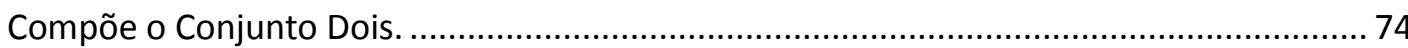

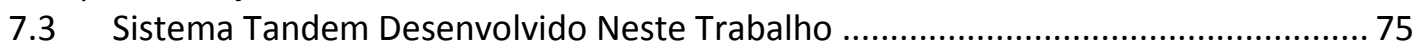

7.4 Avaliação dos valores de CSR já implantadas no LCI - IPEN ..................................... 76

7.5 Determinação das curvas Tandem dos feixes padrões do $\mathrm{LCl}$, utilizando o sistema

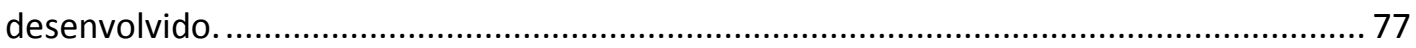

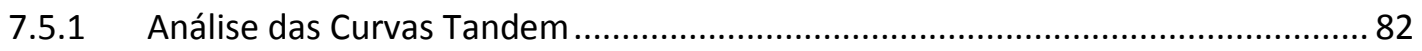

7.6 Testes Realizados com o Sistema Tandem no Hospital A ......................................... 87

7.7 Testes Realizados com o Sistema Tandem no Hospital B ......................................... 87

7.8 Guia Orientativo para Dosimetria em Tomografia Computadorizada....................... 88

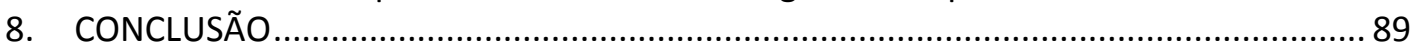

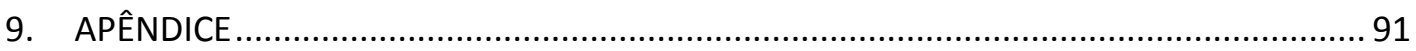

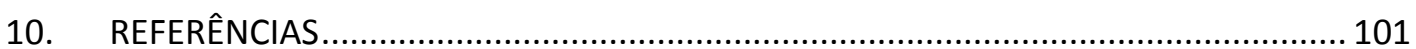




\section{INTRODUÇÃO}

A tomografia computadorizada (TC) é um método de obtenção de imagens através de raios $X$ destinado ao diagnóstico e tratamento médico. Consiste em uma fonte de raios $X$ que em conjunto com detectores opostos a ela, realiza um movimento de rotação em torno do paciente obtendo imagens em fatias da região exposta, e com auxílio de cálculos matemáticos a imagem é reconstruída por computador. A riqueza de informações em uma imagem de TC em relação à imagem plana de um equipamento de raios $X$ convencional vem fazendo com esse tipo de exame seja amplamente utilizado uma vez que não há sobreposição de imagem e perda de informação no diagnóstico ${ }^{(1)}$. No entanto, a dose de radiação em TC é significativamente maior que a dose em comparação com a imagem por raios $X$ convencional. A TC integraliza $40 \%$ da dose de radiação coletiva mundial(2). Entre os anos de 1999 e 2009 no Brasil, houve um aumento de 0,9 para 1,6 tomógrafos por 100 mil habitantes(3). Juntamente com o aumento do uso da TC cresceu também a preocupação com o controle de qualidade desses equipamentos. A publicação da portaria $453^{(4)}$ do ministério da saúde em 1998, aprovou o regulamento técnico que estabelece as diretrizes básicas de proteção radiológica em radiodiagnóstico médico e odontológico e dispõe sobre o uso dos raios $\mathrm{X}$ diagnósticos em todo território nacional, estabelecendo a implantação de programas de garantia de qualidade, bem como sua frequência. Também trouxe em seu texto a indicação da necessidade de que os instrumentos utilizados nos testes que envolvem a averiguação dos níveis de dose de radiação, como dosimetria e levantamento radiométrico, sejam regularmente calibrados em laboratórios com rastreabilidade nacional ou internacional de metrologia das radiações ionizantes, nas qualidades de radiodiagnóstico. Em 2005, a agência nacional de vigilância sanitária (ANVISA), publicou um guia para contribuir na padronização de testes de 
controle de qualidade de equipamentos de radiodiagnostico médico, incluindo Tomografia computadorizada ${ }^{(5)}$.

Desde a década de 80, o Laboratório de Calibração de Instrumentos (LCI) realiza calibrações de câmaras de ionização $(\mathrm{Cl})$ utilizadas em medidas de levantamento radiométrico e na dosimetria em sistemas clínicos de radiodiagnóstico incluindo aqueles indicados para Tomografia Computadorizada $(\mathrm{TC})^{(6)}$.

Em 2007, a Agência Internacional de Energia Atômica (AIEA) publicou um Código de Prática (TRS 457) $)^{(7)}$ indicando as principais diretrizes que incluem tanto procedimentos em laboratórios de calibração e dosimetria, quanto em aplicações clínicas. Em 2010, Dias(8) implantou no equipamento de radiação $X$ do $L C l$ as qualidades de TC (RQT) para calibração através da aplicação de filtros de cobre em qualidades não atenuadas (RQR) obtendo assim energias na faixa de 100 a $150 \mathrm{kV}$, deixando-o dentro das mais recentes recomendações metrológicas seguindo o código de prática TRS $457^{7}$ e a revisão da norma IEC $61267^{(9)}$. No entanto, percebe-se que existe uma lacuna entre a calibração de uma câmara de ionização no laboratório e o seu uso em aplicações clínicas, que leve em consideração os coeficientes e fatores indicados no certificado de calibração fornecido pelo laboratório em que é calibrada.

Devido a dúvidas frequentes dos clientes do LCI com relação ao uso dos fatores indicados nos certificados de calibração, notou-se que muitos usuários cometem equívocos ao utilizar uma câmara de ionização calibrada na dosimetria de seus sistemas de TC. A geometria de irradiação utilizada em uma calibração difere totalmente daquela disponível em um sistema de TC sendo necessária a aplicação de fatores que irão relacionar a grandeza Kerma no ar aquelas específicas para TC. Outra diferença fundamental é que a calibração é feita no ar enquanto as medidas clínicas geralmente são realizadas apenas em simuladores. Ainda não se tem conhecimento da aplicação de simuladores específicos para a calibração que possam relacionar com mais precisão e confiabilidade as grandezas específicas para TC. 
Para melhor esclarecimento da aplicação desses fatores, foram feitos estudos de metodologias para construir curvas de calibração em função da camada semirredutora (CSR) para que o usuário possa encontrar os fatores de correção adequados a energia do feixe clínico. Pela definição, a energia de um feixe é determinada através do valor de CSR. Quando os valores de CSR não são facilmente determinados, como no caso de TC, é possível avaliar a energia efetiva do feixe através de um sistema que consiste na utilização de dosímetros com dependência energética diferentes, onde a razão entre as respostas das curvas de calibração em energia pode fornecer a energia efetiva do feixe (sistema Tandem). A aplicação deste sistema foi proposta por Kenney e Cameron ${ }^{(10)}$ e Gorbics e Attix ${ }^{(11)}$ que utilizaram materiais termoluminescentes para determinar energia de radiações gama e $X$. Trabalhos como Albuquerque e Caldas ${ }^{(6)}$ e Galhardo e Caldas ${ }^{(12)}$ também utilizaram do sistema Tandem como referência para determinação de energia efetiva para dosimetria de feixes de radiodiagnóstico e radioterapia.

Em 2004, Maia ${ }^{(13)}$ estudou a aplicação de um sistema Tandem obtido através de um conjunto formado por uma câmara de ionização do tipo lápis e capas cilíndricas absorvedoras de alumínio, PMMA e cobre, como um método não invasivo para a determinação de valores de CSR em feixes de tomografia computadorizada, levando em consideração a geometria do sistema de TC.

Existem ainda outras metodologias para a obtenção dos valores de CSR como a metodologia do posicionamento, anel e dos simuladores ${ }^{(14)}$.

Através da obtenção dos valores de camada semirredutora (CSR) em feixes clínicos de tomografia computadorizada é possível construir uma curva de calibração para a obtenção do fator de correção para qualidade $(\mathrm{Kq})$ adequada ao feixe de radiação clínico possibilitando sua correta aplicação em medições dosimétricas e diminuindo a lacuna entre calibração e aplicação clínica.

O Guia Orientativo para dosimetria traz orientações aos usuários das câmaras de ionização do tipo lápis calibradas nos feixes padrões do LCl em como utilizar os fatores indicados em seus certificados de calibração, além 
de sugerir metologias para estimar os valores de CSR do feixe clínico em seus sistemas de TC. 


\section{FINALIDADE E OBJETIVOS}

\subsection{Finalidade}

A finalidade deste trabalho é elaborar um Guia Orientativo para dosimetria em Tomografia Computadorizada para instruir os usuários das câmaras de ionização calibradas no LCl no uso dos fatores indicados nos certificados de calibração.

\subsection{Objetivos}

- Avaliar a dependência energética de diferentes câmaras de ionização do tipo lápis de mesma marca e modelo.

- Realizar um estudo das metodologias existentes para avaliação da CSR em equipamentos de tomografia computadorizada.

- Definir qual das metodologias será utilizada neste trabalho, levando em consideração o custo benefício e praticidade no uso.

- Realizar a calibração dos detectores a serem utilizados nas medições.

- Projetar e desenvolver os materiais e o arranjo experimental necessários para a aplicação da metodologia escolhida.

- Testar a metodologia escolhida em laboratório.

- Testar a metodologia em feixes clínicos.

- Desenvolver o guia orientativo para dosimetria em tomografia computadorizada com base nos resultados. 


\section{JUSTIFICATIVA}

Um estudo feito em câmaras de ionização do tipo lápis calibradas no LCl, durante o ano de 2013, para avaliar a dependência energética de diferentes câmaras de mesma marca e modelo, mostrou que houve variações para cada qualidade RQT que compreendiam a faixa de $1,5 \%$ a $4 \%$. Percebeu-se, portanto, que a dependência energética é singular para cada câmara mesmo se tratando do mesmo tipo de equipamento(15).

O Guia irá auxiliar o usuário de uma câmara de ionização do tipo lápis, calibrada nos feixes padrões de tomografia computadorizada, no uso dos fatores de correção para qualidades disponíveis em seu certificado de calibração. O Código de Prática da AIEA TRS $457^{(7)}$ indica a aplicação desses fatores para corrigir as medições de acordo com a energia efetiva do feixe clínico, para isso, o usuário precisa ter um conhecimento prévio da CSR, e construir uma curva de calibração para sua câmara de ionização através dos valores do fator de correção para qualidade $\left(K_{q}\right)$ para as CSR de referência. 


\section{REVISÃO DA LITERATURA}

\subsection{Aspectos da Tomografia Computadorizada}

Os raios X, descobertos em dezembro de 1895 por Wilhelm Conrad Roentgen, revolucionaram o meio cientifico e social deste período ${ }^{(16)}$ e desde então são utilizados para diagnóstico médico.

O radiodiagnóstico ao longo dos anos passou por uma grande evolução tecnológica, usando aparelhos com melhor qualidade e maior potência, acompanhados do uso de um computador para a realização de cálculos matemáticos a partir da atenuação dos fótons liberados pelos raios $X$. Esse avanço foi apresentado por James Ambrose e Godfrey Hounsfield em $1972^{(17)}$, possibilitando a obtenção de imagens com finalidade médica, por meio de medidas de descontinuidade das densidades das estruturas anatômicas.

Em 1971, o primeiro protótipo do tomógrafo para o cérebro (FIG.1) foi instalado, mas só em 1972 o primeiro paciente foi submetido a essa nova técnica de aquisição de imagem ${ }^{(17)}$.

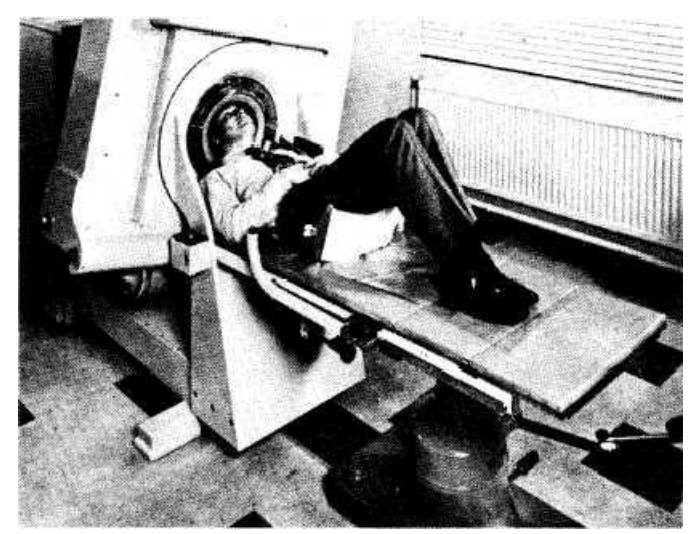

FIGURA 1. Primeiro protótipo de tomógrafo para obter imagens do cérebro. 
A tomografia computadorizada (TC) demonstra as estruturas do corpo, apresentando-as em "fatias", além de propiciar a visualização dos ossos mineralizados e demais delimitações tridimensionais ${ }^{(18)}$.

Desde seu uso inicial, a TC se tornou um dos métodos diagnósticos mais solicitados pelos médicos, porém trabalha com doses elevadas de radiação, quando comparada com outros métodos de diagnóstico usando os raios $\mathrm{X}$, como a radiografia ${ }^{(18)}$.

\subsection{Evolução do Equipamento de Tomografia Computadorizada}

A tomografia computadorizada passou por muitos aprimoramentos ao longo dos anos devido as diferenças no funcionamento e nas técnicas aplicadas para obtenção de imagens. Para marcar essas evoluções, os equipamentos ficaram classificados por geração. O primeiro tomógrafo apresentado por Hounsfield à sociedade científica era constituído de um feixe estreito de radiação $(3 \times 13 \mathrm{~mm})$, e varreduras lineares múltiplas do objeto de estudo, coletando informações de 160 feixes diferentes.

O tubo realizava a rotação de um grau após a primeira varredura para iniciar uma nova e coletar os demais dados dos outros 160 feixes (FIG.2). $O$ tempo de aquisição de um único corte demorava cinco minutos e o processo era repetido por 180 vezes, totalizando uma hora para um único estudo( ${ }^{(19,20)}$. 


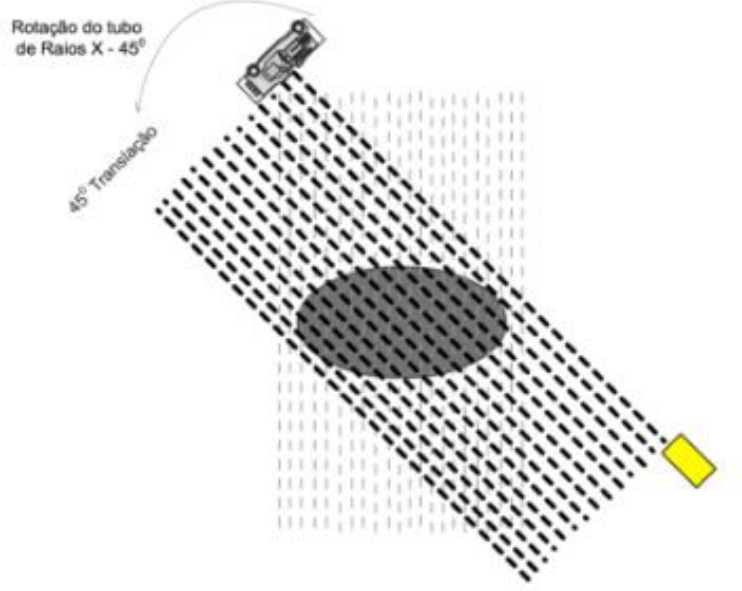

FIGURA 2. Esquema do movimento realizado pelo sistema de detecção de imagens na primeira geração da tomografia computadorizada.

Os equipamentos da segunda geração se diferenciavam da primeira, devido à aquisição de dados a partir de um conjunto de detectores, possibilitando a redução do tempo de aquisição das imagens. Seu feixe passou a ser em forma de leque, cobrindo o conjunto de detectores que variavam de vinte a quarenta, dependendo do fabricante ${ }^{(20)}$ (FIG.3). A desvantagem desse tipo de feixe em forma de leque é a intensidade de radiação nas bordas do feixe por conta da forma do corpo. Isso é reparado através do uso de um filtro tipo "gravata borboleta"(20). 


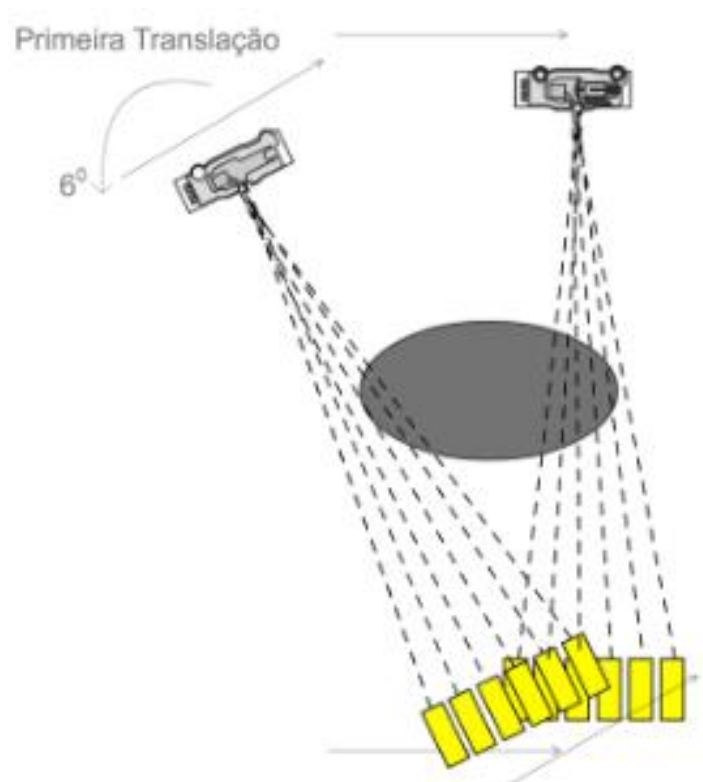

FIGURA 3. Esquema do movimento realizado pelo sistema de detecção de imagens na segunda geração da tomografia computadorizada.

Os equipamentos da terceira geração evoluíram significativamente, quando comparados com os da primeira e segunda gerações. Os tubos de raios $\mathrm{X}$ mudaram o processo de varredura a cada grau e começaram a realizar movimentos rotatórios contínuos com a coleta de dados simultaneamente, extinguindo desta forma a varredura linear das duas gerações anteriores.

O tomógrafo era formado por um conjunto de detectores com seiscentas unidades, que coletavam um feixe largo de radiação, girando ao mesmo tempo com o tubo de raios $X$, reduzindo a aquisição para dois a cinco segundos por imagem (FIG.4). 
18

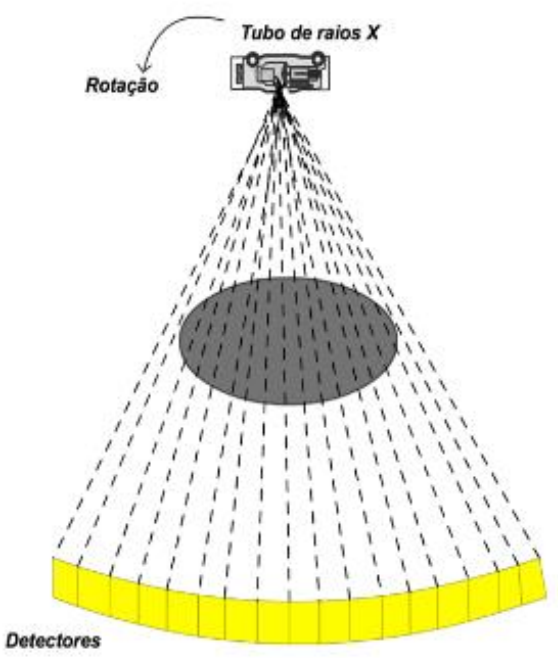

FIGURA 4. Esquema do movimento realizado pelo sistema de detecção de imagens na terceira geração da tomografia computadorizada.

Os equipamentos da quarta geração conhecidos pela tecnologia slipring, possuíam um conjunto de detectores dispostos ao longo dos $360^{\circ}$ do gantry. Essa inovação consistia no uso de anéis deslizantes que fornecia a tensão inicial ao anodo e catodo do tubo de raios $\mathrm{X}$, sem que houvesse a conexão dos cabos.

Um conjunto de escovas conectavam os geradores a superfície do slipring que levavam as informações já ajustadas pelo sistema, em particular, os parâmetros relacionados às doses de radiação (mAs e kV).

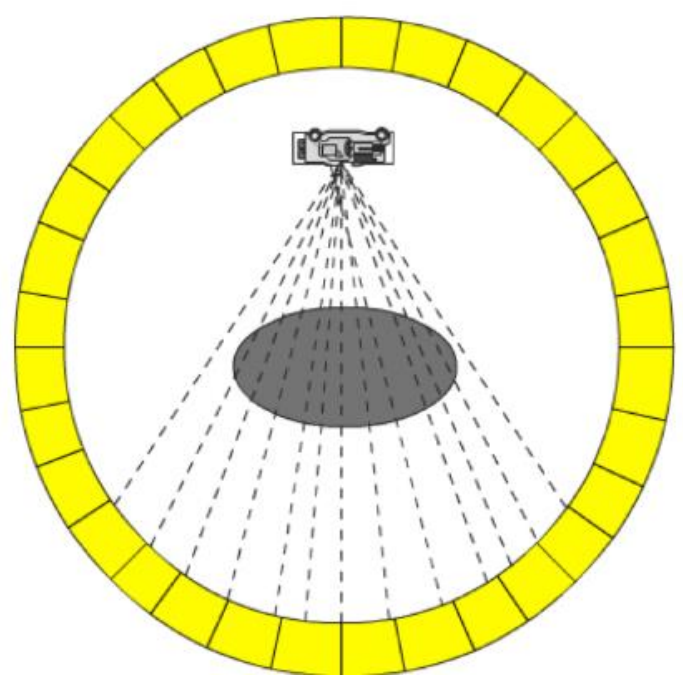

FIGURA 5. Esquema do movimento realizado pelo sistema de detecção de imagens na quarta geração da tomografia computadorizada. 
A tecnologia helicoidal associou a tecnologia de anéis deslizantes com o deslocamento da mesa. Os cortes das imagens são adquiridos ao mesmo tempo em que ocorre a movimentação da mesa, possibilitando a aquisição das "fatias" semelhante a um modelo espiral (FIG.6). Com base na introdução do deslocamento da mesa, foi determinado um fator conhecido por passo ou pitch, que é dado através da Equação $1^{(8)}$ :

$$
p=\frac{d}{h}
$$

Onde:

$d=$ deslocamento da mesa a cada rotação de $360^{\circ}$ do tubo de raios X;

$h=$ Espessura do corte

O sistema de computação também se tornou mais moderno, permitindo a realização de um exame de crânio em menos de vinte segundos, enquanto que nos aparelhos de terceira geração o tempo estimado era de três minutos ${ }^{(20)}$.

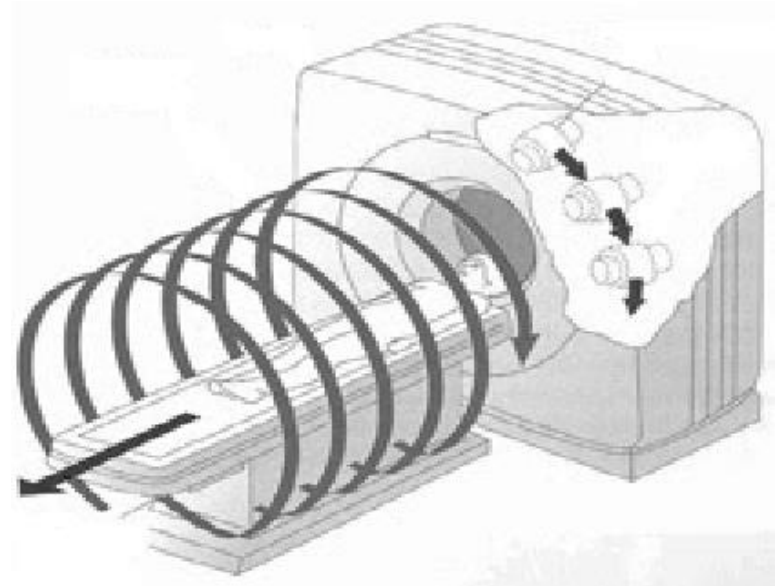

FIGURA 6. Esquema do funcionamento de um equipamento de tomografia computadorizada com sistema helicoidal de aquisição de imagens.

Equipamentos mais modernos, como o tomógrafo de feixe de elétrons e os conhecidos como multidetectores ou multicorte (FIG.7) surgiram a fim de obter imagens rápidas e funcionais. Baseando-se nos equipamentos 
helicoidais com mais de uma fileira de detectores, essa tecnologia possibilitou à aquisição simultânea de vários cortes e os primeiros aparelhos possuíam quatro conjuntos de anéis detectores.

Com o avanço da tomografia, foram acrescentadas mais fileiras de detectores nos aparelhos, dando origem aos equipamentos de 4, 8, 16, 32, $64,128,256$ e 320 cortes. Os tomógrafos de 64 cortes por exemplo possibilitaram uma revolução de 0,5 segundo (viabilizou a realização de exames cardíacos), e uma aquisição de até 140 imagens por segundo. possibilitando a aquisição de cortes de $1 \mathrm{~mm}$, permitindo no pósprocessamento, obtenção de imagens tridimensionais (3D) e reformatação de vasos e artérias com alta resolução(18),(19),(21),(22).
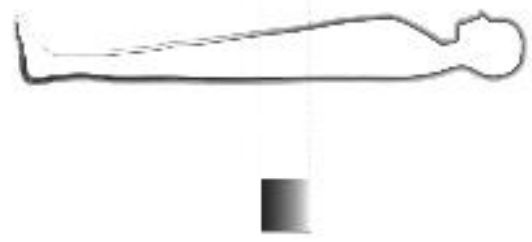

Single-slice scanner

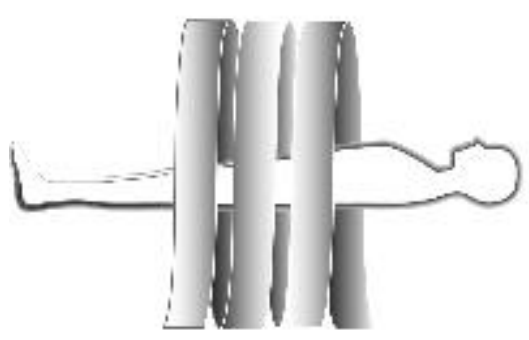

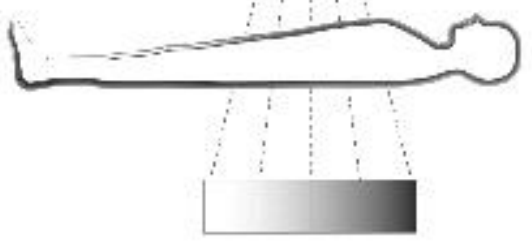

Multislice scanner

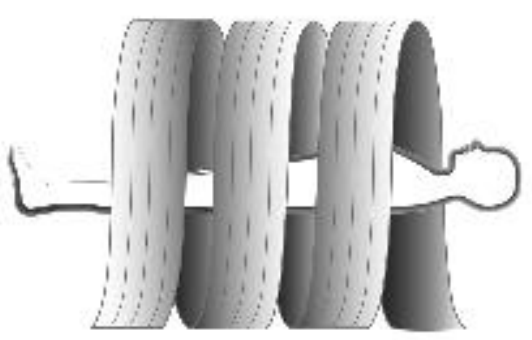

FIGURA 7. Esquema de aquisição de imagens em um tomógrafo multicorte.

\subsection{Componentes do Equipamento de Tomografia Computadorizada}


Os principais componentes de um tomógrafo são: o console de operação, o computador e o gantry (FIG.8). Através desses componentes é que se obtém uma imagem de TC(21).

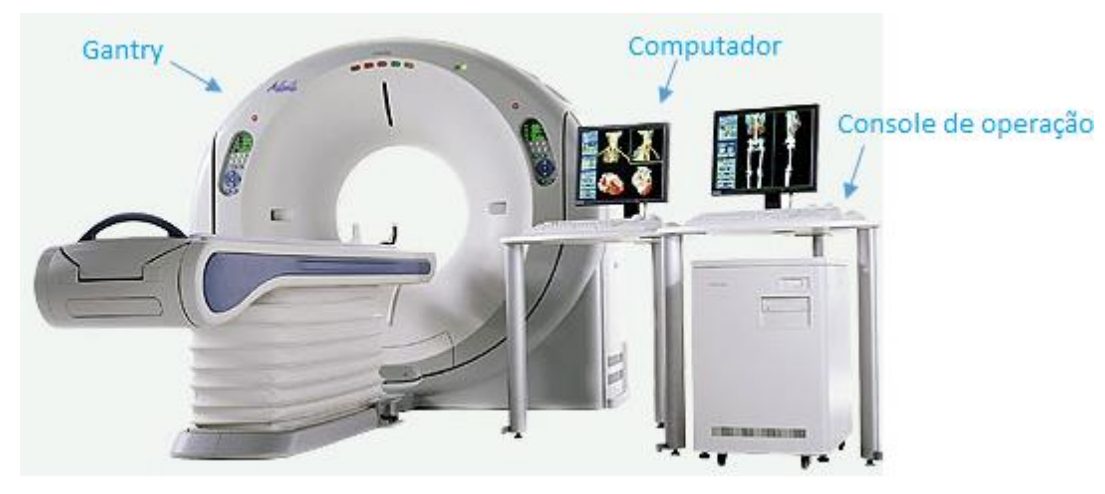

FIGURA 8. llustração dos componentes de um equipamento de tomografia computadorizada.

\subsubsection{Console de Operação}

Um equipamento de tomografia pode ter até 3 consoles de operação: um para que se possa ajustar os parâmetros adequados ao exame, como por exemplo a angulação do gantry; um segundo que serve para ajustar a técnica a ser empregada no processamento de imagens, como, por exemplo; espessura do corte, corrente e tensão aplicadas ao tubo de raios X; e um terceiro que serve como estação de trabalho, na qual é possível que o médico realize ajustes na imagem com a finalidade de obter um diagnóstico mais preciso $^{(21)}$.

\subsubsection{Computador}

O computador é o responsável pela reconstrução da imagem. Quando um feixe de radiação interage com o paciente, sofre atenuações e chega com intensidades diferentes de acordo com o tipo de tecido que interagiu. Dessa forma, os detectores recebem sinais de diferentes intensidades. Esses sinais são processados e através de algoritmos a imagem é reconstruída. Além 
disso, comandos relacionados ao controle de todo o processo de aquisição de imagem como: abertura e fechamento do colimador, emissão dos raios $X$, ativação e desativação dos colimadores, armazenamento de dados e imagens, entre outros, são executados pelo computador.

\subsubsection{Gantry}

Tubo de raios $\mathrm{X}$, conjunto de detectores, gerador de alta voltagem, mesa de suporte do paciente e seus devidos suportes mecânicos estão incluídos no gantry (FIG.9).

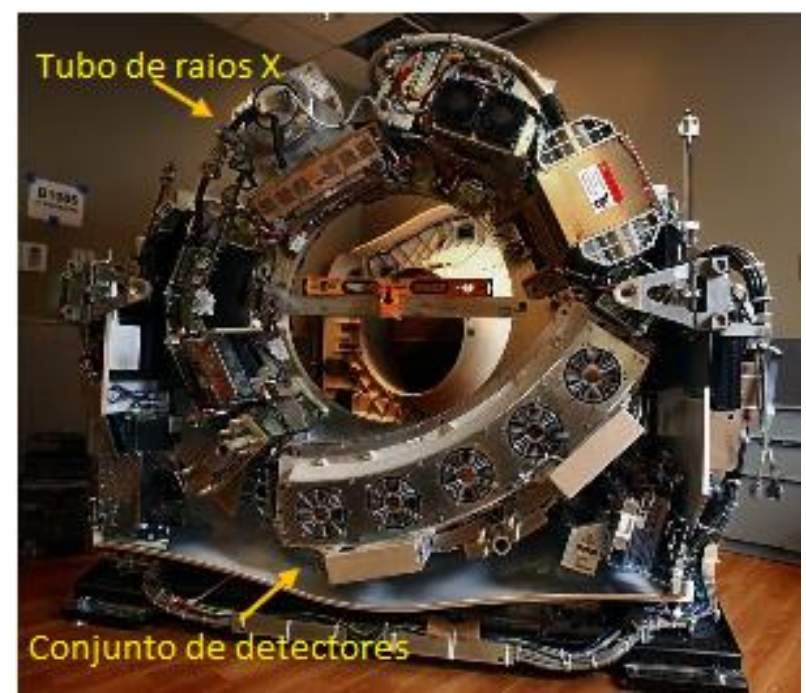

FIGURA 9. Ilustração do interior de um gantry de um equipamento de tomografia computadorizada.

\subsubsection{Tubo De Raios $X$}

Os feixes contínuos emitidos do tomógrafo produzem muito calor. Isso exige dos tubos de raios X (FIG.10) projetados para esse tipo de equipamento grande capacidade térmica, e faz com que o desgaste no tubo seja a principal causa de problemas técnicos com o tomógrafo. Rotores de alta qualidade são utilizados na dissipação do calor. 


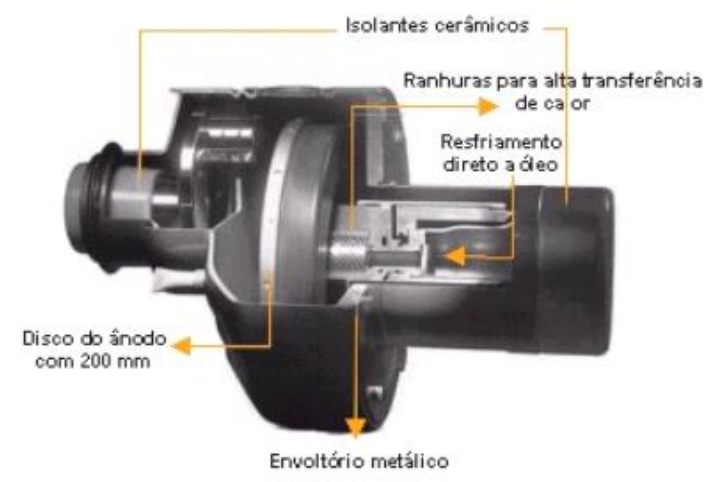

FIGURA 10. llustração de um tubo de raios $X$ de TC helicoidal. (Adaptada de Seeram ${ }^{17}$ )

\subsubsection{Conjunto de Detectores}

Os tomógrafos possuem milhares de detectores localizados em um arranjo oposto ao tubo de raios $\mathrm{X}$. Esses detectores são formados por cristais cintiladores e por fotodiodos que são responsáveis pela conversão da luz em sinal eletrônico (FIG.11). Os detectores de cintilação possuem alta eficiência na produção da imagem contribuindo na diminuição da dose no paciente e aumentando a velocidade na produção da imagem. Tungstato de cádmio $\left(\mathrm{CdWO}_{4}\right)$ e cerâmicas especiais são exemplos de cristais utilizados atualmente(21).

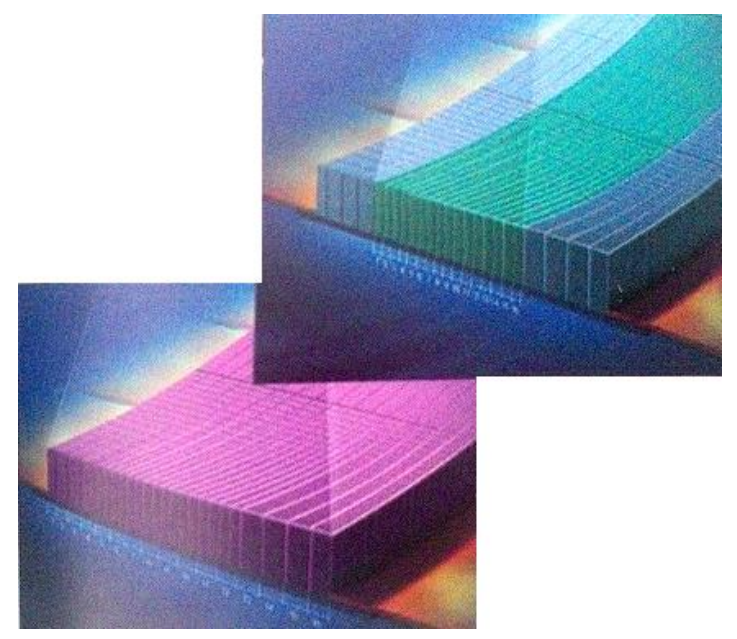

FIGURA 11. Ilustração de um conjunto de detectores. (Adaptada de Bushong ${ }^{(21)}$ ) 


\subsubsection{Sistema de Colimação}

O sistema de colimação em TC é formado pelo colimador pré paciente e o colimador pré detector. $\mathrm{O}$ colimador pré-paciente está localizado no cabeçote do tubo de raios $\mathrm{X}$ ou adjacente a ele, assegurando o ângulo de abertura do feixe e limitando a área do paciente a ser irradiada, desta forma pode-se definir a espessura do corte tomográfico. Esse processo contribui na determinação da dose para o paciente. $O$ colimador pré detector reduz a radiação espalhada nos detectores contribuindo na melhora do contraste da imagem.

\subsubsection{Sistema de Filtração}

O sistema de filtração em TC tem como principal papel o endurecimento do feixe, ou seja, a remoção de fótons de baixa energia que não contribuem na formação da imagem e podem gerar uma dose adicional e desnecessária ao paciente bem como artefatos na imagem. $O$ corpo humano é formado por diferentes tecidos e cada um deles atenua a radiação de forma diferente. Por isso, os filtros possuem espessura irregular compensando a falta e/ou excesso de tecidos na área irradiada do paciente, atuando na diminuição da dose ${ }^{(14)}$.

\subsection{A Imagem de Tomografia Computadorizada}

Em TC, os sinais eletrônicos gerados através dos raios $\mathrm{X}$ formam uma imagem que é mostrada no monitor como uma matriz bi ou tri dimensional onde cada célula é um pixel e a informação associada ao seu coeficiente de atenuação médio do seu elemento de volume é chamada de voxel e expresso em número de TC. No monitor, cada pixel possui um nível de brilho correspondente a uma faixa de número de TC que varia entre -1000 e +3000 
indicando diferentes densidades. +3000 representa ossos densos e 0 representa água por exemplo(21).

O valor de número de TC é dado pela Equação 2:

$$
\text { Número de } T C=k\left(\frac{\mu_{t}-\mu_{w}}{\mu_{w}}\right)
$$

Onde:

$\mu_{t}$ É o coeficiente de atenuação do tecido no pixel em análise;

$\mu_{w}$ É o coeficiente de atenuação dos raios $\mathrm{X}$ na água;

$k$ É a constante que determina o fator de escala para a faixa de números de TC

As projeções obtidas pelos detectores durante o exame de TC são armazenadas na memória do computador e através de algoritmos são reconstruídas. A reconstrução de uma imagem de TC requer a solução de mais de 250.000 equações simultaneamente ${ }^{(21)}$.

\subsection{Controle de Qualidade em Equipamentos de Tomografia Computadorizada}

Segundo a IEC (Internacional Eletrotechnical Comission) $61267^{(9)}$, têm-se por definição:

Garantia de Qualidade: são ações sistemáticas e planejadas, necessárias para prover confiança adequada, assegurando que o produto ou o serviço satisfaça às exigências de qualidade;

Programa de Garantia de Qualidade: São instruções detalhadas para a realização de ações de garantia de qualidade para cada componente 
do equipamento, sistemas de equipamentos ou instalações, incluindo elementos de gestão da qualidade e técnicas de controle de qualidade;

Controle de Qualidade: É um conjunto de técnicas operacionais e atividades que são utilizadas para atender à exigência de qualidade.

Teste de Aceitação: É aquele ensaio realizado após a instalação de um novo equipamento, ou modificações maiores no equipamento existente, a fim de verificar a concordância com as especificações contratuais;

Teste de Estado: É o ensaio realizado para estabelecer o estado funcional do equipamento em um determinado instante;

Teste de Constância: Compõem uma série de ensaios feitos para assegurar que o desempenho funcional do equipamento atende a critério estabelecido ou para verificar alterações nas propriedades de componentes do equipamento.

A partir das definições pode-se dizer que o controle de qualidade é um conjunto de procedimentos sistemáticos e constantes a fim de verificar o desempenho do equipamento como por exemplo: testes de verificação do sistema de colimação, alinhamento da mesa em relação ao gantry, espessura de corte, índice de dose, incluindo testes de CSR, entre outros.

Todo equipamento de raios $X$ diagnósticos deve ser mantido em condições adequadas de funcionamento e submetido regularmente a verificações de desempenho( ${ }^{(4)}$. 


\subsection{Dose em Tomografia Computadorizada}

A dose de radiação em TC é significativamente alta, devido ao fato de que em TC, a dose é quase igualmente distribuída no plano da varredura ${ }^{(8)}$. A informação da dose em TC é importante pois, essa é uma modalidade de radiodiagnóstico amplamente utilizada, que proporciona uma das mais altas doses em radiologia. Além disso, essa técnica produz melhores imagens quando a dose é aumentada ${ }^{(8)}$. Na TAB.1 estão as doses típicas para algumas técnicas radiológicas.

TABELA 1. Doses típicas para algumas técnicas radiológicas.

\begin{tabular}{c|c|c}
\hline Tipo de Procedimento & $\begin{array}{c}\text { Dose Efetiva Média } \\
\text { em Adulto } \\
(\mathbf{m S v})\end{array}$ & $\begin{array}{c}\text { Dose Equivalente } \\
\text { Estimada } \\
\text { (No de raios X de } \\
\text { tórax })\end{array}$ \\
\hline Raios X dental & $0,005-0,01$ & $0,25-0,5$ \\
\hline Raios X de tórax & 0,02 & 1 \\
\hline Mamografia & 0,4 & 20 \\
\hline TC & $2-16$ & $100-800$ \\
\hline Fluoroscopia Intervencionista & $5-70$ & $250-3500$ \\
\hline
\end{tabular}

\subsection{Grandezas e Unidades}

As grandezas e unidades dosiétricas foram criadas para mensurar os fenômenos físicos causados através da interação da radiação com a matéria, tanto do campo de radiação no ponto de medida (através de grandezas radiométricas), quanto da energia transferida ou depositada na matéria, sendo de interesse efetuar medições físicas que possam ser diretamente correlacionadas com os efeitos reais ou potenciais da radiação(26). 


\subsubsection{Grandezas Dosimétricas Básicas}

As grandezas dosimétricas básicas, são grandezas utilizadas para indicar níveis de radiação, bem como seus limites relacionados aos possíveis riscos, evitando que o limiar de dose seja excedido e garantindo a redução dos efeitos estocásticos. Essas grandezas podem ser classificadas como grandezas físicas: Kerma (K), Dose absorvida (D); e grandezas de proteção: Dose equivalente em órgão ou tecido $\left(H_{T}\right)$ e Dose efetiva $(\mathrm{E})$, onde:

Kerma (K): É o quociente entre a soma das energias cinéticas iniciais, $E_{T, R}$, de todas as partículas ionizantes carregadas liberadas pelas partículas não ionizantes depositadas na matéria de massa $d m$, como na Equação (3). Esta grandeza é mensurável e sua unidade é o J.Kg ${ }^{-1}$, também conhecida como Gray (Gy) $)^{(27,28)}$.

$$
K=\frac{d E_{T, R}}{d m}
$$

Dose Absorvida (D): É a grandeza física fundamental utilizada para todos os tipos de radiação ionizante e para qualquer geometria de irradiação. Ela é definida pelo quociente entre $d \bar{\varepsilon}$ e $d m$, onde $d \bar{\varepsilon}$ é a energia média depositada em uma dada massa - $d m$, como na Equação (4). Esta grandeza

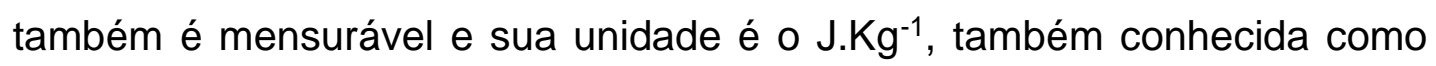
Gray (Gy).

$$
D=\frac{d \bar{\varepsilon}}{d m}
$$

Dose Equivalente $\left(\boldsymbol{H}_{T}\right)$ : Está baseada na definição da dose absorvida média, $D_{T}$, em um órgão ou tecido específico $T$. É dada pelo produto $W_{R} \cdot D_{T}$, 
onde $W_{R}$ é o fator de ponderação da radiação, que reflete a eficiência biológica das radiaçõs de alto LET compensada com as de baixo LET para o tipo de radiação $R$, como na Equação (5). Para diversos tipos de radiação individual no órgão, a dose equivalente em órgão ou tecido $\left(H_{T}\right)$, é dada em J.Kg-1 ${ }^{-1}$ também conhecida como Sievert (Sv) ${ }^{(7,27)}$.

$$
H_{T}=\sum_{R} W_{R} D_{T, R}
$$

Dose Efetiva (E): É o somatório dos fatores de ponderação de todos os órgãos e tecidos do corpo $\left(W_{T}\right)$ multiplicado pelo somatório das doses absorvidas ponderadas pelo fator de ponderação $\left(W_{R}\right)$, como na Equação (6). Essa grandeza é dada em J.Kg ${ }^{-1}$, também conhecida como Sievert (Sv) ${ }^{(27)}$.

$$
E=\sum_{T} W_{T} \sum_{R} W_{R} \cdot D_{T, R}
$$

\subsubsection{Grandezas Dosimétricas em Tomografia Computadorizada}

Em 2007 a Agência Internacional de Energia Atômica (IAEA), publicou - Technical Report Series 457(7), com as grandezas específicas para TC, essas grandezas são: Índice de Kerma no ar $\left(C_{a, 100}\right)$, Índice de dose ponderado $\left(C_{W}\right)$, Índice de Kerma no ar volumétrico $\left(C_{V O L}\right)$, e o Produto Kerma - comprimento $\left(P_{K, L}\right)$.

Índice de Kerma no ar $\left(\boldsymbol{C}_{\boldsymbol{a}, \mathbf{1 0 0}}\right)$ : Medido livre no ar para uma rotação do tubo, é o quociente da integral Kerma no ar ao longo de uma linha paralela ao eixo de rotação do tomógrafo considerando o comprimento de $100 \mathrm{~mm}$ da 
câmara de ionização tipo lápis e $T$ a espessura nominal do corte, onde a faixa de integração está posicionada simetricamente sobre o volume digitalizado, como na Equação (7).

$$
C_{a, 100}=\frac{1}{T} \int_{-50}^{+50} K(z) d z
$$

Em equipamentos multicorte deve ser considerado o valor $N T$, que representa a colimação do feixe, onde $N$ é o número de canais e $T$ a espessura nominal do corte, como na Equação (8).

$$
C_{a, 100}=\frac{1}{N T} \int_{-50}^{+50} K(z) d z
$$

Índice de dose ponderado $\left(\boldsymbol{C}_{W}\right)$ : Medido com a câmara de ionização tipo lápis posicionada dentro do orifício central CPMMA,100,c e periféricos CPMma,100,p dos simuladores de cabeça e tronco, para se obter o índice de Kerma no ar dentro desses simuladores, como na Equação (9).

$$
C_{W}=\frac{1}{3}\left(C_{P M M A, 100, c}+2 C_{P M M A, 100, p}\right)
$$

Quando as grandezas $C_{W}$ e/ou $C_{a, 100}$ são normalizadas para o produto tempo de exposição por unidade da corrente do tubo $P_{I t}$, são representadas por $n C_{W}$ ou $n C_{a, 100}$, como nas Equações (10 e 11). 


$$
{ }_{n} C_{W} \frac{C_{W}}{P_{I t}}
$$

$$
n C_{a, 100} \frac{C_{a, 100}}{P_{I t}}
$$

Índice de Kerma no ar volumétrico $\left(C_{V O L}\right)$ : Para calcular o $\left(C_{V O L}\right)$ considera-se o pitch (p), como na Equação (12). A grandeza normalizada para o produto tempo de exposição por unidade da corrente do tubo $P_{I t}$, é mostrada na Equação (13).

$$
\begin{gathered}
C_{V O L} \frac{C_{W}}{p} \\
n C_{V O L} \frac{C_{V O L}}{P_{I t}}
\end{gathered}
$$

O pitch(p), é utilizado para aquisições helicoidais, ou pode ser calculado para aquisições axiais (sequenciais), através do incremento da mesa e espessura de corte, como na Equação (14).

$$
p=\frac{\text { incremento da mesa }}{\text { espessura de corte }}
$$


Produto Kerma - Comprimento $\left(\boldsymbol{P}_{K, L}\right)$ : É calculado através da Equação (15), onde:

$j$, representa cada sequencia ou série de varreduras helicoidais que fazem parte do exame;

$l_{j}$, representa a distância varrida do paciente; e,

$P_{I t}$, é o produto tempo de exposição por unidade da corrente do tubo para uma única varredura axial.

$$
P_{K, L}=\sum_{j} n C_{V O L j} l_{j} P_{I t}
$$

\subsection{Detectores de Radiação}

\subsubsection{Câmaras de lonização}

Dos vários tipos de detectores de radiação, um dos mais utilizados são os detectores com base nos efeitos produzidos quando uma partícula carregada passa através de um gás. Os principais modos de interação envolvem excitação e ionização das moléculas de gás ao longo da trajetória da partícula.

Câmaras de ionização, em princípio, são os mais simples de todos os detectores de gás. Seu funcionamento normal é baseado em coleta de todas as cargas criadas por ionização direta dentro do gás através da aplicação de um campo elétrico. Tal como acontece com outros detectores, as câmaras de ionização podem ser operadas no modo de corrente (a quantidade medida diretamente na saída do detector é uma média resultante das várias interações das partículas com o detector) ou modo pulso (a quantidade de carga na saída do detector é medida em série de sinais separados no tempo, 
onde cada sinal representa a interação de uma partícula com o detector). Em aplicações mais comuns, câmaras de ionização são usadas como dispositivos de corrente contínua, embora existam algumas aplicações do modo pulso.

O termo câmara de ionização é utilizado exclusivamente para o tipo de detector em que pares de íons são recolhidas a partir de gases ${ }^{(29)}$.

Em meados dos anos 30, devido à alta sensibilidade, à boa estabilidade e à boa reprodutibilidade, que fazem parte de suas características operacionais, a câmara de ionização tornou-se o instrumento principal para a detecção de radiação X. No Brasil, nos últimos anos, diversas câmaras de ionização foram projetadas e construídas para diferentes aplicações, apresentando bons resultados. As câmaras de ionização possuem basicamente um eletrodo coletor central e uma parede de material apropriado que delimita uma cavidade preenchida por um gás ${ }^{(8,13,21,30)}$ como mostra a FIG.12.

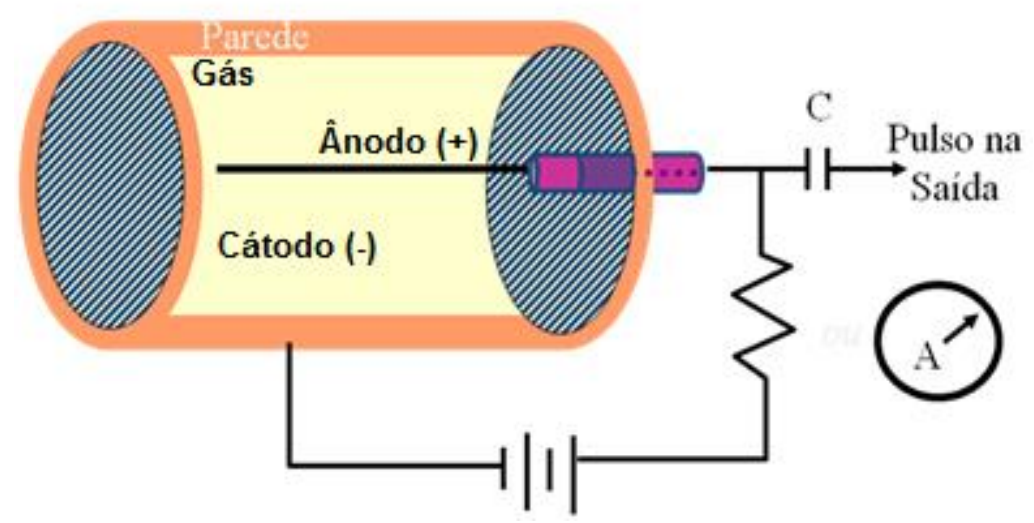

FIGURA 12. Esquema simples dos componentes de um detector a gás.

Para câmaras de ionização não seladas, é feita a correção de sua leitura para variação de temperatura e pressão ambientais utilizando-se o fator de correção como mostra a Equação (16). 


$$
F_{T, p}=\left[\frac{(273,15+T)}{(273,15+20)}\right] \times\left[\frac{101,3}{p}\right]
$$

Onde:

$T$ É a temperatura em ${ }^{\circ} \mathrm{C}$; e

$p$ É a pressão em Kpa;

\subsubsection{Câmara de Ionização do Tipo Lápis}

As câmaras de ionização do tipo lápis (FIG.13 A e 13 B), possuem forma cilíndrica, comprimento de $100 \mathrm{~mm}$ (podendo chegar a $150 \mathrm{~mm}^{(31)}$ ) e apresentam resposta uniforme as radiações que incidem em qualquer um de seus ângulos ao redor de seu eixo, sendo indicada para equipamentos que possuam tubo de raios $\mathrm{X}$ rotacionais como os tomógrafos, tanto para medições de Kerma no ar como também em simuladores. A leitura apresentada por este tipo de câmara é em unidades de dose ou exposição vezes o comprimento (mGy.cm ou R.cm), facilitando o cálculo das grandezas específicas para $\mathrm{TC}^{(8)}$.

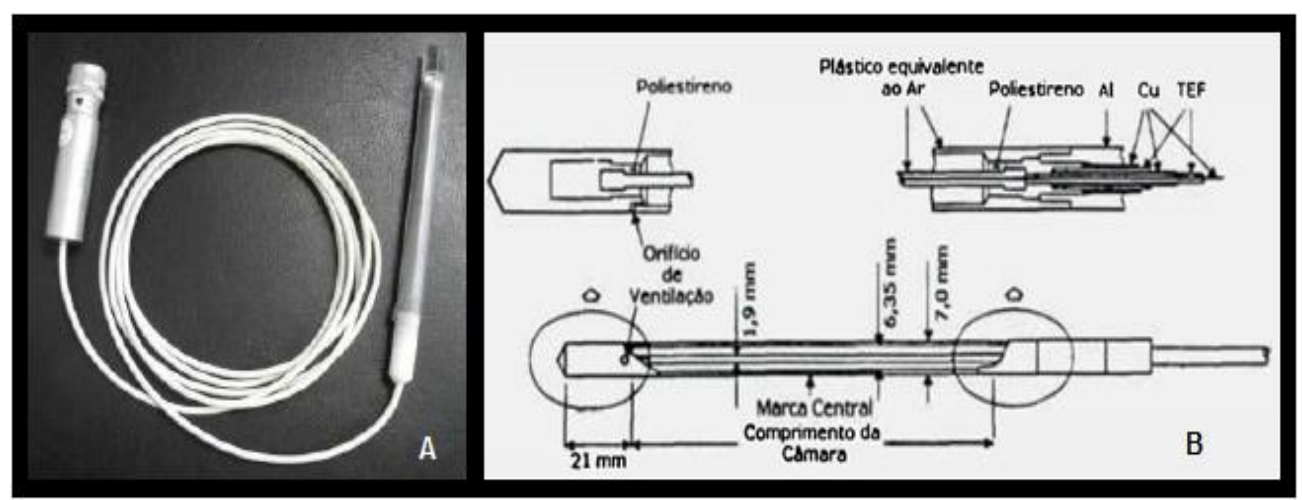

FIGURA 13A: câmara de ionização do tipo lápis. FIGURA 13B: esquema elétrico de uma câmara de ionização do tipo lápis. 


\subsection{Metrologia das Radiações lonizantes}

A Metrologia é a ciência que abrange todos os aspectos teóricos e práticos relativos às medições, qualquer que seja a incerteza em qualquer campo da ciência ou tecnologia(32).

A credibilidade das medições com radiações ionizantes pode ser obtida através de sua cadeia metrológica, ou seja, sua rastreabilidade. Isso se dá através de um esquema essencialmente hierárquico onde as definições das unidades básicas de medida do Sistema Internacional de Unidades (SI), encontram-se no topo como mostra a FIG.14. Logo abaixo das definições das unidades básicas de medidas do SI, está o BIPM (Bureau International des Poids et Mesures), que é o laboratório internacional de metrologia responsável pela prática da metrologia de maior exatidão. Compete ao BIPM a guarda dos padrões internacionais de medida e a disseminação das unidades SI aos NMI (Nacional Measumerent Institute) que são os laboratórios nacionais.

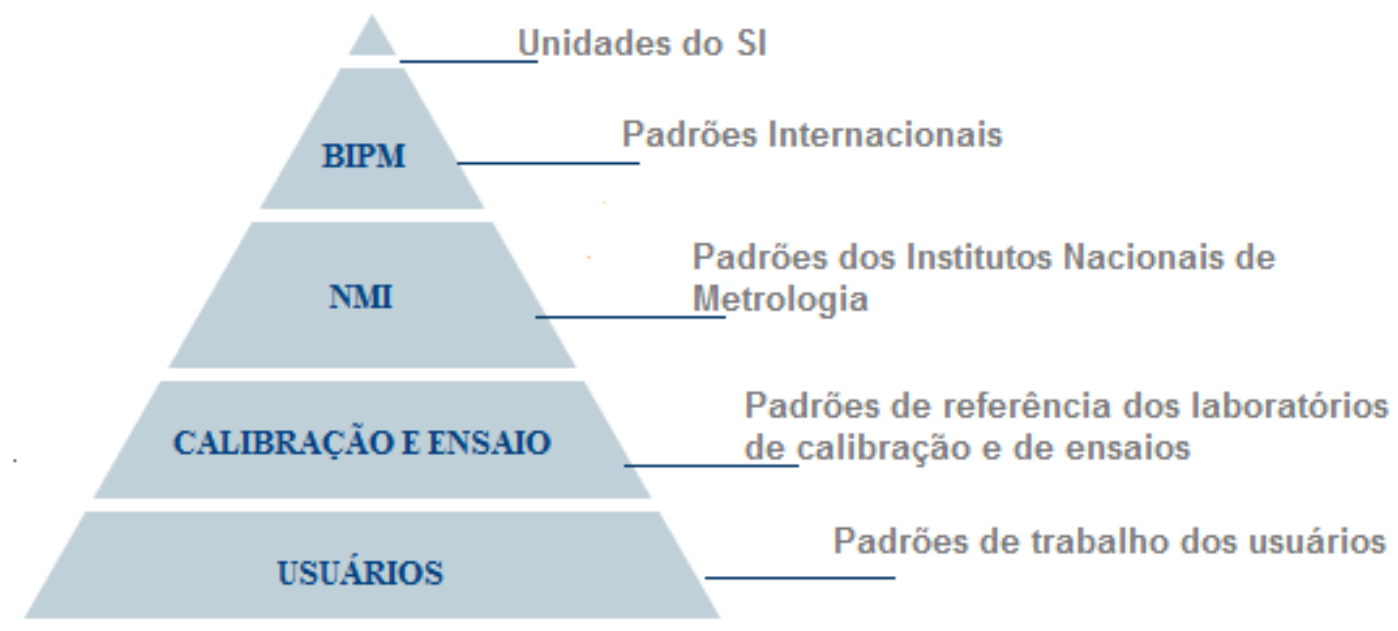

FIGURA 14. Hierarquia do sistema metrológico.

Aos NMI cabe a guarda dos padrões nacionais e a disseminação das unidades SI para os padrões de referência dos laboratórios credenciados de calibração de seus respectivos países. Em seguida, encontram-se os 
laboratórios credenciados de ensaios que são responsáveis pela qualificação e avaliação de conformidade de produtos que buscam a certificação. Os padrões de referência dos laboratórios de ensaio são calibrados em relação aos padrões de referência dos laboratórios de calibração credenciados. $\mathrm{Na}$ base da estrutura, situam-se os padrões de trabalho dos usuários cuja calibração também provém dos padrões de referência dos laboratórios de calibração credenciados $^{(33)}$.

\subsubsection{Calibração de Instrumentos}

Para que um instrumento medidor de radiação seja utilizado é necessário que antes seja calibrado, garantindo a confiabilidade da relação entre a leitura feita pelo equipamento e os valores de referência das grandezas de interesse. Para calibrar um instrumento é utilizado um instrumento de referência ou instrumento padrão.

De acordo com o VIM (Vocabulário Internacional de Metrologia), "calibração é a operação que estabelece, sob condições especificadas, numa primeira etapa, uma relação entre os valores e as incertezas de medição fornecidos por padrões e as indicações correspondentes com as incertezas associadas; em uma segunda etapa, utiliza esta informação para estabelecer uma relação visando a obtenção de um resultado de medição a partir duma indicação. Uma calibração pode ser expressa por meio de uma declaração, uma função de calibração, um diagrama de calibração, uma curva de calibração ou uma tabela de calibração. Em alguns casos, pode consistir de uma correção aditiva ou multiplicativa da indicação com uma incerteza de medição associada" (INMETRO(34), [2016]) ${ }^{1}$.

Quando um instrumento é calibrado, encontra-se um valor multiplicativo para converter o valor indicado, adequando-o a condições de

\footnotetext{
${ }^{1}$ www.inmetro.gov.br
} 
valores de referência para um valor de grandeza medida, denominado "coeficiente de calibração".

\subsubsection{Qualidade de Radiação e CSR}

Um feixe de raios $X$ é caracterizado em função de sua qualidade e sua quantidade. A qualidade está relacionada a energia dos fótons, ou seja, sua capacidade de penetração. A quantidade, está relacionada ao número de fótons no feixe. A intensidade de um feixe é dependente tanto da qualidade quanto da quantidade. Quando um feixe de raios $X$ atravessa um material, ele sofre atenuação e consequentemente sua intensidade diminui. A atenuação obedece a lei exponencial mostrada na Equação (17)(35).

$$
I=I_{0} e^{-\mu x} \text { ou } N=N_{0} e^{-\mu x}
$$

Onde:

Io e I: são, respectivamente, a intensidade do feixe antes e depois de atravessar um material com espessura $x$;

$e$ : é a base dos logaritmos neperianos;

$\mu$ : é o coeficiente de atenuação linear do meio;

No e N: São, respectivamente, o número de fótons antes e depois de atravessar um material com espessura $x$;

A FIG.15, ilustra como ocorre a atenuação de um feixe de raios $X$. 


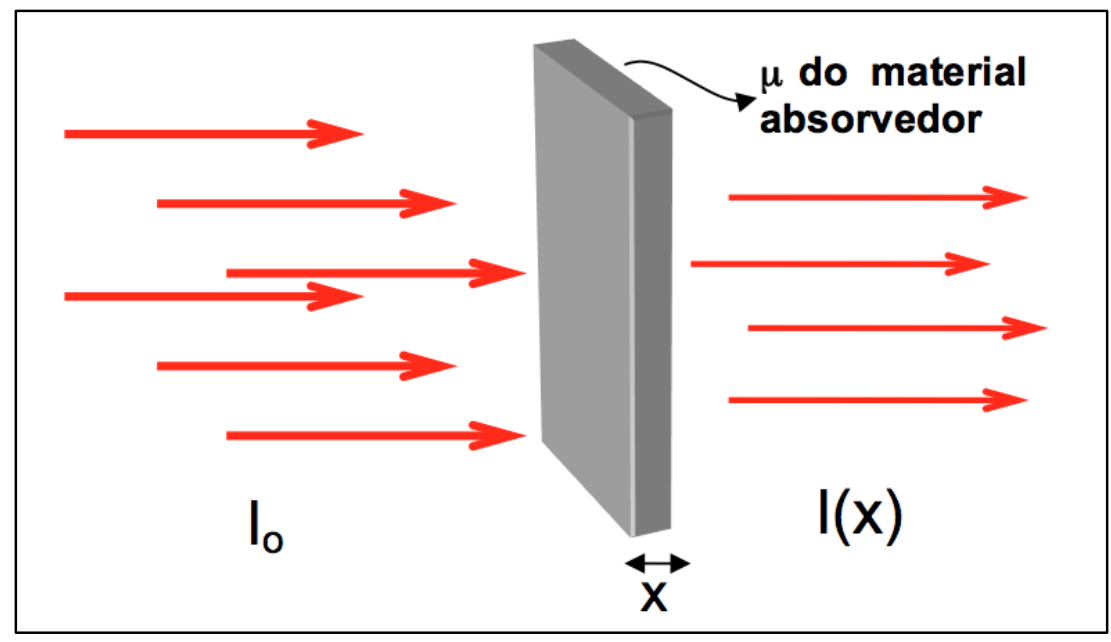

FIGURA 15. llustração mostrando um feixe de raios $X$ sofrendo atenuação após atravessar um material absorvedor de espessura $x$ e coeficiente de atenuação linear $\mu$.

Pela definição, camada semirredutora (CSR) é a espessura de um dado material que reduz a intensidade da radiação à metade.

Em um feixe monoenergético, a intensidade é proporcional ao número de fótons, e por isso, podemos dizer que o número de fótons que atravessa um material com espessura $X_{1 / 2}$ sem interagir, se reduz à metade do número de fótons incidentes, como mostra a Equação(35) (18).

$$
I=\frac{I_{0}}{2}=I_{0} e^{-\mu X_{1 / 2}} \text { ou } N=\frac{N_{0}}{2}=N_{0} e^{-\mu X_{1 / 2}}
$$

De onde podemos concluir que:

$$
\begin{gathered}
\frac{1}{2}=e^{-\mu X_{\frac{1}{2}}} \\
\ln 2=0,693=\mu X_{1 / 2} \\
X_{1 / 2}=0,693 / \mu
\end{gathered}
$$

Onde, $\mathrm{X}_{1 / 2}$ chama-se camada semirredutora e $\mu$ é o coeficiente de atenuação linear do meio. 
Assim sendo, a determinação dos valores de CSR, para as diversas energias do feixe torna-se um método indireto e alternativo para a determinação do poder de penetração de um feixe em alguns materiais.

O gráfico da FIG.16 mostra a relação entre a CSR e energia equivalente de fótons em keV para chumbo $(\mathrm{Pb})$, cobre $(\mathrm{Cu})$ e alumínio $(\mathrm{Al})$.

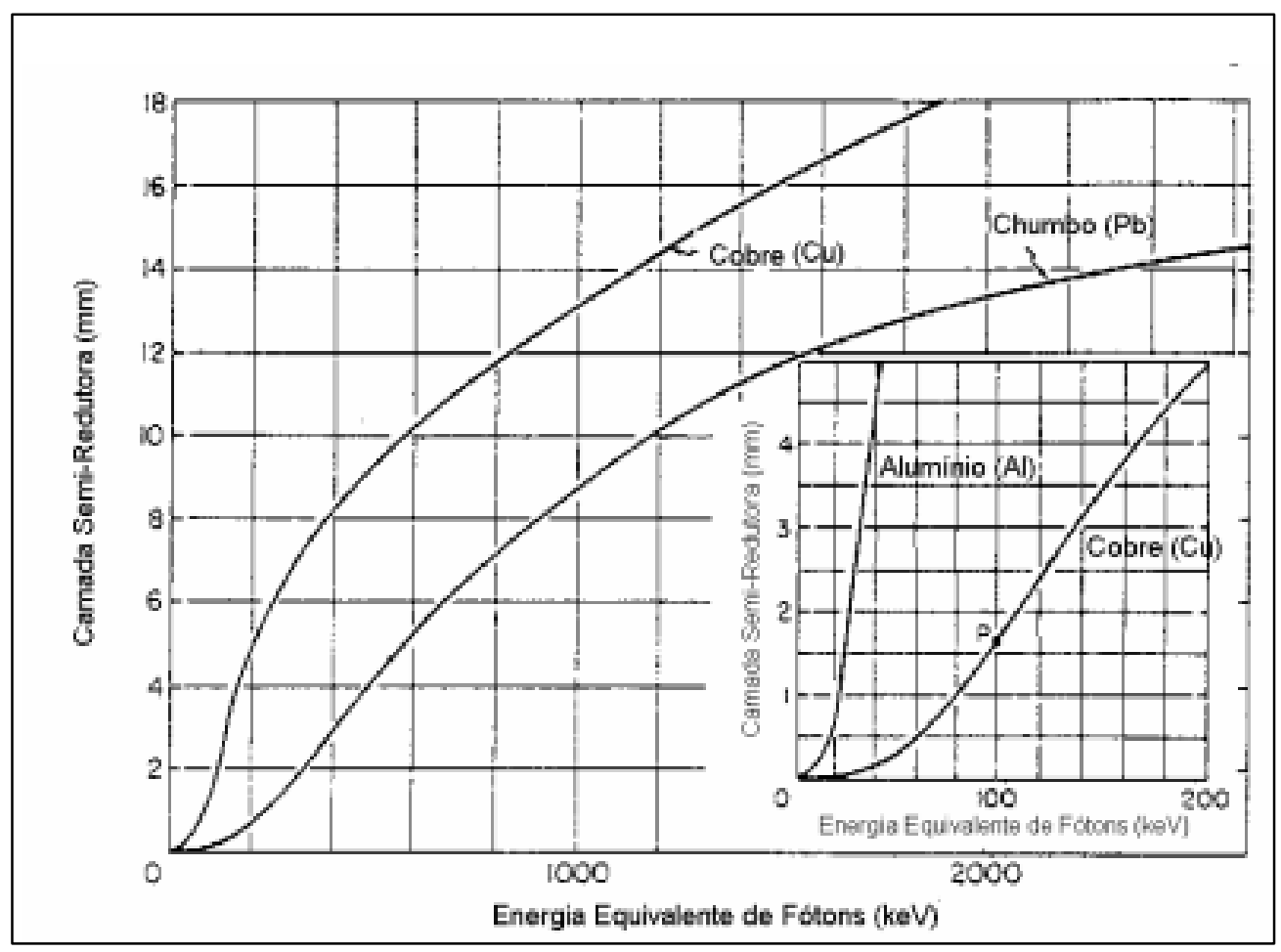

FIGURA 16. Relação entre a CSR e energia equivalente para Pb, Cu e Al. (JOHNS_83)

\subsubsection{Laboratório de Calibração de Instrumentos do IPEN (LCI-IPEN)}

Desde a década de 80, o Laboratório de Calibração de Instrumentos (LCI) realiza calibrações de câmaras de ionização $(\mathrm{Cl})$ utilizadas em medidas de levantamento radiométrico e, no ano 2000 , passou a efetuar este serviço também para os instrumentos utilizados na dosimetria em sistemas clínicos de radiodiagnóstico incluindo aqueles indicados para Tomografia Computadorizada $(\mathrm{TC})^{(6)} \mathrm{Em}$ 2010, Dias ${ }^{(8)}$ implantou no equipamento de 
radiação $X$ do $L C l$ as qualidades de TC (RQT) para calibração através da aplicação de filtros de cobre em qualidades não atenuadas (RQR) obtendo assim energias na faixa de 100 a $150 \mathrm{kV}$, deixando-o dentro das mais recentes recomendações metrológicas seguindo o código de prática TRS $457^{(7)}$ e a revisão da norma IEC $61267^{(9)}$. Além dessas, outras qualidades de radiodiagnóstico foram implantadas seguindo as mesmas recomendações. $A$ TAB.2 mostra as qualidades de radiação RQT implantadas.

TABELA 2. Qualidades de radiação RQT, recomendadas pela norma IEC $61267^{\left({ }^{(8)}\right.}$ a partir das qualidades RQR.

\begin{tabular}{c|c|c|c}
\hline Qualidade & $\begin{array}{c}\text { Tensão nominal } \\
\text { aplicada ao tubo } \\
(\mathrm{kV})\end{array}$ & $\begin{array}{c}\text { Filtro Adicional } \\
(\mathrm{mmCu})\end{array}$ & $\begin{array}{c}1^{\text {a }} \mathrm{CSR} \\
(\mathrm{mmAl})\end{array}$ \\
\hline RQT 8 & 100 & 0,20 & 6,9 \\
\hline RQT 9 & 120 & 0,25 & 8,4 \\
\hline RQT 10 & 150 & 0,30 & 10,1 \\
\hline
\end{tabular}

\subsubsection{Calibração da Câmara de Ionização do Tipo Lápis}

A câmara de ionização do tipo lápis possui geometria e características diferentes por se tratar de instrumento de medição utilizado em equipamentos de tomografia computadorizada. A calibração e as medições realizadas com a câmara de ionização do tipo lápis são feitas em termos de $P_{k, l}$ (produto Kerma no ar - comprimento).

Para a determinação do coeficiente de calibração $N_{k . l}$ utiliza-se 0 método da irradiação parcial, ou seja, de $50 \%$ do comprimento sensível da câmara de ionização. Os valores do $P_{k}$. dado em Gy.cm e do Kerma no ar em Gy, podem ser encontrados utilizando as Equações (19) e (20).

$$
P_{k, l}=M . N_{k, l} \cdot K_{q}
$$




$$
K_{\text {ar }}=P_{k, l} / w
$$

Onde:

Pk.l. É a taxa do produto Kerma no ar - comprimento.

$N_{k, l .}$ É o coeficiente de calibração em termos de produto Kerma no ar comprimento $\left(P_{k, l}\right)$ para qualidade de radiação de referência RQT9.

Kq. É o fator de correção para qualidade.

Kar. É o Kerma no ar em Gy.

W. É o comprimento irradiado da câmara em cm.

M. É a leitura no instrumento.

Na FIG.17 pode ser visto o arranjo experimental utilizado para calibrar a câmara de ionização do tipo lápis no LCl segundo as recomendações do TRS $457^{(7)}$.

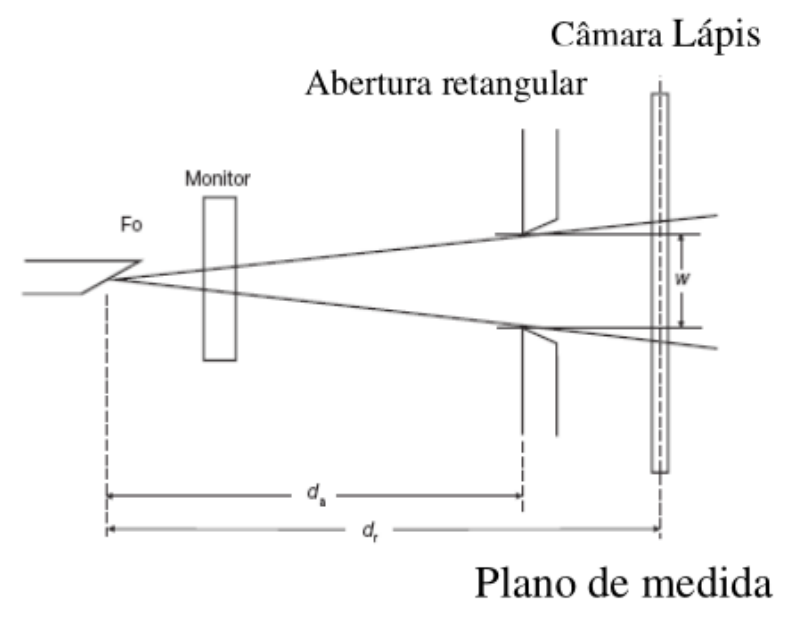

FIGURA 17. Exemplo de arranjo experimental utilizado para calibração em TC, segundo a TRS 457 ( $d_{\mathrm{a}}$ : distância foco-colimador e $d_{r}$ : distância foco-medida). 


\subsubsection{Certificado de Calibração}

O certificado de calibração é um documento emitido por laboratórios de calibração, quando é realizada a calibração do instrumento ou sistema de medição. Nos certificados são registrados os resultados obtidos, bem como as suas incertezas, além das condições ambientais durante a calibração.

A NBR ISO/IEC $17025^{(36)}$ determina o conteúdo mínimo que os certificados de calibração e relatórios devem possuir.

- Título

- Nome e endereço do laboratório

- Identificação única do certificado de calibração.

- Nome e endereço do cliente.

- Identificação do método utilizado.

- Identificação do instrumento calibrado.

- Data da realização da calibração

- Resultado da calibração com as unidades de medida. As unidades de medida devem estar relacionadas ao sistema internacional de unidades (SI). Caso o resultado seja declarado em unidade de medida que não pertença ao SI, um fator de conversão ou tabela correspondente deve estar contido no certificado ${ }^{(36)}$.

- Nome, função e assinatura ou identificação equivalente da pessoa autorizada para emissão do certificado de calibração.

- Declaração de que os resultados se referem somente aos itens calibrados.

- Condições ambientais em que foi executada a calibração.

- Declaração da incerteza da medição 


\subsection{Incertezas}

A incerteza associada a uma medição possibilita a avaliação de sua confiabilidade. Indica um intervalo de valores onde seria possível encontrar o valor verdadeiro, que é uma grandeza desconhecida. A variação da incerteza pode estar relacionada a diversos fatores como: precisão do instrumento, manuseio do operador, condições ambientais, entre outros.

De acordo com o Vocabulário Internacional de Termos Fundamentais e Gerais de Metrologia, a incerteza de medição é definida como sendo um parâmetro, associado ao resultado de uma medição que caracteriza a dispersão dos valores que podem ser fundamentadamente atribuídos a um mensurando ${ }^{(38)}$.

A incerteza da medição pode ser caracterizada por:

Incerteza do Tipo A - Tem como referência a análise estatística, ou seja, a média e os seus desvios.

Incerteza do Tipo B - Ao contrário da incerteza do tipo $A$, tem como referência os parâmetros não estatísticos como informações fornecidas através de manuais, certificados de calibração, entre outros que forneçam informações prévias.

Incerteza Combinada - É a associação das incertezas do tipo A e do tipo B, como mostra a Equação (21).

$$
u_{c}=\sqrt{u_{1}^{2}+u_{2}^{2}+\cdots u_{n}^{2}}
$$

Incerteza Expandida - É calculada pela multiplicação do fator de abrangência $(k)$, resultante do $v$ efetivo ( $v_{\text {eff }}$ ), o qual está relacionado aos graus de liberdade $v=n-1$, onde $n$ é o número de medições realizadas, dos componentes envolvidos. 
Para calcular a incerteza expandida é necessário utilizar os componentes da incerteza como:

a. Obtém-se a incerteza combinada.

b. Obtêm-se o v efetivo (Veff) pela Equação(37) (22).

$$
V_{\text {eff }}=\frac{(\text { incerteza combinada })^{4}}{\left[(\text { Incerteza tipo } A)^{4} /(\text { graus de liberdade })\right]}
$$

c. Verifica-se na Tabela de Coeficientes de Student, em função do $V_{\text {eff, }}$ o valor do fator de abrangência $k$;

d. Multiplica-se a incerteza combinada pelo fator k, para a obtenção da incerteza expandida.

\subsubsection{Incertezas nas Medidas com Dosímetros em Radiodiagnóstico}

A incerteza nas medições em radiodiagnóstico depende de fatores como: Tipo de dosímetro utilizado, qualidade da radiação, aplicação do $\mathrm{k}_{\mathrm{q}}$ para a qualidade, a precisão com o qual o dosímetro está localizado no ponto de medição, entre outros. Na prática, recomenda-se que o usuário selecione o nível de incerteza desejado para uma determinada tarefa e em seguida tome as medidas necessárias para alcançar esse nível. Algumas referências sobre os níveis de incertezas podem ser vistas na TAB.3(7). São mostrados 3 cenários de medição onde:

- Cenário 1 - Refere-se ao caso em que um instrumento está em conformidade com a norma IEC 61674, onde se constitui um nível mínimo de desempenho que pode ser ultrapassado por instrumentos "ótimos". As correções aplicadas nesse cenário são referentes a temperatura média na sala de medição e correção da densidade do ar com base na pressão normal numa altitude acima do nível do mar. O limite aceitável sobre o qual a 
resposta do dosímetro pode variar deve estar dentro do limite calculado através da incerteza do tipo $A^{(7)}$.

Cenário 2 - Refere-se ao caso do uso de um dosímetro de referência. As propriedades desse dosímetro podem ser vistas na TAB.4. Neste cenário é necessário utilizar valores reais de pressão e temperatura tomados no momento da medição. A redução da incerteza do cenário 1 para um cenário 2 é conseguida através da redução do erro intrínseco através de uma calibração de um SSDL e usando um detector com uma pequena dependência energética de resposta ${ }^{(7)}$.

Cenário 3 - Descreve o caso em que as condições de exposição são rigidamente controladas (ou seja, em termos de qualidade de radiação, direção de incidência da radiação, densidade do ar, etc.) e onde correções para as grandezas de influência relevantes são feitas. Por exemplo, um coeficiente de calibração ou $\mathrm{k}_{q}$ é interpolado a partir dos valores para qualidades que rodeiam a qualidade do feixe medido e, em seguida, é feita provisão para a resposta energética do dosímetro(7). 
TABELA 3. Exemplos de valores de incerteza para medições realizadas por dosímetro de diagnóstico. (Tabela adaptada de TRS457 ${ }^{(7)}$ )

\begin{tabular}{|c|c|c|c|c|}
\hline \multirow[t]{2}{*}{ Medida de Influência } & \multirow{2}{*}{$\begin{array}{c}\text { IEC } 61674 \\
L( \pm \%)\end{array}$} & \multicolumn{3}{|c|}{$\begin{array}{l}\text { Incerteza } \\
(\mathrm{K}=1) /(\%)\end{array}$} \\
\hline & & Cenário 1 & Cenário 2 & Cenário 3 \\
\hline $\begin{array}{l}\text { Erro intrínseco } \\
N_{K, Q} \text { ou } N_{k, Q_{0}, K_{Q}}\end{array}$ & 5 & 2,89 & 1,6 & 1,6 \\
\hline $\begin{array}{l}\text { Qualidade da radiação, } \\
\text { i.e. diferenças entre } \\
\text { laboratório e usuário }\end{array}$ & 5 & 2,89 & 1,5 & 0,5 \\
\hline Taxa de Kerma & 2 & 1,15 & 0,5 & 0,5 \\
\hline $\begin{array}{c}\text { Direção da radiação } \\
\text { incidente }\end{array}$ & 3 & 1,73 & 1,0 & 0,5 \\
\hline Pressão & 2 & 1,15 & 0,5 & 0,5 \\
\hline Temperatura e umidade & 3 & 1,73 & 0,5 & 0,5 \\
\hline $\begin{array}{l}\text { Compatibilidade } \\
\text { eletromagnética }\end{array}$ & 5 & 2,89 & 1,5 & 1,0 \\
\hline $\begin{array}{c}\text { Tamanho e } \\
\text { homogeneidade de } \\
\text { campo }\end{array}$ & 3 & 1,73 & 1,0 & 1,0 \\
\hline Tensão operacional & 2 & 1,15 & 1,2 & 1,0 \\
\hline $\begin{array}{l}\text { Estabilidade a longo } \\
\text { prazo }\end{array}$ & 2 & 1,15 & 1,0 & 0,5 \\
\hline $\begin{array}{c}\text { Incerteza padrão } \\
\text { combinada relativa } \\
\qquad(\mathrm{k}=1)\end{array}$ & - & 6,3 & 3,5 & 2,7 \\
\hline $\begin{array}{c}\text { Incerteza expandida } \\
\text { relativa } \\
(k=2)\end{array}$ & - & 12,6 & 7,0 & 5,4 \\
\hline
\end{tabular}


TABELA 4. Propriedades recomendadas para um dosímetro de referência (Por aplicação). (Tabela adaptada de TRS457(7)).

\begin{tabular}{|c|c|c|c|c|c|c|}
\hline \multirow{2}{*}{ Aplicação } & \multirow{2}{*}{$\begin{array}{l}\text { Tipo de } \\
\text { detector }\end{array}$} & \multirow{2}{*}{$\begin{array}{l}\text { Intervalo de } \\
\text { tensão } \\
(k V)\end{array}$} & \multirow{2}{*}{$\begin{array}{c}\text { Erro } \\
\text { intrínseco } \\
(\%)\end{array}$} & \multirow{2}{*}{$\begin{array}{c}\text { Máxima } \\
\text { variação } \\
\text { da } \\
\text { resposta } \\
\text { (\%) }\end{array}$} & \multicolumn{2}{|c|}{$\begin{array}{c}\text { Intervalo da taxa de } \\
\text { Kerma }\end{array}$} \\
\hline & & & & & $\begin{array}{c}\text { Feixe } \\
\text { não } \\
\text { atenuado }\end{array}$ & $\begin{array}{c}\text { Feixe } \\
\text { atenuado }\end{array}$ \\
\hline $\begin{array}{l}\text { Radiologia } \\
\text { convencional }\end{array}$ & $\begin{array}{l}\text { Cilíndrico / } \\
\text { placas } \\
\text { paralelas }\end{array}$ & $60-150$ & 3,2 & $\pm 2,6$ & $\begin{array}{c}1 \mathrm{mgy} / \mathrm{s}- \\
500 \\
\mathrm{mgy} / \mathrm{s}\end{array}$ & $\begin{array}{l}10 \mu \mathrm{gy} / \mathrm{s}- \\
5 \mathrm{mgy} / \mathrm{s}\end{array}$ \\
\hline Fluoroscopia & $\begin{array}{c}\text { Cilíndrico / } \\
\text { placas } \\
\text { paralelas } \\
\text { (Recomendado) }\end{array}$ & $50-100$ & 3,2 & $\pm 2,6$ & $\begin{array}{l}10 \mu \mathrm{gy} / \mathrm{s}- \\
10 \mathrm{mgy} / \mathrm{s}\end{array}$ & $\begin{array}{c}0,1 \mu \mathrm{gy} / \mathrm{s} \\
-100 \\
\mu \mathrm{gy} / \mathrm{s}\end{array}$ \\
\hline Mamografia & $\begin{array}{c}\text { Placas } \\
\text { paralelas }\end{array}$ & $22-40$ & 3,2 & $\pm 2,6$ & $\begin{array}{l}10 \mu \mathrm{gy} / \mathrm{s}- \\
10 \mathrm{mgy} / \mathrm{s}\end{array}$ & \\
\hline $\begin{array}{c}\text { Tomografia } \\
\text { computadorizada }\end{array}$ & $\begin{array}{l}\text { Cilíndrica } \\
\text { (tipo lápis) }\end{array}$ & $100-150$ & 3,2 & $\pm 2,6$ & $\begin{array}{c}0,1 \mathrm{mgy} / \mathrm{s} \\
-50 \\
\mathrm{mgy} / \mathrm{s}\end{array}$ & \\
\hline $\begin{array}{c}\text { Radiologia } \\
\text { odontológica }\end{array}$ & $\begin{array}{c}\text { Cilíndrico / } \\
\text { placas } \\
\text { paralelas }\end{array}$ & $50-90$ & 3,2 & $\pm 2,6$ & $\begin{array}{l}1 \mu \mathrm{gy} / \mathrm{s}- \\
10 \mathrm{mgy} / \mathrm{s}\end{array}$ & \\
\hline
\end{tabular}




\subsection{Dosimetria Clínica em TC e Protocolos Disponíveis}

Existem alguns protocolos disponíveis para auxiliar na dosimetria em sistemas clínicos de radiodiagnóstico. Os principais são:

- European Guidelines on Quality Criteria for Computed Tomography - EUR16262, 1999.

- Radiodiagnóstico Médico: Desempenho De Equipamentos E Segurança - Anvisa, 2005.

- Dosimetry in Diagnostic Radiology: Na International Code Of Practice - TRS 457, IAEA 2007.

- The Measurement, Reporting and Management Of Radiation Dose In CT - AAPM Report No. 96, 2008.

Desses protocolos, o TRS $457^{(7)}$ traz as principais diretrizes que incluem tanto procedimentos em laboratórios de calibração e dosimetria, quanto em aplicações clínicas. Foi seguindo esse protocolo que se implantou as qualidades de radiação no $\mathrm{LCI}$ - IPEN, e por isso é o documento de referência para este trabalho.

Neste código de prática as grandezas básicas para a dosimetria clínica em TC, são: Índice de Kerma no ar $\mathrm{C}_{\mathrm{a}, 100}$; Índice de dose ponderado $\mathrm{C}_{\mathrm{w}}$; Índice de Kerma volumétrico $\mathrm{C}_{\mathrm{vol}}$; e produto Kerma - comprimento $\mathrm{P}_{\mathrm{K}, \mathrm{L}}$.

Para realizar medições na dosimetria em TC, é necessário utilizar uma câmara de ionização do tipo lápis calibrada (FIG.18) e um eletrômetro, além de simuladores de cabeça e tronco (FIG.19), termômetro e barômetro. 


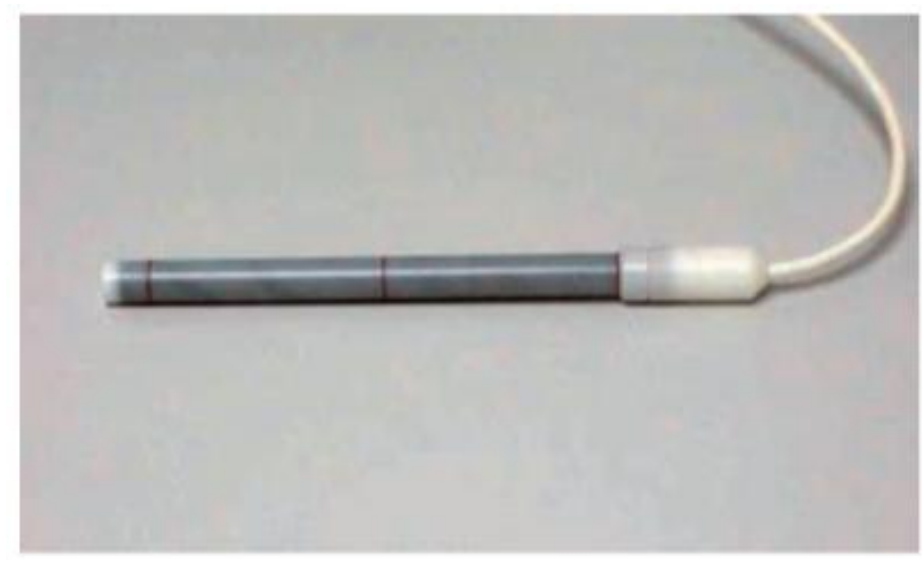

FIGURA 18. Câmara de ionização do tipo lápis. (Adaptada de TRS $457^{(7)}$ ).

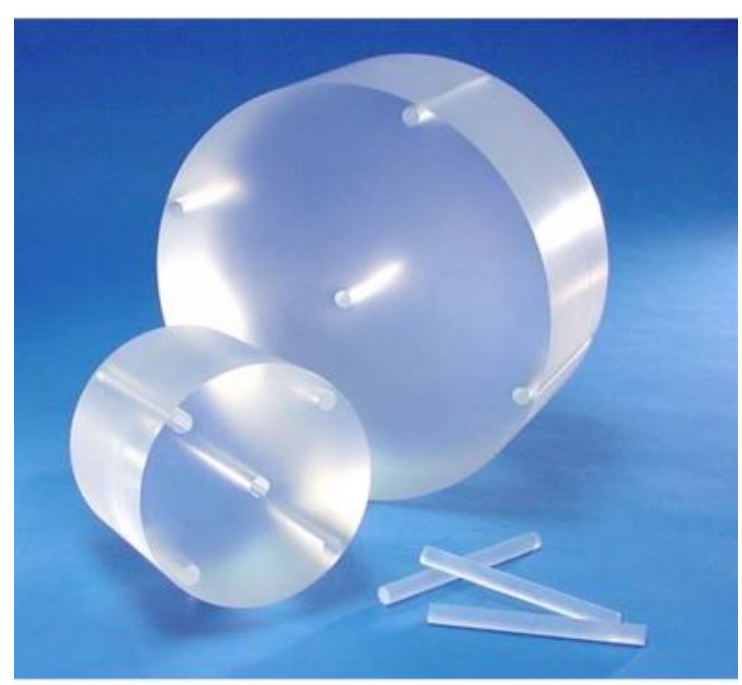

FIGURA 19. Simuladores de cabeça e tronco.

\subsubsection{Medidas Da Taxa De Kerma No Ar E Medidas Com Simuladores}

As medições do índice de Kerma no ar Ca,100, (FIG.20) e as medições com a câmara de ionização tipo lápis posicionada dentro do orifício central CPMma,100,c e periféricos CPMma,100,p (FIG.21) dos simuladores devem ser determinadas para uma única rotação axial do tubo, com parâmetros utilizados em exames de rotina nos pacientes, empregando os simuladores quando apropriado. É possível realizar medições para rotações axiais consecutivas, mas é necessário normalizar as leituras para uma única 
rotação ${ }^{(7)}$. Para Tomógrafos multicorte, é necessário ter cautela no momento de identificar corretamente o número de canais $\mathrm{N}$ (que representa o número de cortes simultaneamente adquiridos) e a espessura nominal de corte $T$ que pode não ser a mesma que a espessura nominal do corte reconstruído. $O$ produto NT deve demonstrar a espessura nominal total do feixe de raios $\mathrm{X}$. As leituras realizadas para aquisição do $\mathrm{C}_{a, 100} \mathrm{e}$ do $\mathrm{C}_{w}$ normalizadas para o produto tempo de exposição por unidade da corrente do tubo $P_{I t}$, são também calculadas.

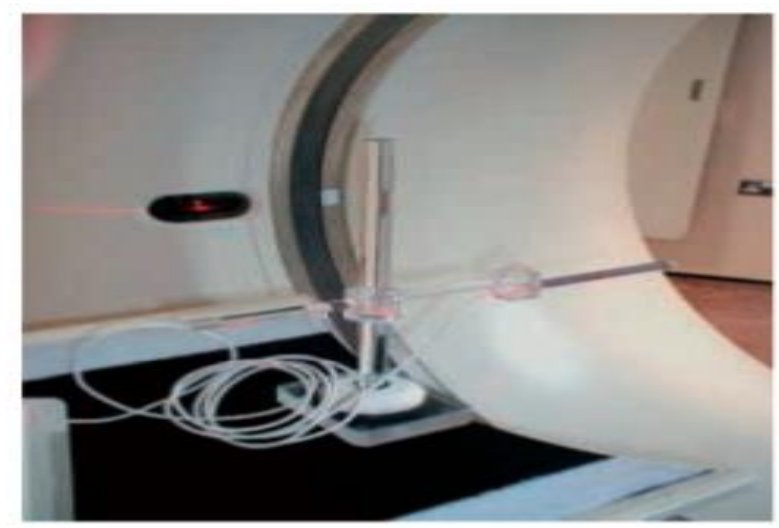

FIGURA 20. Arranjo para medições do índice de Kerma no ar $C_{a, 100}$. A câmara de ionização é posicionada com auxilio de um suporte e alinhada no isocentro com o laser de rotação posicionado no volume sensível da câmara. A angulação do gantry deve ser nula. (Adaptada de TRS $457^{(7)}$ )

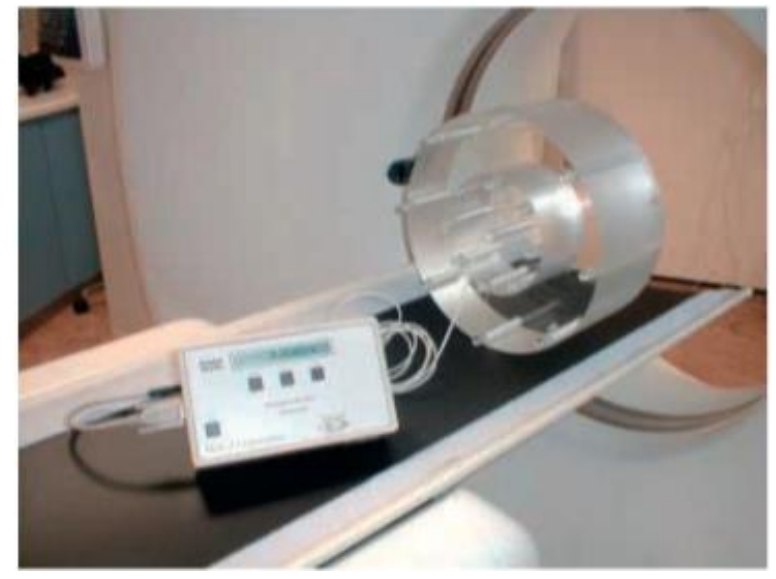

FIGURA 21. Arranjo para medições com simulador de tronco. O simulador é posicionado na mesa e a câmara de ionização é inserida no orifício do simulador para leitura. Deve ser utilizada a capa da câmara para garantir um bom ajuste dentro do simulador. $O$ laser de rotação deve estar alinhado com a área sensível da câmara. (Adaptado de TRS $457^{(7)}$ ) 


\section{MATERIAIS}

\subsection{Sistema de radiação $X$}

- Sistema de radiação X marca Pantak/Seifert, modelo Isovolt HS, na faixa de operação de radiodiagnóstico clínico (40 kV-160 kV) localizado no Laboratório de Calibração de Instrumentos (LCI) do Instituto de Pesquisas Energéticas e Nucleares (IPEN). A corrente aplicada foi de $10 \mathrm{~mA}$, para as séries de qualidades RQT implantadas, anteriormente relacionadas na TAB.2.

- Tomógrafo Philips IDT 16 - Hospital A

- Tomógrafo Siemens Somaton Definition AS - Hospital B.

\subsection{Sistema de detecção}

- Câmara de ionização do tipo lápis padrão pertencente ao $\mathrm{LCl}$, marca Radcal, modelo RC 3CT.

- Eletrômetro padrão pertencente ao LCI, marca Keithley, modelo 6517A;

- Conjunto formado por câmara de ionização do tipo lápis, marca Radcal, modelo 10x5 3 CT, acoplada a um eletrômetro marca Radcal, modelo 9015, denominado conjunto um;

- Conjunto formado por câmara de ionização do tipo lápis, marca Radcal, modelo 10x5 3 CT, acoplada a um eletrômetro marca Radcal, modelo 9015, denominado conjunto dois;

\subsection{Sistema de tratamento de dados}

- Software LabView. 


\subsection{Certificados de calibração}

- Certificados de calibração de 8 câmaras de ionização do tipo lápis, todas da marca Radcal sendo: 5 Câmaras de ionização modelo 10x5 CT; 2 Câmaras de ionização modelo 10x6 CT; 1 Câmara de ionização modelo 20x6 CT; Essas câmaras foram enviadas para calibração no LCl durante o ano de 2013.

\subsection{Sistema Tandem desenvolvido no IPEN}

- Conjunto formado por cinco capas absorvedoras cilíndricas de alumínio projetadas e confeccionadas na oficina do IPEN. Este conjunto foi projetado com base em estudos realizados no IPEN por Maia ${ }^{13}$. As capas possuem $150 \mathrm{~mm}$ de comprimento e espessuras que somadas totalizam $10 \mathrm{mmAl}$; sendo uma de $3 \mathrm{~mm}$, três de $2 \mathrm{~mm}$ e uma de $1 \mathrm{~mm}$; o diâmetro interno da primeira capa que constitui o conjunto possui $12,5 \mathrm{~mm}$, dimensão adequada a câmara de ionização do tipo lápis utilizada neste trabalho. O diâmetro interno das outras capas corresponde ao diâmetro externo das capas subsequentes que formam o conjunto.

- Conjunto formado por três capas absorvedoras cilíndricas de acrílico (PMMA) projetadas e confeccionadas na oficina do IPEN. Este conjunto foi projetado com base em estudos realizados no IPEN por Maia ${ }^{13 .}$ As capas possuem $150 \mathrm{~mm}$ de comprimento e espessuras que somadas totalizam $35 \mathrm{~mm}$; sendo uma de $15 \mathrm{~mm}$ e duas de $10 \mathrm{~mm}$. O diâmetro interno da primeira capa que constitui o conjunto possui $12,5 \mathrm{~mm}$, dimensão adequada a câmara de ionização do tipo lápis utilizada neste trabalho. O diâmetro interno das outras capas corresponde ao diâmetro externo das capas subsequentes que formam o conjunto. 


\subsection{Sistema de filtros}

- Composição de filtros de alumínio referentes a 1a CSR das qualidades RQT de 6,9 mmAl, 8,4 mmAl e 10,1 mmAl disponíveis no LCl.

\subsection{Outros}

- Termômetro

- Barômetro

- Micrômetro 


\section{METODOLOGIA}

A metodologia utilizada neste trabalho seguiu a ordem de objetivos a serem cumpridos:

- Avaliar a dependência energética de diferentes câmaras de ionização do tipo lápis de mesma marca e modelo.

- Realizar um estudo das metodologias existentes para avaliação da CSR em equipamentos de tomografia computadorizada.

- Definir qual das metodologias será utilizada neste trabalho, levando em consideração o custo benefício e praticidade no uso.

- Realizar a calibração dos detectores a serem utilizados nas medições.

- Projetar e desenvolver os materiais e o arranjo experimental necessários para a aplicação da metodologia escolhida.

- Testar a metodologia escolhida em laboratório.

- Testar a metodologia em feixes clínicos.

- Desenvolver o guia orientativo para dosimetria em tomografia computadorizada com base nos resultados.

\subsection{Avaliação da Dependência Energética de Diferentes Câmaras de lonização do Tipo Lápis de Mesmo Modelo e Fabricante}

Foram utilizados oito certificados de calibração de câmaras de ionização do tipo lápis calibradas no LCI durante o ano de 2013, sendo todas as câmaras de mesmo modelo e fabricante. Foram analisados os coeficientes de calibração e os fatores de correção para a qualidade $(\mathrm{Kq})$, para cada uma das qualidades RQT estabelecidas, para cada câmara de ionização do tipo 
lápis calibrada. A avaliação dos fatores de correção para a qualidade foi realizada para 0 intervalo correspondente a um feixe de tomografia computadorizada (CT), mostrado na TAB.5.

TABELA 5. Qualidades de radiação RQT, recomendadas pela norma IEC $61267^{(8)}$ a partir das qualidades RQR.

\begin{tabular}{c|c|c|c}
\hline Qualidade & $\begin{array}{c}\text { Tensão nominal } \\
\text { aplicada ao tubo } \\
(\mathrm{kV})\end{array}$ & $\begin{array}{c}\text { Filtro Adicional } \\
(\mathrm{mmCu})\end{array}$ & $\begin{array}{c}1^{\text {a } \mathrm{CSR}} \\
(\mathrm{mmAl})\end{array}$ \\
\hline RQT 8 & 100 & 0,20 & 6,9 \\
\hline RQT 9 & 120 & 0,25 & 8,4 \\
\hline RQT 10 & 150 & 0,30 & 10,1 \\
\hline
\end{tabular}

\subsection{Estudo das Metodologias Utilizadas para Avaliação da CSR em Tomografia Computadorizada}

A geometria de um equipamento de tomografia computadorizada torna a determinação da CSR uma tarefa difícil. Apesar de a maioria dos protocolos não incluir a determinação da CSR no programa de controle de qualidade, pois, em TC, a CSR é normalmente determinada pelo fabricante, essa avaliação da CSR pode não só trazer informações importantes sobre possíveis desvios no funcionamento do equipamento, como também, auxiliar na construção da curva de calibração da câmara de ionização do tipo lápis. Muitos usuários têm dúvidas em relação ao uso dos fatores de correção para qualidade $\left(\mathrm{k}_{\mathrm{q}}\right)$ indicados no certificado de calibração ao utilizar uma câmara de ionização calibrada na dosimetria de seus sistemas de TC. Para que o $\mathrm{K}_{\mathrm{q}}$ seja aplicado de maneira correta, é necessário conhecer á faixa de energia que está sendo utilizada, ou seja, a qualidade do feixe de radiação em questão. Algumas metodologias foram desenvolvidas e estudadas para auxiliar na determinação da CSR em tomógrafos. 


\subsubsection{Metodologia de Localização}

A metodologia de localização( ${ }^{(37)}$ consiste em utilizar a técnica scout ou prescan para calcular o valor de CSR. Nessa técnica o tubo de raios $X$ permanece parado enquanto a mesa realiza um movimento de translação. É necessário desconsiderar a movimentação da mesa durante os testes. A geometria utilizada para o teste é parecida com a geometria utilizada para o cálculo em radiologia convencional. Utiliza-se de placas de alumínio de espessuras diferentes fixadas no gantry na direção do eixo do tubo de raios X, como mostra a FIG.22. A partir das médias do Kerma no ar obtidas sem filtração e com a adição dos filtros calcula-se a CSR pela Equação (23) ${ }^{(37)}$.

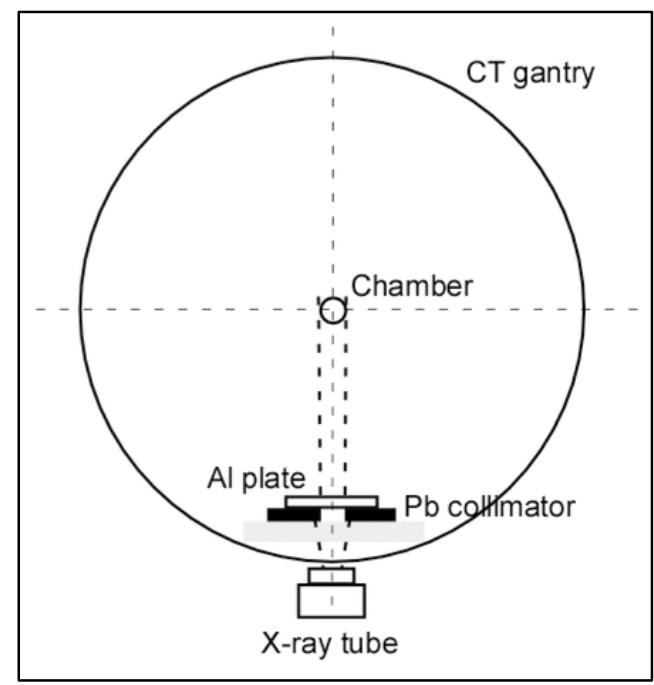

FIGURA 22. Esquema de arranjo montado para testes da metodologia de posicionamento para cálculo de CSR em tomógrafos.

$$
\operatorname{CSR}=\frac{x_{b} \cdot \ln \left(\frac{2 L_{a}}{L_{0}}\right)-x_{a} \cdot \ln \left(\frac{2 L_{b}}{L_{0}}\right)}{\ln \left(\frac{L_{a}}{L_{b}}\right)}
$$

Onde:

Lo: É a média dos valores de Kerma no ar medidos sem filtro.

$\mathrm{L}_{a}$ : É a leitura imediatamente superior a $\mathrm{L}_{0}$. 
Lb: É a leitura imediatamente inferior a Lo/2.

Xa: É a espessura de alumínio correspondente a leitura $L_{a}$.

$\mathrm{X}_{\mathrm{b}}$ : É a espessura de alumínio correspondente a leitura $L_{b}$.

\subsubsection{Metodologia do Anel}

Diferente da metodologia de localização, nessa utiliza-se a técnica corte a corte de aquisição de imagens para realização dos testes ${ }^{(37)}$. Neste modo, seleciona-se o incremento da mesa ou pitch zero, para que não se movimente no interior do gantry durante a rotação do tubo de raios $\mathrm{X}$ e é feita apenas uma aquisição de imagem em modo axial. A mesa também serve de apoio para a câmara de ionização. Os anéis de alumínio são posicionados na abertura do gantry como pode ser visto na FIG.23. A partir das médias do Kerma no ar obtidas sem filtração e com a adição dos filtros calcula-se a CSR pela Equação (23) mostrada na seção anterior.

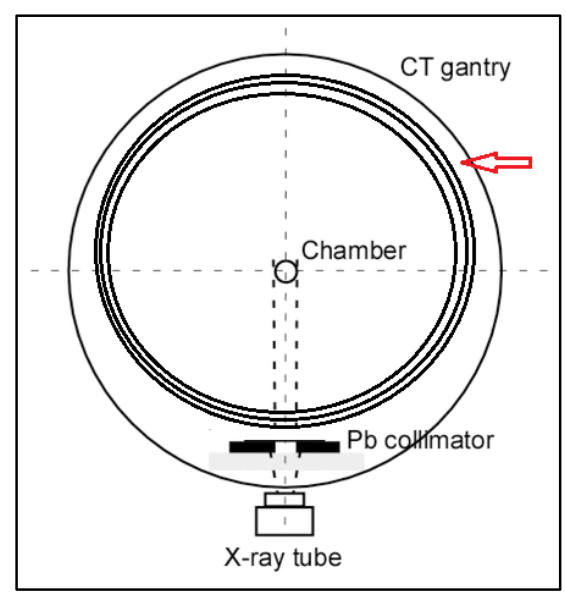

FIGURA 23. Esquema de arranjo montado para testes da metodologia do anel para cálculo de CSR em tomógrafos. 


\subsubsection{Sistema Tandem}

Com o objetivo de contribuir para o controle de qualidade nos tomógrafos, Maia(13) realizou um estudo para definir uma forma prática de avaliação de CSR, com base em um sistema simples e de baixo custo.

Pela definição, a energia de um feixe é determinada através do valor de camada semirredutora (CSR). Quando os valores de CSR não são facilmente determinados como no caso de TC, é possível avaliar a energia efetiva do feixe através de um sistema que consiste na utilização de dosímetros com dependência energética diferentes, onde a razão entre as respostas das curvas de calibração em energia pode fornecer a energia efetiva do feixe (sistema Tandem). A aplicação deste sistema foi proposta por Kenney e Cameron(10) e Gorbics e Attix ${ }^{(11)}$ que utilizaram materiais termoluminescentes para determinar energia de radiações gama e $X$. $O$ sistema desenvolvido por Maia(13) é composto por dois conjuntos de câmara de ionização do tipo lápis e duas capas absorvedoras de materiais com dependência energética diferentes. Foram confeccionadas 9 capas de 3 materiais diferentes: 3 de acrílico (com 5, 15, e $25 \mathrm{~mm}$ de espessura), 3 de alumínio (com 1, 3, e 5 mm de espessura) e 3 de cobre (com 0,051, 0,152 e 0,254 mm de espessura) conforme FIG.24.

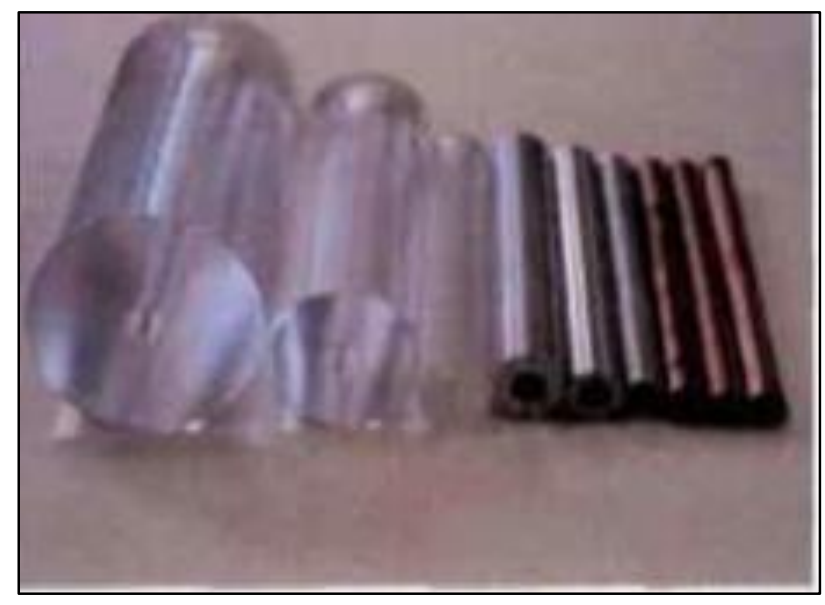

FIGURA 24. Capas absorvedoras que constituem o sistema Tandem desenvolvido por MAIA $^{13}$.

Os conjuntos que apresentaram melhor resultado foram da câmara de ionização do tipo lápis com a capa de $5 \mathrm{mmAl}$ e o da câmara de ionização do 
tipo lápis com a capa de $15 \mathrm{~mm}$ de alumínio (FIG. 25 ${ }^{(13)}$ ). Quanto maior for a inclinação da curva Tandem, mais útil é o sistema para avaliação da CSR.

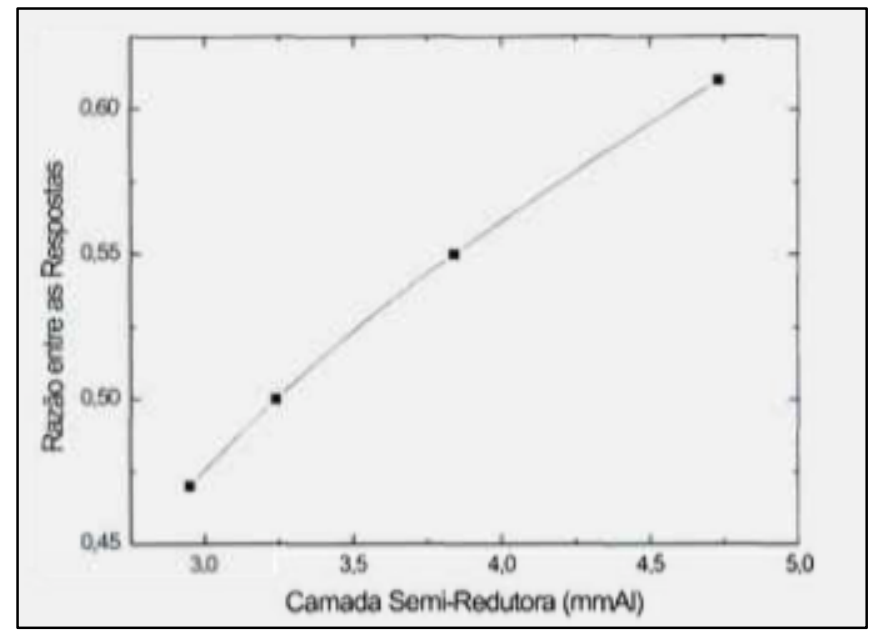

FIGURA 25. Curva Tandem obtida por Maia(13). A curva representa a razão entre as respostas da câmara de ionização do tipo lápis com a capa de $5 \mathrm{mmAl}$ pelas respostas da câmara de ionização do tipo lápis com a capa de $15 \mathrm{~mm}$ de acrílico. As medidas foram feitas para as qualidades RQR 7, RQR 8, RQR 9 e RQR 10. (Adaptada de Maia ${ }^{(13)}$ )

Neste trabalho optou-se em testar um sistema Tandem devido ao baixo custo de produção e praticidade na aplicação clínica.

\subsection{Calibração das Câmaras de Ionização do Tipo Lápis}

As câmaras de ionização do tipo lápis possuem características de uso e geometria peculiares e, por isso, o método de calibração dessas câmaras é também diferenciado. Existem diferentes métodos de calibração onde a principal diferença está relacionada a área irradiada da câmara de ionização(8). É comum, em várias aplicações da câmara lápis, a irradiação total da câmara, mas sabe-se que testes de homogeneidade da resposta ao longo do seu comprimento sensível mostraram que há uma perda de sensibilidade nas suas extremidades ${ }^{(13)}$. Levando em consideração as peculiaridades da câmara lápis, no código de prática da Agência Internacional de Energia Atômica (AIEA) TRS $457^{(7)}$ foi estabelecida a metodologia para calibração em SSDL's onde a câmara é irradiada parcialmente como mostram as FIG.26 e 27. 


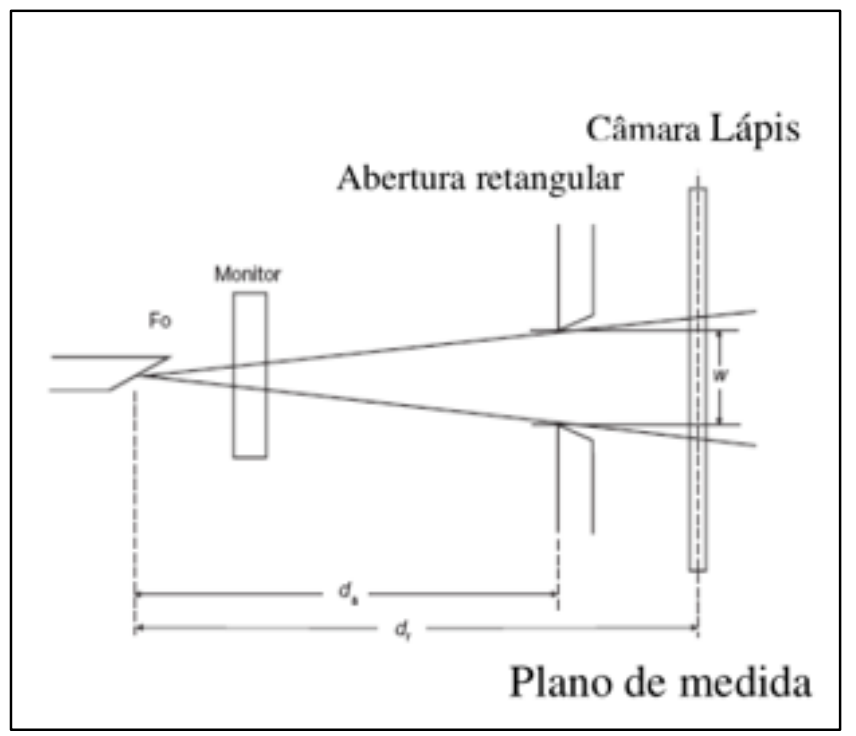

FIGURA 26. Exemplo de arranjo experimental utilizado para calibração em TC, de acordo com o TRS 457( $d_{a}$ : distância foco-colimador e $d_{r}$ : distância foco-medida).

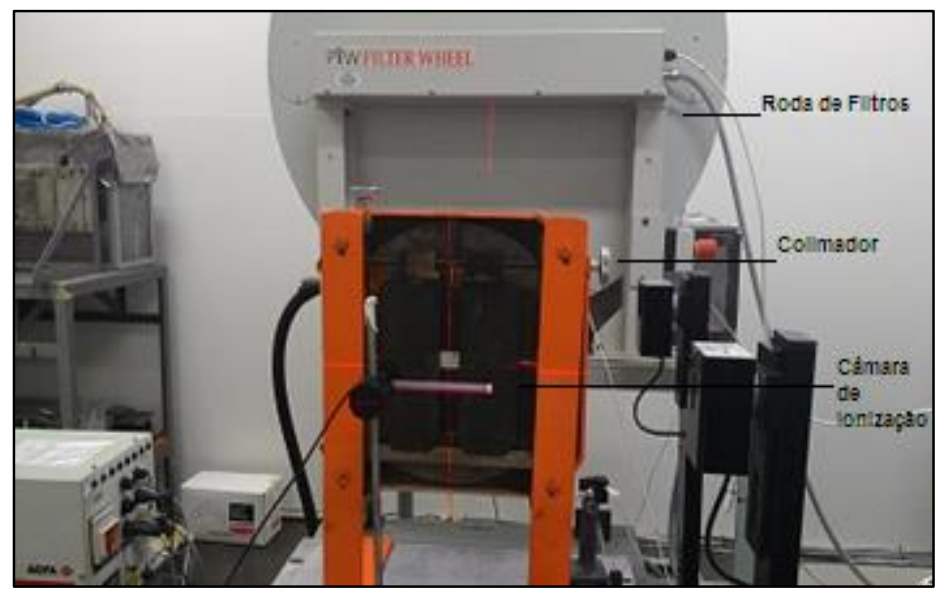

FIGURA 27. Câmara de ionização do tipo lápis posicionada de acordo com o arranjo proposto pelo TRS 457, no LCl.

As câmaras são calibradas nas qualidades RQT correspondentes a faixa de energia utilizada em tomografia computadorizada. É possível observar as características dessas qualidades na TAB.5. 


\subsubsection{Procedimento de Calibração das Câmaras De lonização do Tipo Lápis}

Utilizando-se as qualidades de radiação estabelecidas para o intervalo correspondente a um feixe de tomografia computadorizada (CT), RQT8, RQT9 e RQT10, e a câmara de ionização padrão do $\mathrm{LCl}$, foram aplicados os procedimentos de calibração segundo o código de prática da agência internacional de energia atômica TRS457 conforme FIG.26 da seção anterior.

O método utilizado foi o método da substituição, onde as medições de kerma no ar são feitas primeiramente com o padrão na mesma posição da câmara de ionização em calibração e corrigidas pelas condições ambientais e em seguida são realizadas com a câmara de ionização a ser calibrada.

\subsubsection{Determinação das Taxas de Kerma no Ar com a Câmara Padrão}

Para determinar a taxa de kerma no ar $\left(K_{a r}\right)$, foram utilizados os fatores de correção para qualidade $\left(K_{q}\right)$ e coeficientes de calibração $\left(\mathrm{N}_{k, l}\right)$ fornecidos pelo laboratório primário alemão PTB, e multiplicados pelas leituras obtidas com a câmara padrão como mostra a Equação (24).

$$
K_{a r}=\mathrm{Nk}, \mathrm{l} \times K_{q} \times M
$$

Onde M é a leitura com o instrumento de referência.

\subsubsection{Determinação dos Coeficientes de Calibração $N_{k, 1}$}

O coeficiente de calibração $N_{k, l}$ foi determinado a partir do quociente entre a leitura da taxa de Kerma no ar da câmara padrão, pela média das leituras de taxa de kerma no ar da câmara em calibração e corrigida pelas condições ambientais como na Equação (25): 


$$
N_{k, l}=\frac{K_{a r}}{M \times F_{T, p}}
$$

Onde:

$K_{a r}$ É a taxa de Kerma no ar obtida através da câmara padrão;

M É a média das leituras de taxa de kerma obtidas com a câmera em calibração;

$F_{T, p}$ É o fator de correção para temperatura e pressão.

\subsubsection{Determinação do Fator de Correção para Qualidade $K_{q}$}

O fator de correção para qualidade $\mathrm{Kq}$, foi determinado através do coeficiente de calibração $N_{k, l}$ como mostra a Equação (26):

$$
K_{q}=\frac{N_{k, l}}{N_{K, l r e f}}
$$

Onde,

$K_{\mathrm{q}}$ É o fator de correção para qualidade.

$\mathrm{N}_{\mathrm{k}, \mathrm{l}}$ É o coeficiente de calibração em termos de $\mathrm{P}_{\mathrm{k}, \mathrm{l}}$ (Produto Kerma no ar comprimento) da qualidade RQT8, 9 ou 10.

$N_{k, l \text { ref }} E$ o fator de calibração em termos de $P_{k, l}$ (Produto Kerma no ar comprimento) da qualidade de referência RQT9.

Com os valores do $\mathrm{K}_{q}$ das qualidades de referência obtidos durante a calibração dos conjuntos 1 e 2 , foi possível construir a curva de calibração para cada conjunto, para aplicação do sistema Tandem proposto neste trabalho. 


\subsection{Projeto e Construção de um Sistema Tandem}

Com base nas capas absorvedoras construídas por Maia(13) para formar um sistema Tandem e já mostradas anteriormente na FIG.23, foi desenvolvido um sistema similar para avaliar a CSR em tomógrafos.

Diferente das capas utilizadas como referência, onde cada uma possui espessura fixa, as capas utilizadas neste trabalho foram confeccionadas para serem acopladas formando a espessura necessária de acordo com a faixa de energia utilizada pelo usuário durante o teste.

Foram confeccionadas cinco capas absorvedoras cilíndricas de alumínio sendo: uma de $1 \mathrm{~mm}$, três de $2 \mathrm{~mm}$, e uma de $3 \mathrm{~mm}$, sendo possível obter espessuras de 1, 3, 5, 7 e $10 \mathrm{mmAl}$. Dessa forma foi possível obter as espessuras em mmAl correspondente a faixa de energia que cobre o intervalo de energia utilizado em TC.

O projeto para construção das capas de alumínio pode ser visto na FIG.28.

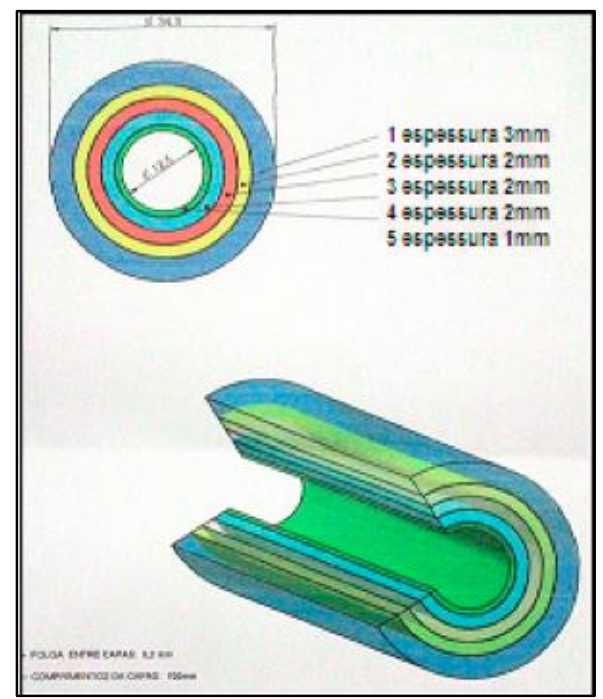

FIGURA 28. Projeto elaborado para confecção das capas absorvedoras cilíndricas de alumínio (Al). 
As capas absorvedoras cilíndricas de acrílico (PMMA) são três: uma de $15 \mathrm{~mm}$ e duas de $10 \mathrm{~mm}$, sendo possível obter espessuras de 15, 25 e 35mmPMMA. A FIG.29 mostra o projeto elaborado para confecção das capas absorvedoras de acrílico (PMMA).

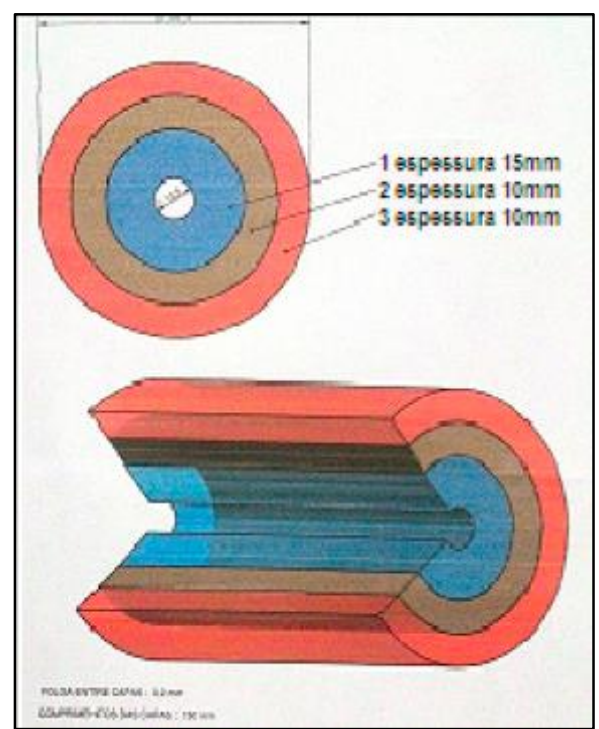

FIGURA 29. Projeto elaborado para construção das capas absorvedoras cilíndricas de acrílico. (PMMA)

\subsection{Avaliação dos Valores de CSR nos Feixes Padrões do LCI}

Primeiramente foram realizados testes para verificar os valores de camada semirredutora (CSR) para as qualidades de TC existentes no equipamento de radiação $X$ do $L C l$. Para este teste foi utilizado o conjunto de detectores 1 (câmara de ionização acoplada ao eletrômetro).

Foram feitas 3 séries de leituras para cada qualidade de radiação RQT sem filtração e em seguida 3 séries de 5 leituras com a filtração correspondente, para checar a CSR. O programa desenvolvido Labview fornece para cada série de leituras a média $(M)$, o coeficiente de calibração $\left(N_{K, l}\right)$, a média das leituras da câmara monitora como também a taxa de Kerma medido, os valores médios de temperatura e pressão para cálculo do fator de correção para temperatura e pressão $\left(F_{T, p}\right)$ e as incertezas. 
O arranjo montado para os testes foi com a câmara de ionização do tipo lápis no ar, posicionada há 1 metro de distância do ponto focal, com o feixe colimado no centro da câmara de ionização como na FIG.30. A abertura do feixe em sua altura é de duas vezes a área sensível do detector, ou seja, $2 \mathrm{~cm}$ e largura de $2,4 \mathrm{~cm}$, com um campo de $4,8 \mathrm{~cm}^{2}$.

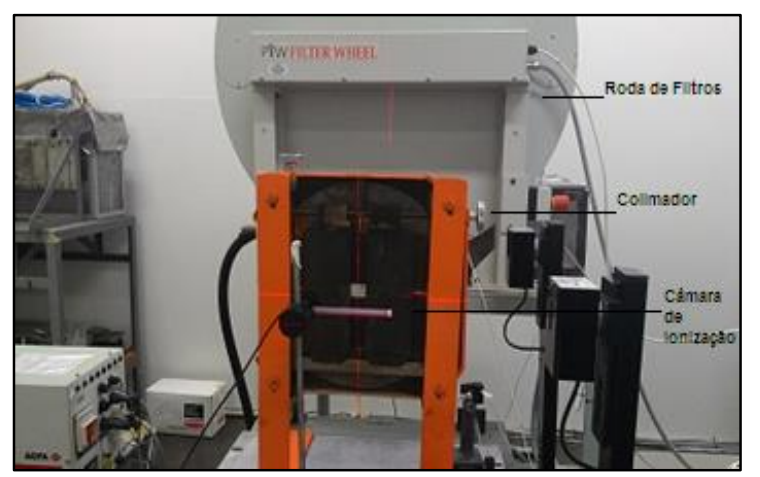

FIGURA 30. Câmara de ionização do tipo lápis posicionada de acordo com o arranjo proposto pelo TRS 457.

A corrente aplicada foi de $10 \mathrm{~mA}$ e os filtros colocados em um suporte posicionado na saída do feixe como na FIG.31.

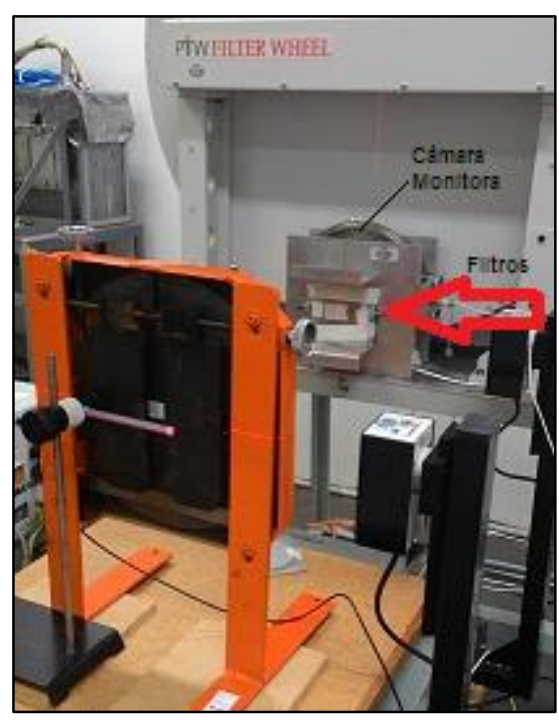

FIGURA 31. Arranjo utilizado para avaliação dos valores de CSR das qualidades de referência. 


\subsection{Construção das Curvas Tandem}

Em seguida, foram realizadas 3 séries de 5 leituras com as capas absorvedoras cilíndricas de $1 \mathrm{~mm}, 3 \mathrm{~mm}, 5 \mathrm{~mm}, 7 \mathrm{~mm}$ e $10 \mathrm{~mm}$ de alumínio como mostra a FIG.32, e com as capas absorvedoras cilíndricas de $15 \mathrm{~mm}, 25 \mathrm{~mm}$ e $35 \mathrm{~mm}$ de PMMA, respectivamente, para cada qualidade RQT, afim de se construir curvas Tandem através das razões entre as repostas obtidas pelos conjuntos formados entre a câmara de ionização e as capas.

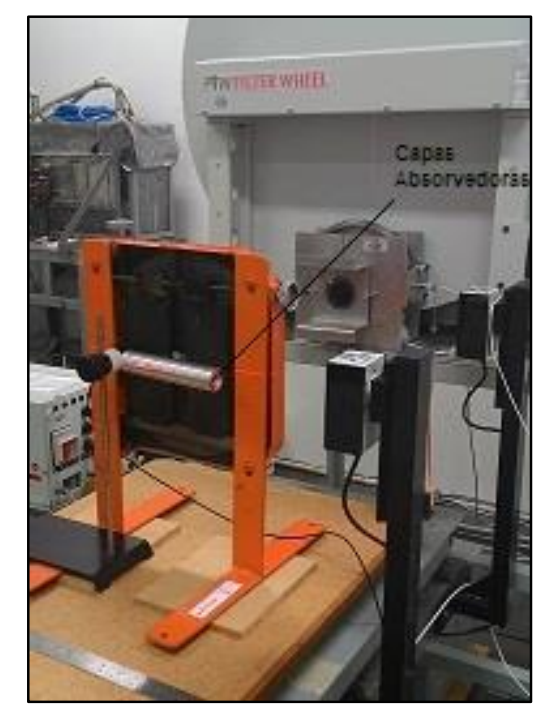

FIGURA 32. Testes realizados com as capas absorvedoras cilíndricas de alumínio sobre a câmara de ionização.

\subsubsection{Análise das Curvas Tandem}

Após os testes com o sistema Tandem proposto neste trabalho, foram analisadas as curvas referentes às razões entre as respostas obtidas pelos conjuntos formados entre a câmara de ionização do tipo lápis e cada capa absorvedora cilíndrica de alumínio e PMMA, com as respostas da câmara de ionização no ar. Além das razões entre as respostas dos conjuntos formados pela câmara de ionização do tipo lápis e as capas absorvedoras cilíndricas de alumínio e as respostas da câmara de ionização do tipo lápis e as capas absorvedoras cilíndricas de acrílico (PMMA). 
Foram identificadas as diferenças percentuais entre as razões obtidas por cada conjunto para camadas semirreduroras subsequentes. Os valores correspondem as CSR das qualidades RQT (TAB.5), correspondentes à faixa de energia utilizada em tomografia computadorizada.

\subsection{Testes Realizados com o Sistema Tandem no Hospital A}

Para verificar o comportamento do sistema Tandem desenvolvido neste trabalho em um feixe clínico de TC, algumas medições foram realizadas no tomógrafo instalado no hospital A.

O conjunto de detectores utilizado neste teste foi o conjunto um. A câmara de ionização foi posicionada no isocentro, alinhada ao laser de posicionamento através de um suporte de acrílico e presa por uma fita adesiva para evitar possíveis movimentações durante os testes conforme FIG.33.

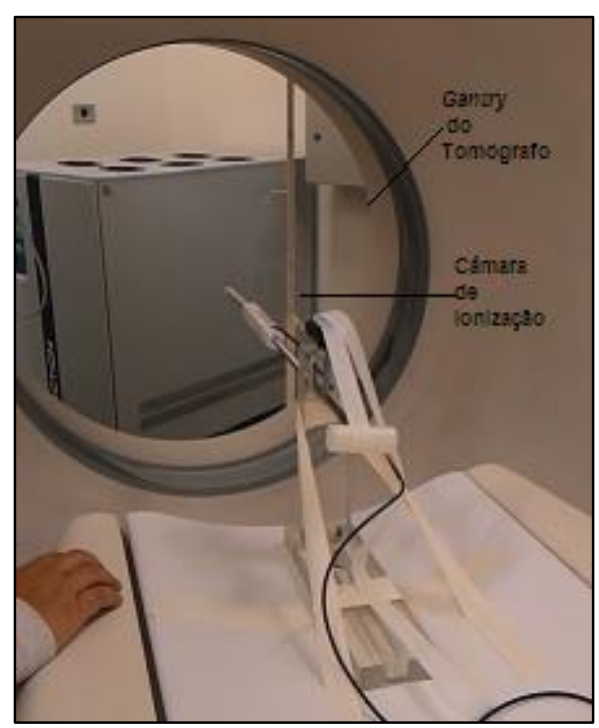

FIGURA 33. Arranjo experimental para testes de avaliação da CSR do feixe, através do sistema Tandem no tomógrafo do hospital A. 
Foram realizadas 3 leituras com a câmara de ionização no ar e com a capa absorvedora cilíndrica de $10 \mathrm{mmAl}$. O protocolo escolhido foi o de crânio e os parâmetros utilizados encontram-se na TAB.6.

TABELA 6. Parâmetros do protocolo de crânio do tomógrafo do Hospital A.

\begin{tabular}{c|c|c|c}
\hline $\begin{array}{c}\text { Espessura Nominal } \\
\text { de Corte }\end{array}$ & Número de Slices & Pit (mA.s) & kV \\
\hline $12 \mathrm{~mm}$ & 1 & 100 & 120 \\
\hline
\end{tabular}

Devido a dificuldades no posicionamento, e falta de material que pudesse servir como base para apoiar as capas absorvedoras cilíndricas de acrílico, não foi possível realizar medições com a capa de PMMA no tomógrafo do hospital A.

\subsection{Testes Realizados com o Sistema Tandem no Hospital B}

Para realização dos testes no hospital $B$, foram utilizados os parâmetros mostrados na TAB.7.

TABELA 7. Parâmetros do protocolo de abdome do tomógrafo do hospital B.

\begin{tabular}{c|c|c|c}
\hline $\begin{array}{c}\text { Espessura Nominal } \\
\text { de Corte }\end{array}$ & Número de Slices & Pit (mA.s) & kV \\
\hline $2 \mathrm{~mm}$ & 1 & 170 & 130 \\
\hline
\end{tabular}

O conjunto de detectores utilizado neste teste foi o conjunto dois. Foram realizadas 5 leituras com a câmara de ionização do tipo lápis no ar.

O arranjo montado para realização dos testes pode ser visto na FIG.34. 


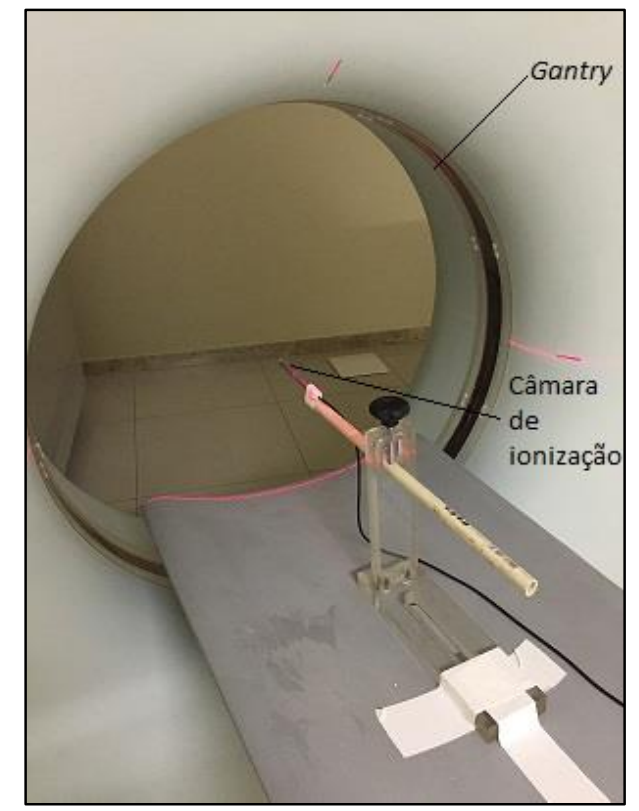

FIGURA 34. Arranjo experimental para testes de determinação da energia efetiva do feixe através do sistema Tandem no hospital B.

Em seguida foram realizadas 5 leituras com as capas absorvedoras cilíndricas de $10 \mathrm{mmAl}$ e $35 \mathrm{mmPMMA}$. Nas FIG. 35 e 36, pode ser visto o arranjo montado para os testes com as capas absorvedoras.

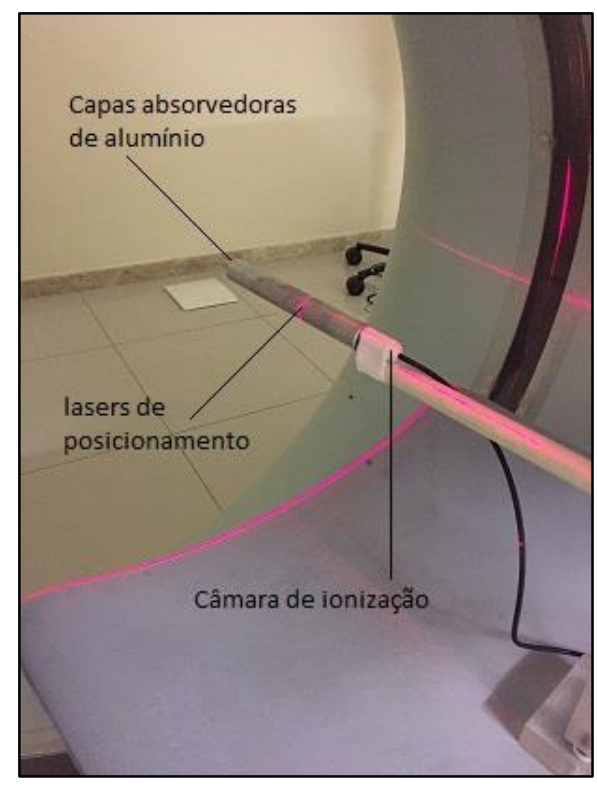

FIGURA 35. Arranjo experimental para testes com a capa absorvedora cilíndrica de $10 \mathrm{mmAl}$, no tomógrafo do hospital B. 


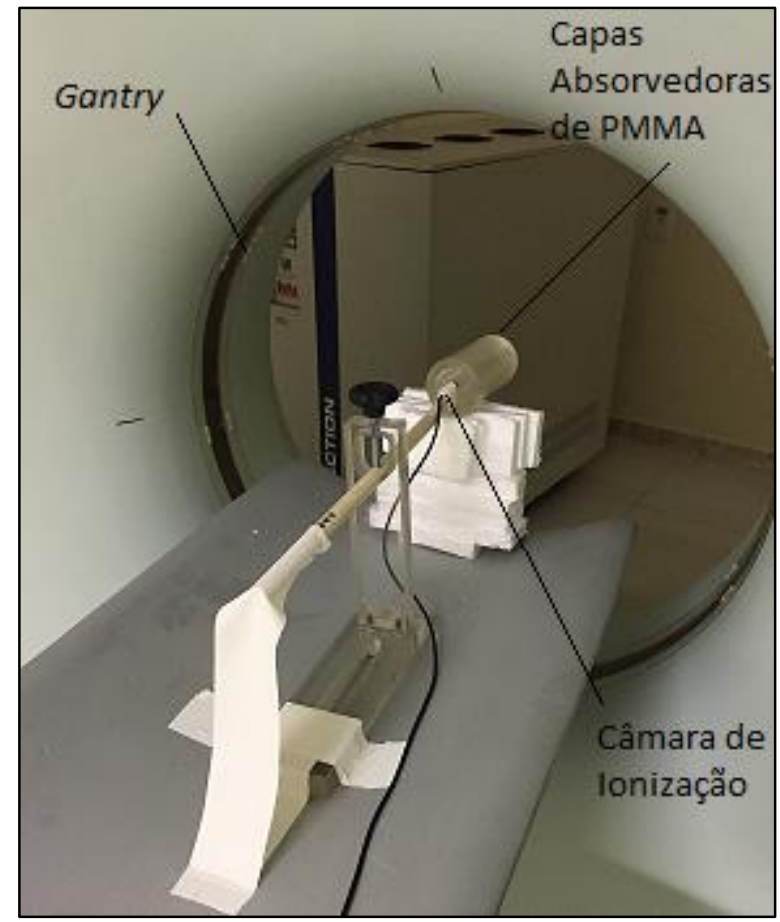

FIGURA 36. Arranjo experimental para testes com a capa absorvedora cilíndrica de 35mmPMMA, no tomógrafo do hospital B. Para realizar esse teste, foi necessário utilizar uma base de isopor para sustentar o peso da capa absorvedora de 13mmPMMA e evitar a inclinação da câmara de ionização. 


\section{RESULTADOS}

\subsection{Avaliação da Dependência Energética de Diferentes Câmaras de lonização do Tipo Lápis de Mesmo Modelo e Fabricante}

Após a determinação dos fatores de correção para qualidade Kq no intervalo padrão (RQT) foi possível comparar os valores e observar a dependência energética existente nas câmaras de ionização do tipo lápis calibradas no LCI -IPEN conforme TAB.8:

TABELA 8. Valores de Kq para qualidade de referência.

\begin{tabular}{|c|c|c|c|c|c|c|}
\hline \multirow{4}{*}{$\mathrm{Cl}$} & \multirow{4}{*}{$\begin{array}{l}\text { Fabricante } \\
\text { e Modelo }\end{array}$} & \multicolumn{5}{|c|}{ Fator de correção para qualidade $\mathrm{K}_{\mathrm{q}}$} \\
\hline & & \multirow{3}{*}{$\begin{array}{c}\begin{array}{c}\text { RQT8 } \\
\text { (CSR) }\end{array} \\
\begin{array}{c}6,9 \\
\mathrm{mmAl}\end{array}\end{array}$} & \multirow{3}{*}{$\begin{array}{c}\text { RQT9 } \\
\text { (CSR) }\end{array}$} & \multirow{3}{*}{$\begin{array}{c}\text { RQT10 } \\
\text { (CSR) } \\
\begin{array}{c}10,1 \\
\mathrm{mmAl}\end{array}\end{array}$} & \multicolumn{2}{|c|}{$\begin{array}{l}\text { Variação no intervalo entre } \\
\text { CSR subsequentes (\%) }\end{array}$} \\
\hline & & & & & \multirow{2}{*}{$\begin{array}{c}\text { Intervalo } 1 \\
(6,9 \text { a } 8,4) \\
\text { mmAl }\end{array}$} & \multirow{2}{*}{$\begin{array}{c}\text { Intervalo } 2 \\
(8,4 \text { a } 10,1) \\
\text { mmAl }\end{array}$} \\
\hline & & & & & & \\
\hline $\mathbf{A}$ & $\begin{array}{l}\text { Radcal } \\
10 \times 5 \mathrm{CT}\end{array}$ & 0,994 & 1 & 0,992 & 0,6 & 0,8 \\
\hline B & $\begin{array}{l}\text { Radcal } \\
10 \times 5 \mathrm{CT}\end{array}$ & 1 & 1 & 0,96 & 0,0 & 4,1 \\
\hline C & $\begin{array}{c}\text { Radcal } \\
10 \times 5 \mathrm{CT}\end{array}$ & 0,993 & 1 & 1,015 & 0,7 & 1,4 \\
\hline D & $\begin{array}{l}\text { Radcal } \\
10 \times 5 \mathrm{CT}\end{array}$ & 0,989 & 1 & 1,01 & 1,1 & 0,9 \\
\hline $\mathbf{E}$ & $\begin{array}{l}\text { Radcal } \\
10 \times 5 \mathrm{CT}\end{array}$ & 0,987 & 1 & 1,011 & 1,3 & 1,0 \\
\hline $\mathbf{F}$ & $\begin{array}{l}\text { Radcal } \\
10 \times 6 \mathrm{CT}\end{array}$ & 1,01 & 1 & 0,991 & 0,9 & 0,9 \\
\hline $\mathbf{G}$ & $\begin{array}{l}\text { Radcal } \\
10 \times 6 \mathrm{CT}\end{array}$ & 1,03 & 1 & 1 & 2,9 & 0,0 \\
\hline $\mathbf{H}$ & $\begin{array}{c}\text { Radcal } \\
20 \times 6 \text { CT }\end{array}$ & 0,995 & 1 & 0,984 & 5,0 & 1,6 \\
\hline Padrão & $\begin{array}{l}\text { Radcal } \\
\text { RC 3CT }\end{array}$ & 0,997 & 1 & 1,005 & 3,0 & 0,5 \\
\hline
\end{tabular}

É possível notar que nos casos B e C onde as câmaras são do mesmo fabricante e modelo houve uma variação da dependência energética de 4,1\% 
e 1,4\% respectivamente, o que nos leva a deduzir que a dependência energética é singular para cada equipamento mesmo se tratando de equipamentos de mesmo fabricante e modelo.

\subsection{Calibração da Câmara de Ionização do Tipo Lápis Utilizada que Compõe o Conjunto Um.}

Foi realizada a calibração do conjunto um composto de câmara de ionização do tipo lápis e eletrômetro comerciais utilizados no sistema clínico do hospital A. O coeficiente de calibração e os valores de $K_{q}$ encontrados estão relacionados TAB.9.

TABELA 9. Condições de calibração da câmara de ionização que compõe o conjunto um utilizada neste trabalho e seus coeficientes.

\begin{tabular}{c|c|c|c|c}
\hline Qualidade & $\begin{array}{c}\text { Tensão } \\
\text { Aplicada } \\
(\mathbf{k V})\end{array}$ & $\begin{array}{c}\text { CSR } \\
(\mathbf{m m A l})\end{array}$ & $\begin{array}{c}\boldsymbol{N}_{\boldsymbol{k}, \boldsymbol{l}} \\
(\text { Gy.cm.ue-1) }\end{array}$ & $\boldsymbol{K}_{\boldsymbol{q}}$ \\
\cline { 1 - 2 } RQT 8 & 100 & 6,9 & \multirow{2}{*}{$9,158 \times 10^{-3}$} & 1,015 \\
\cline { 1 - 2 } RQT 9 & 120 & 8,4 & & 1,00 \\
\hline RQT 10 & 150 & 10,1 & & 0,995 \\
\hline
\end{tabular}

$\mathrm{ue}=$ unidade de escala $=\mathrm{mG} / \mathrm{min}$

\subsubsection{Determinação da Curva de Calibração da Câmara de lonização do Tipo Lápis que Compõe o Conjunto Um.}

Com os fatores de correção que são fornecidos pelo certificado de calibração e neste caso podem ser visualizados na TAB.9 mostrada anteriormente, foi construída a curva de calibração da câmara de ionização do tipo lápis utilizada para os testes no hospital A. 
A curva de calibração foi construída para encontrar o fator de correção para qualidade ( $K_{q}$ adequado ao feixe clínico). O gráfico da FIG.39 mostra a curva de calibração em termos de CSR para a câmara utilizada para realização dos testes.

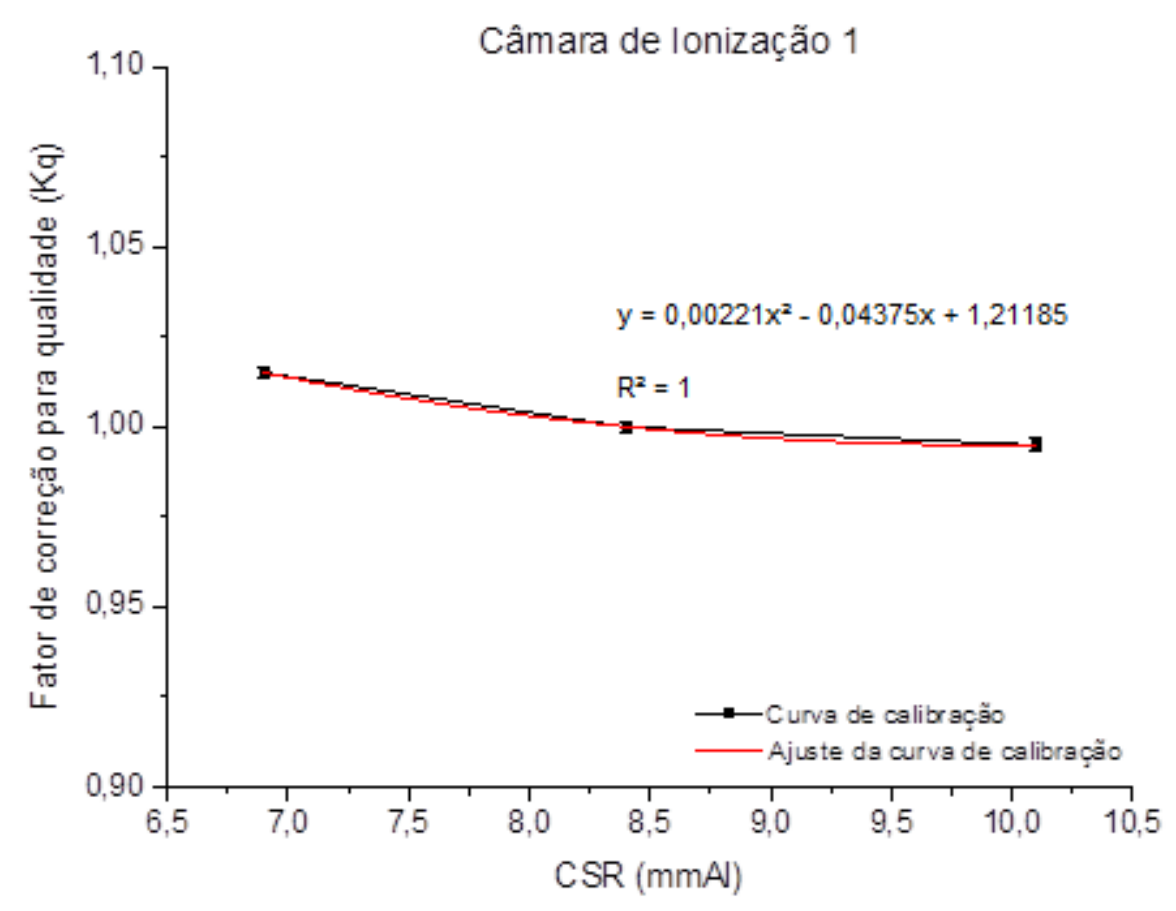

FIGURA 39. Curva de calibração em termos de CSR da câmara de ionização do tipo lápis Radcal 10x5-3CT, que compõe o conjunto um.

\subsubsection{Calibração da Câmara de lonização do Tipo Lápis Utilizada que Compõe o Conjunto Dois.}

O coeficiente de calibração e o $K_{q}$ resultados da calibração do conjunto dois composto de câmara de ionização do tipo lápis e eletrômetro comerciais utilizados no sistema clínico do hospital B, estão relacionados na TAB.10. 
TABELA 10. Condições de calibração da câmara de ionização que compõe o conjunto dois utilizada neste trabalho e seus coeficientes.

\begin{tabular}{|c|c|c|c|c|}
\hline Qualidade & $\begin{array}{l}\text { Tensão } \\
\text { Aplicada } \\
\text { (kV) }\end{array}$ & $\begin{array}{c}\text { CSR } \\
\text { (mmAl) }\end{array}$ & $\begin{array}{c}N_{k, l} \\
\left(G y . c m . u e^{-1}\right)\end{array}$ & $K_{q}$ \\
\hline RQT 8 & 100 & 6,9 & \multirow{3}{*}{$9,30 \times 10^{-3}$} & 0,995 \\
\hline RQT 9 & 120 & 8,4 & & 1,00 \\
\hline RQT 10 & 150 & 10,1 & & 1,00 \\
\hline
\end{tabular}

\subsubsection{Determinação da Curva de Calibração da Câmara de lonização do Tipo Lápis que Compõe o Conjunto Dois.}

Com os fatores de correção fornecidos no certificado de calibração e relacionados na TAB.10 mostrada anteriormente, foi construída a curva de calibração da câmara de ionização do tipo lápis utilizada para os testes no hospital B. A curva de calibração foi construída para encontrar o fator de correção para qualidade $\left(K_{q}\right)$ adequado ao feixe clínico.

O gráfico da FIG.40 mostra a curva de calibração em termos de CSR para a câmara utilizada para realização dos testes.

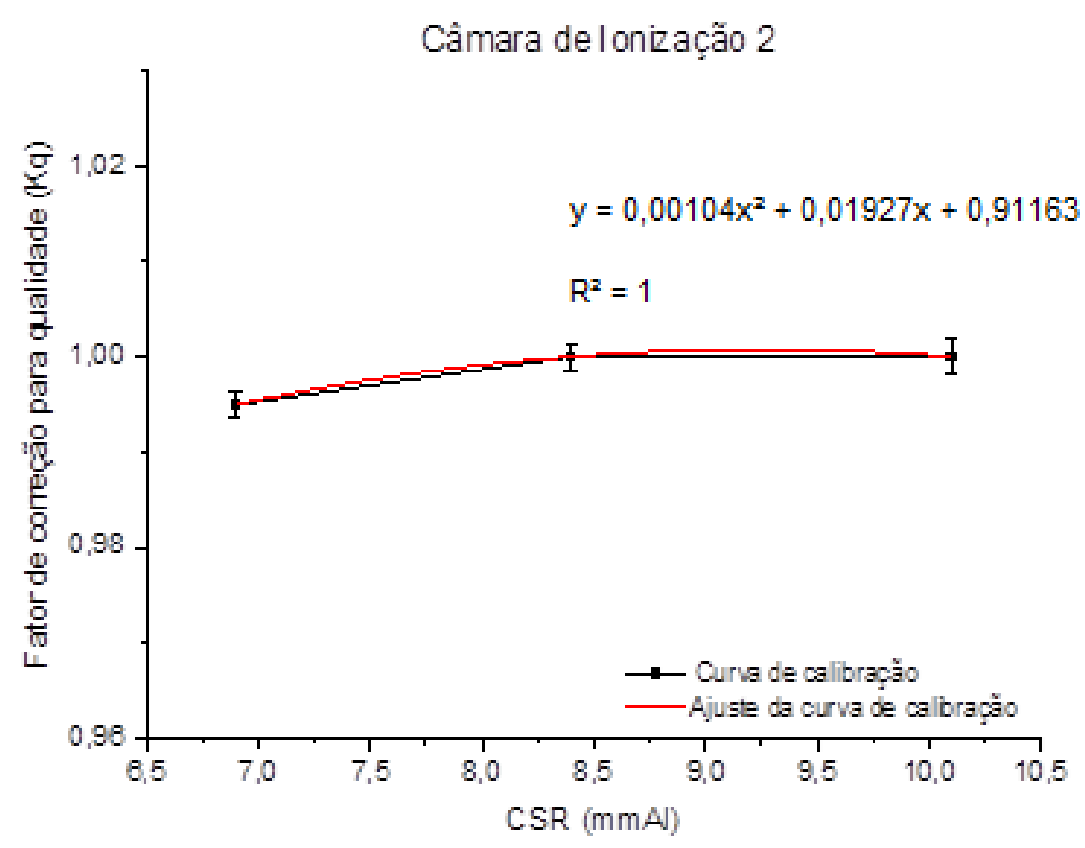

FIGURA 40. Curva de calibração em termos de CSR da câmara de ionização do tipo lápis Radcal 10x5-3CT, que compõe o conjunto dois. 


\subsection{Sistema Tandem Desenvolvido Neste Trabalho}

As capas que compõem o sistema Tandem foram desenvolvidas de acordo com o projeto apresentado no item 6.3.

Foram construídas cinco capas absorvedoras cilíndricas de alumínio e três capas absorvedoras cilíndricas de acrílico (PMMA), com 150mm de comprimento. As espessuras e suas incertezas para cada capa construída podem ser vistas na TAB.11

TABELA 11. Espessuras das capas absorvedoras cilíndricas de aluimínio confeccionadas para compor o sistema Tandem.

\begin{tabular}{c|c}
\hline Capas & $\begin{array}{c}\text { Espessuras } \\
(\mathbf{m m A l})\end{array}$ \\
\hline $1 \mathrm{mmAl}$ & $1 \pm 0,54$ \\
\hline $2 \mathrm{mmAl}$ & $2 \pm 0,33$ \\
\hline $2 \mathrm{mmAl}$ & $2 \pm 0,39$ \\
\hline $2 \mathrm{mmAl}$ & $2 \pm 0,28$ \\
\hline $3 \mathrm{mmAl}$ & $2 \pm 0,09$ \\
\hline $15 \mathrm{mmPMMA}$ & $15 \pm 0,17$ \\
\hline $10 \mathrm{mmPMMA}$ & $10 \pm 0,10$ \\
\hline $10 \mathrm{mmPMMA}$ & $10 \pm 0,48$ \\
\hline
\end{tabular}

O diâmetro interno da primeira capa que constitui o conjunto de alumínio possui $12,5 \pm 0,08 \mathrm{~mm}$ e o diâmetro interno da primeira capa que constitui o conjunto de acrílico (PMMA) possui 12,5 \pm 0,03 mm dimensão adequada a câmara de ionização do tipo lápis utilizada neste trabalho. $O$ diâmetro interno das outras capas corresponde ao diâmetro externo das capas subsequentes que formam o conjunto.

As incertezas envolvidas foram estimadas atráves da incerteza expandida, com $v=4$ graus de liberdade, $\mathrm{k}=2,13^{(39)}$ e nível de confiança de $95 \%$. 
Nas FIG.41 e 42 podem ser vistas as capas absorvedoras cilíndricas de já confeccionadas.

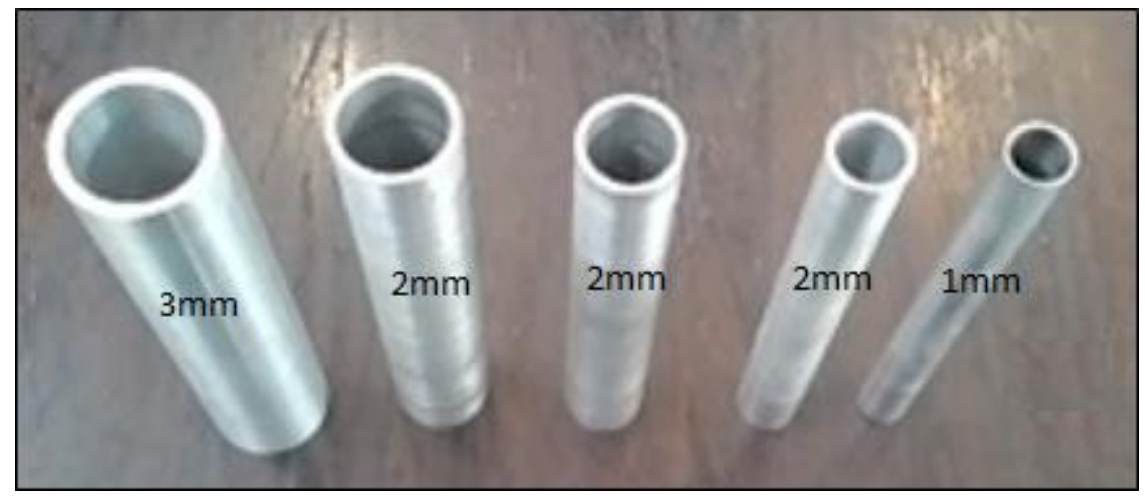

FIGURA 41. Capas absorvedoras cilíndricas de alumínio confeccionadas. Da esquerda para a direita: uma capa de $3 \mathrm{~mm}$, três de $2 \mathrm{~mm}$ e uma de $1 \mathrm{~mm}$. 0 comprimento das capas é de $150 \mathrm{~mm}$.

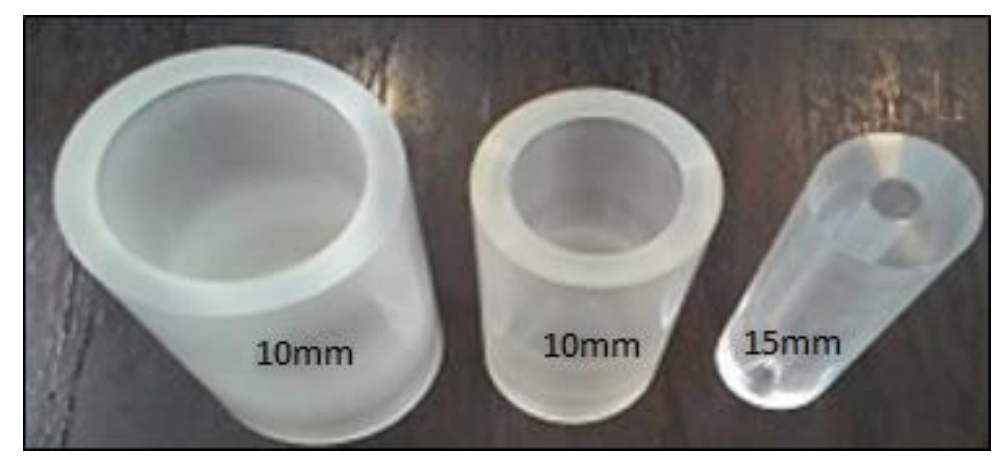

FIGURA 42. Capas absorvedoras de acrílico (PMMA) confeccionadas. Da esquerda para direita: duas capas de $10 \mathrm{~mm}$ e uma de $15 \mathrm{~mm}$. O comprimento das capas é de $150 \mathrm{~mm}$.

\subsection{Avaliação dos valores de CSR já implantadas no LCI - IPEN}

A filtração total equivalente a cada CSR foi colocada na saída do feixe e foram realizadas as medições. Os valores da taxa do Kerma no Ar foram comparados com aqueles obtidos antes de se adicionar a filtração. Os valores encontrados demonstraram uma variação de até $13 \%$ em relação aos valores de referência, o que comprova a necessidade de se estabelecer uma metodologia prática para avaliar possíveis variações e até mesmo determinar 
os valores de CSR em feixes clínicos. A variação encontrada pode ter ocorrido devido a influências de diversos fatores durante o processo de aquisição de dados como, por exemplo, a contribuição da radiação espalhada, as incertezas, entre outros. É importante ressaltar que durante a caracterização dos feixes implantados no $\mathrm{LCl}$, a câmara utilizada foi a câmara padrão de TC, que é a mesma utilizada para calibrar as câmaras de ionização tipo lápis.

\subsection{Determinação das curvas Tandem dos feixes padrões do $\mathrm{LCl}$, utilizando o sistema desenvolvido.}

O passo seguinte foi analisar o comportamento do sistema Tandem proposto neste trabalho através das curvas obtidas para cada capa absorvedora cilíndrica. Nas TAB.12 e 13, estão os valores da razão entre as respostas da câmara de ionização com cada capa absorvedora cilíndrica e as respostas com a câmara de ionização no ar.

TABELA 12. Razão obtida entre as médias das leituras feitas com cada capa absorvedora cilíndrica de alumínio e a média das leituras com a câmara de ionização no ar para cada CSR de referência.

\begin{tabular}{c|c|c|c|c|c}
\hline $\begin{array}{c}\mathbf{C S R} \\
(\mathbf{m m A L})\end{array}$ & 1mmAl/Ar & 3mmAl/Ar & 5mmAl/Ar & 7mmAl/Ar & 10mmAl/Ar \\
\hline $\mathbf{6 , 9}$ & 0.9628 & 0,8695 & 0,7744 & 0,6852 & 0,5879 \\
\hline $\mathbf{8 , 4}$ & 0,9723 & 0,9007 & 0,8191 & 0,7436 & 0,6536 \\
\hline $\mathbf{1 0 , 1}$ & 0,9771 & 0,9219 & 0,8606 & 0,7927 & 0,7144 \\
\hline
\end{tabular}

TABELA 13. Razão obtida entre as médias das leituras feitas com cada capa absorvedora cilíndrica de acrílico (PMMA) e a média das leituras com a câmara de ionização no ar para cada CSR de referência.

\begin{tabular}{c|c|c|c}
\hline $\begin{array}{c}\text { CSR } \\
(\mathbf{m m A l})\end{array}$ & 15mmPMMA/ Ar & 25mmPMMA/ Ar & 35mmPMMA/ Ar \\
\hline $\mathbf{6 , 9}$ & 0,9140 & 0,7915 & 0,6807 \\
\hline $\mathbf{8 , 4}$ & 0,9168 & 0,8008 & 0,6923 \\
\hline $\mathbf{1 0 , 1}$ & 0,9158 & 0,8039 & 0,7007 \\
\hline
\end{tabular}


A eficiência do sistema Tandem está relacionado com as incertezas inerentes ao dosímetro utilizado bem como ao grau de dependência energética de cada conjunto. No gráfico da FIG.43, é possível perceber que para as curvas de materiais mais absorvedores a dependência energética foi maior. Isso pode ser visto pela inclinação da curva; quanto maior a inclinação da curva Tandem melhor será a identificação dos valores próximos de CSR o que torna o sistema útil.

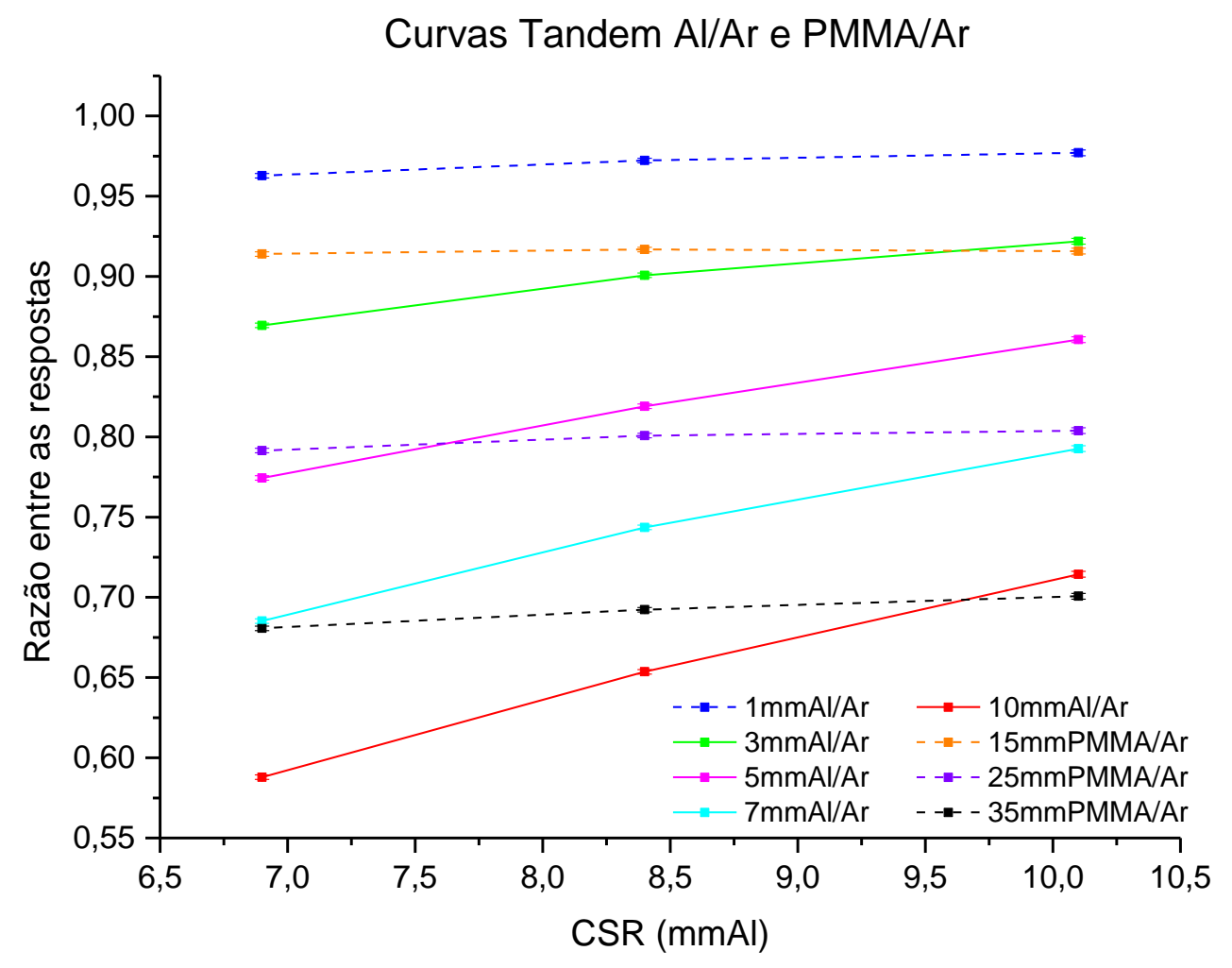

FIGURA 43. Curvas Tandem obtidas para os conjuntos formados pela câmara de ionização do tipo lápis e cada capa absorvedora cilíndrica, para cada valor CSR de referência. As linhas tracejadas rferem-se as capas menos absorvedoras e as linhas sólidas representam as capas mais absorvedoras.

Nas TAB. 13, 14 e 15, estão os valores da razão entre as respostas dos conjuntos formados pela câmara de ionização do tipo lápis e as capas 
absorvedoras cilíndricas de alumínio, e câmara de ionização do tipo lápis e as capas absorvedoras cilíndricas de acrílico (PMMA).

TABELA13. Razão obtida entre as médias das leituras dos conjuntos formados pela câmara de ionização do tipo lápis e cada capa absorvedora cilíndrica de alumínio, e câmara de ionização do tipo lápis e a capa absorvedora cilíndrica de $15 \mathrm{~mm}$ de acrílico (PMMA).

\begin{tabular}{c|c|c|c|c|c}
\hline $\begin{array}{c}\text { CSR } \\
(\mathbf{m m A l})\end{array}$ & $\begin{array}{c}\mathbf{1 m m A l} / \\
\mathbf{1 5 m m} \\
\text { (PMMA) }\end{array}$ & $\begin{array}{c}\mathbf{3 m m A l} / \\
\mathbf{1 5 m m} \\
\text { (PMMA) }\end{array}$ & $\begin{array}{c}\mathbf{5 m m A l} / \\
\mathbf{1 5 m m} \\
\text { (PMMA) }\end{array}$ & $\begin{array}{c}\mathbf{7 m m A l} / \\
\mathbf{1 5 m m} \\
\text { (PMMA) }\end{array}$ & $\begin{array}{c}\mathbf{1 0 m m A l} / \\
\mathbf{1 5 m m} \\
\text { (PMMA) }\end{array}$ \\
\hline $\mathbf{6 , 9}$ & 1,0534 & 0,9513 & 0,8472 & 0,7490 & 0,6432 \\
\hline $\mathbf{8 , 4}$ & 1,0907 & 0,9825 & 0,8934 & 0,8111 & 0,7129 \\
\hline $\mathbf{1 0 , 1}$ & 1,0669 & 1,0066 & 0,9397 & 0,8655 & 0,7800 \\
\hline
\end{tabular}

O gráfico da FIG.44 mostra as curvas Tandem referentes as razões mostradas na TAB.13.

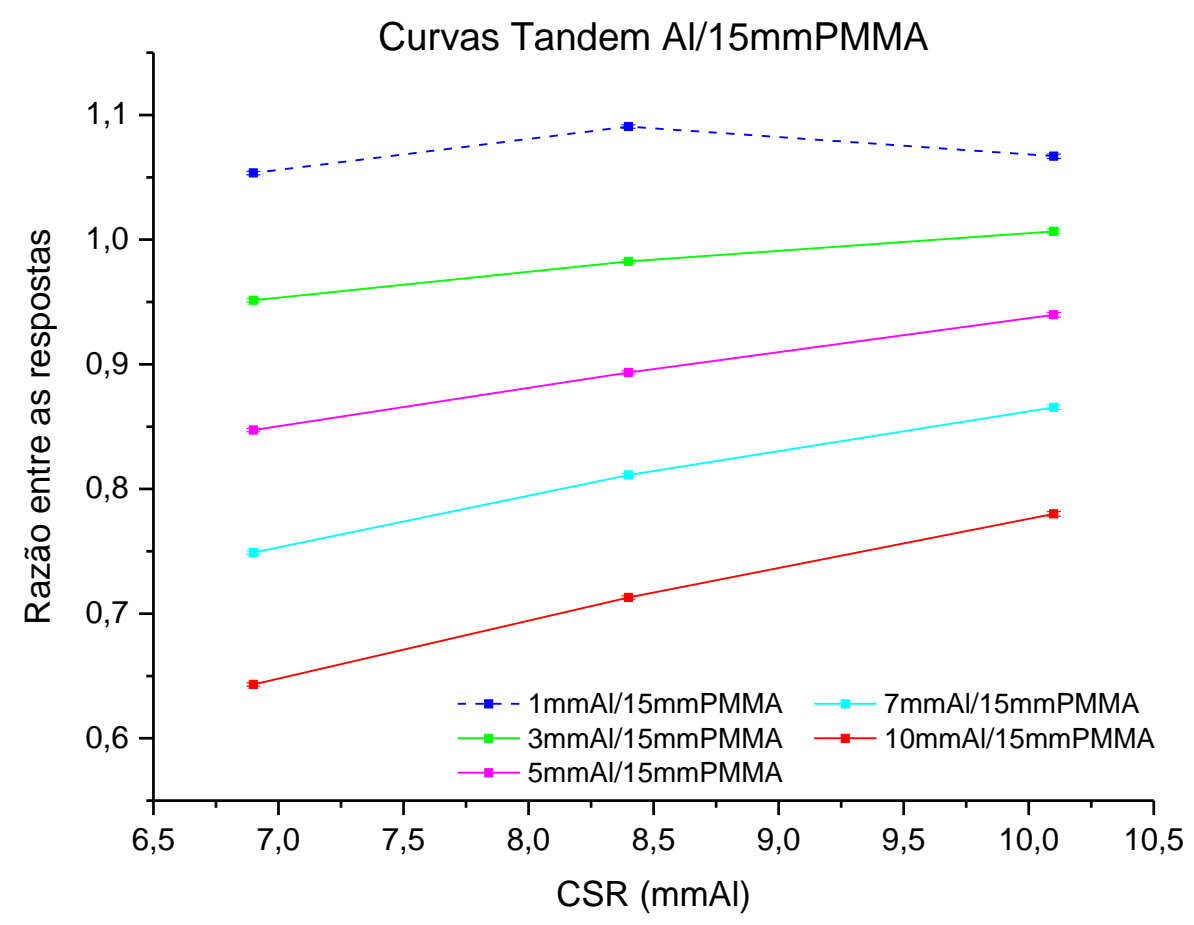

FIGURA 44. Curvas Tandem obtidas através da razão entre as respostas dos conjuntos formados pela câmara de ionização do tipo lápis e as capas absorvedoras cilíndricas de $1,3,5,7$ e 10mmAl e da câmara de ionização do tipo lápis com a capa absorvedora cilíndrica de 15mmPMMA. As linhas tracejadas referem-se as curvas que apresentaram menor inclinação e as linhas sólidas referem-se as curvas que apresentaram maior inclinação. 
TABELA 14. Razão obtida entre as médias das leituras dos conjuntos formados pela câmara de ionização do tipo lápis e cada capa absorvedora cilíndrica de alumínio, e câmara de ionização do tipo lápis e a capa absorvedora cilíndrica de $25 \mathrm{~mm}$ de acrílico (PMMA).

\begin{tabular}{c|c|c|c|c|c}
\hline $\begin{array}{c}\mathbf{C S R} \\
(\mathbf{m m A l})\end{array}$ & $\begin{array}{c}\mathbf{1 m m A l} / \\
\mathbf{2 5 m m} \\
(\mathbf{P M M A})\end{array}$ & $\begin{array}{c}\mathbf{3 m m A l} / \\
\mathbf{2 5 m m} \\
(\mathbf{P M M A})\end{array}$ & $\begin{array}{c}\mathbf{5 m m A l} / \\
\mathbf{2 5 m m} \\
(\mathbf{P M M A})\end{array}$ & $\begin{array}{c}\mathbf{7 m m A l} / \\
\mathbf{2 5 m m} \\
(\mathbf{P M M A})\end{array}$ & $\begin{array}{c}\mathbf{1 0 m m A l} / \\
\mathbf{2 5 m m} \\
(\mathbf{P M M A})\end{array}$ \\
\hline $\mathbf{6 , 9}$ & 1,2164 & 1,0985 & 0,9783 & 0,8656 & 0,7427 \\
\hline $\mathbf{8 , 4}$ & 1,2140 & 1,1247 & 1,0228 & 0,9286 & 0,8162 \\
\hline $\mathbf{1 0 , 1}$ & 1,2154 & 1,1468 & 1,0705 & 0,9860 & 0,8886 \\
\hline
\end{tabular}

O gráfico da FIG.45 mostra as curvas Tandem referentes às razões mostradas na TAB.14.

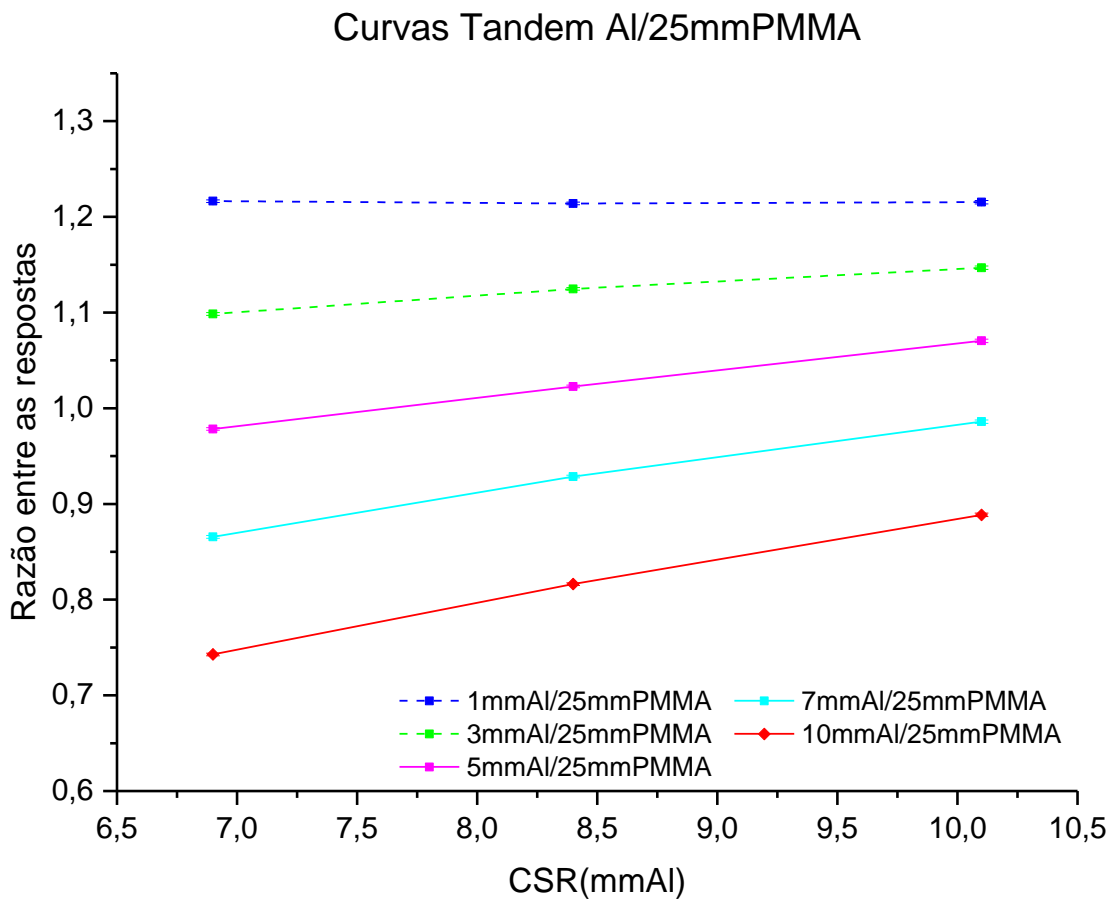

Figura 45. Curvas Tandem obtidas através da razão entre as respostas dos conjuntos formados pela câmara de ionização do tipo lápis e as capas absorvedoras cilíndricas de $1,3,5,7$ e 10mmAl e da câmara de ionização do tipo lápis com a capa absorvedora cilíndrica de 25mmPMMA. As linhas tracejadas referem-se as curvas que apresentaram menor inclinação e as linhas sólidas referem-se as curvas que apresentaram maior inclinação. 
TABELA 15. Razão obtida entre as médias das leituras dos conjuntos formados pela câmara de ionização do tipo lápis e cada capa absorvedora cilíndrica de alumínio, e câmara de ionização do tipo lápis e a capa absorvedora cilíndrica de $35 \mathrm{~mm}$ de acrílico (PMMA).

\begin{tabular}{c|c|c|c|c|c}
\hline $\begin{array}{c}\text { CSR } \\
(\mathbf{m m A l})\end{array}$ & $\begin{array}{c}\mathbf{1 m m A l} / \\
\mathbf{3 5 m m} \\
\text { (PMMA) }\end{array}$ & $\begin{array}{c}\mathbf{3 m m A l} / \\
\mathbf{3 5 m m} \\
\text { (PMMA) }\end{array}$ & $\begin{array}{c}\mathbf{5 m m A l} / \\
\mathbf{3 5 m m} \\
\text { (PMMA) }\end{array}$ & $\begin{array}{c}\mathbf{7 m m A l} / \\
\mathbf{3 5 m m} \\
\text { (PMMA) }\end{array}$ & $\begin{array}{c}\mathbf{1 0 m m A l} / \\
\mathbf{3 5 m m} \\
\text { (PMMA) }\end{array}$ \\
\hline $\mathbf{6 , 9}$ & 1,4145 & 1,2773 & 1,1376 & 1,0066 & 0,8636 \\
\hline $\mathbf{8 , 4}$ & 1,4044 & 1,3011 & 1,1831 & 1,0742 & 0,9441 \\
\hline $\mathbf{1 0 , 1}$ & 1,3944 & 1,3157 & 1,2282 & 1,1102 & 1,0194 \\
\hline
\end{tabular}

O gráfico da FIG.46 mostra as curvas Tandem referentes às razões mostradas na TAB.15.

Curvas Tandem Al/25mmPMMA

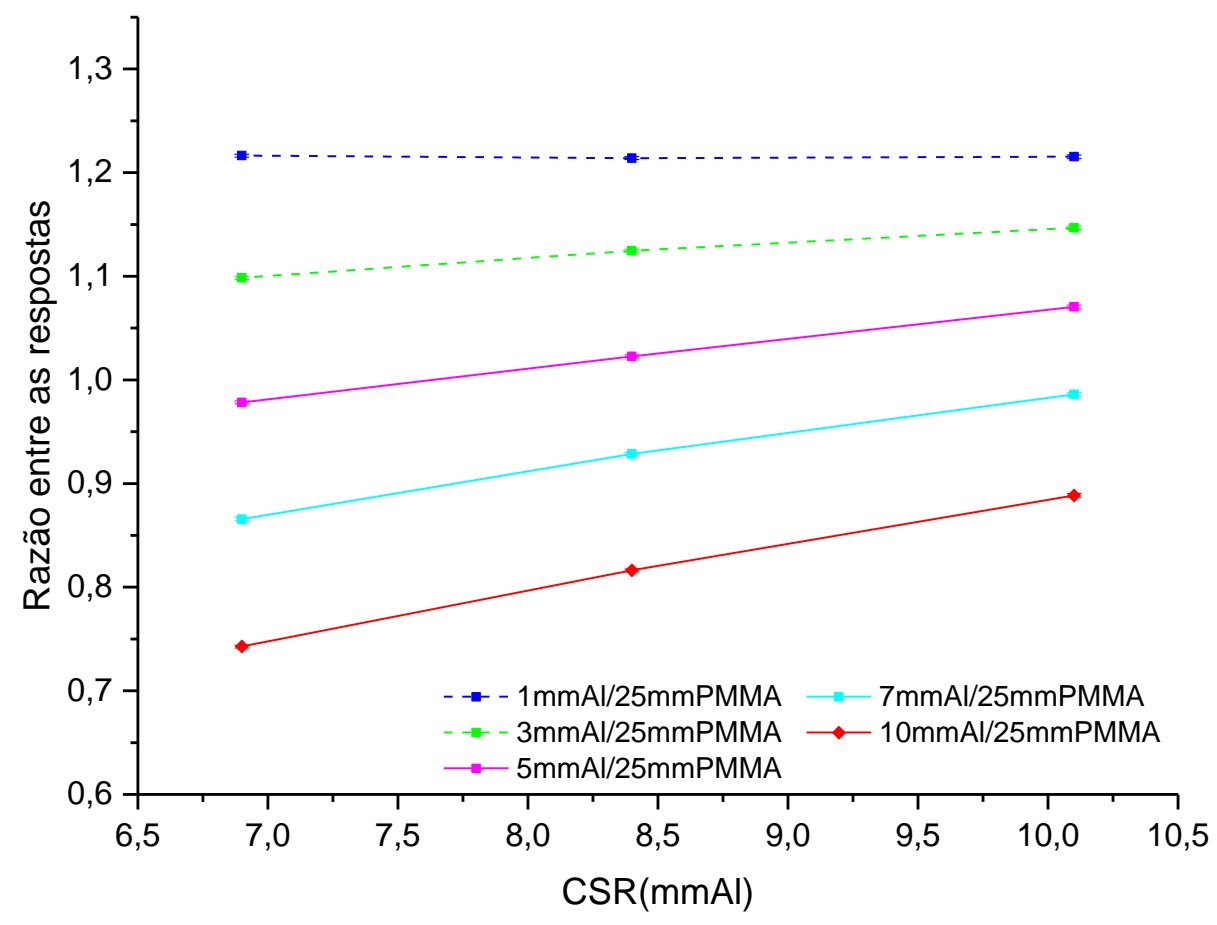

FIGURA 46. Curvas Tandem obtidas através da razão entre as respostas dos conjuntos formados pela câmara de ionização do tipo lápis e as capas absorvedoras cilíndricas de $1,3,5,7$ e 10mmAl e da câmara de ionização do tipo lápis com a capa absorvedora cilíndrica de 35mmPMMA. As linhas tracejadas referem-se as curvas que apresentaram menor inclinação e as linhas sólidas referem-se as curvas que apresentaram maior inclinação. 


\subsubsection{Análise das Curvas Tandem}

As curvas Tandem construídas foram analisadas com base nas diferenças percentuais entre as razões obtidas por cada conjunto, para camadas semirredutoras subsequentes. Os valores de CSR correspondentes as qualidades RQT8, 9 e 10 de refêrencia para um feixe de tomografia computadorizada são respectivamente: 6,9, 8,4 e 10,1 mmAl. Nos gráficos das FIG. 47,48,49 e 50 é possível observar que essas variações para o intervalo 1 (6,9 a 8,4 mmAl) e o intervalo 2 (8,4 a 10,1 mmAl) aumentam com o poder de absorção da capa, o que explica a inclinação das curvas referentes ao sistema Tandem formado pelas capas mais absorvedoras, vistas anteriormente, na seção 7.5 .

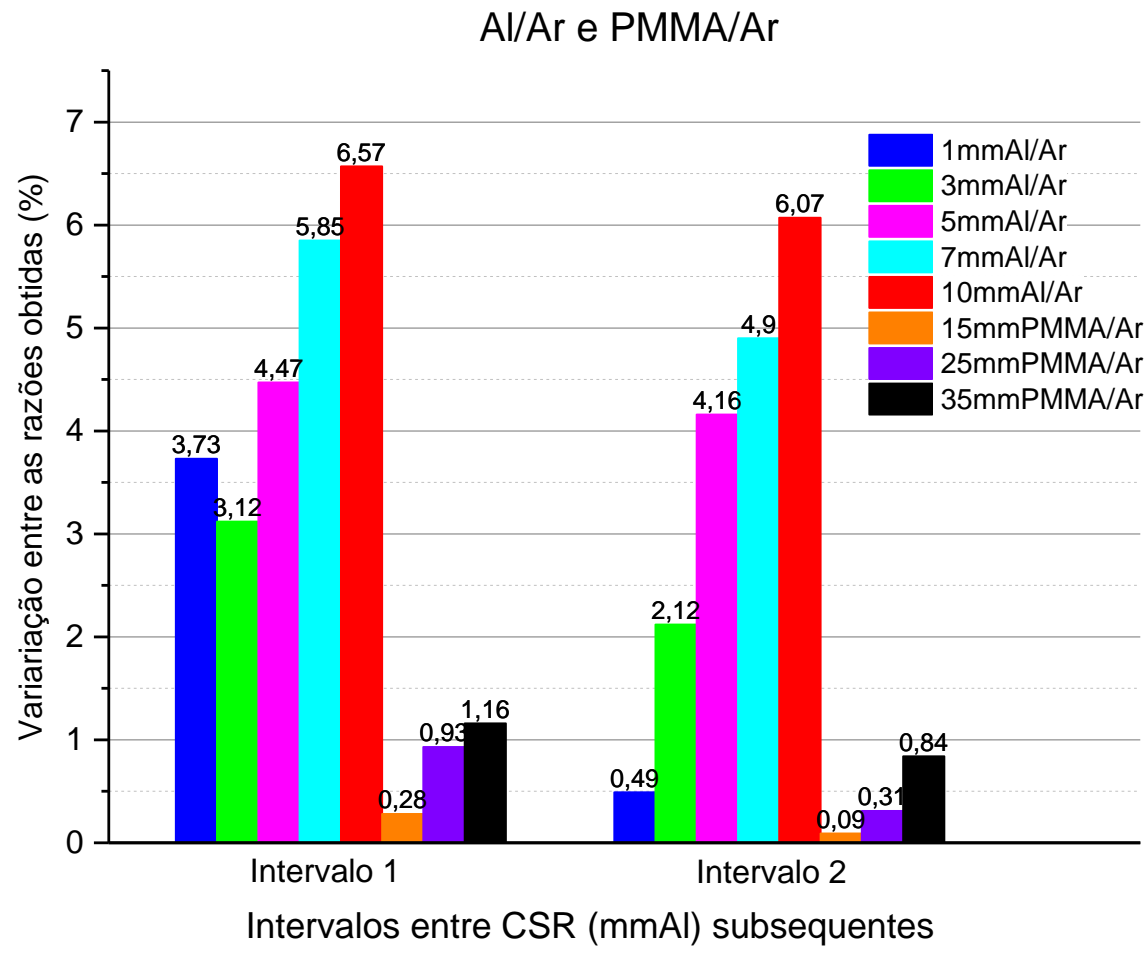

FIGURA 47. Gráfico das diferenças percentuais das razões entre as respostas obtidas pelos conjuntos formados com a câmara de ionização do tipo lápis e as capas absorvedoras cilíndricas de alumínio e acrílico(PMMA) e a câmara de ionização do tipo lápis no ar. 


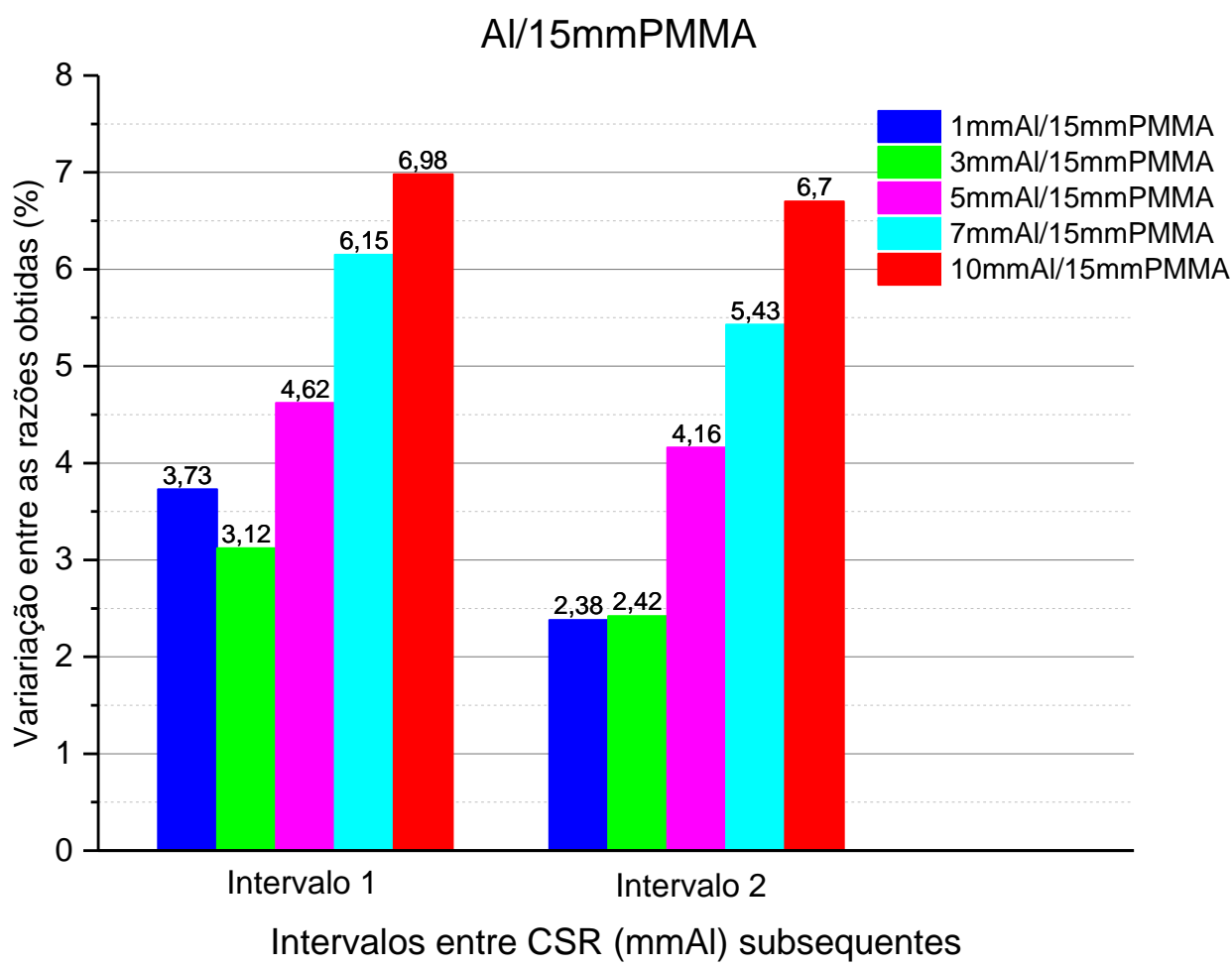

FIGURA 48. Gráfico das diferenças percentuais das razões entre as respostas obtidas pelos conjuntos formados com a câmara de ionização do tipo lápis e as capas absorvedoras cilíndricas de alumínio e a câmara de ionização do tipo lápis com a capa absorvedora cilíndrica 15mmPMMA. 


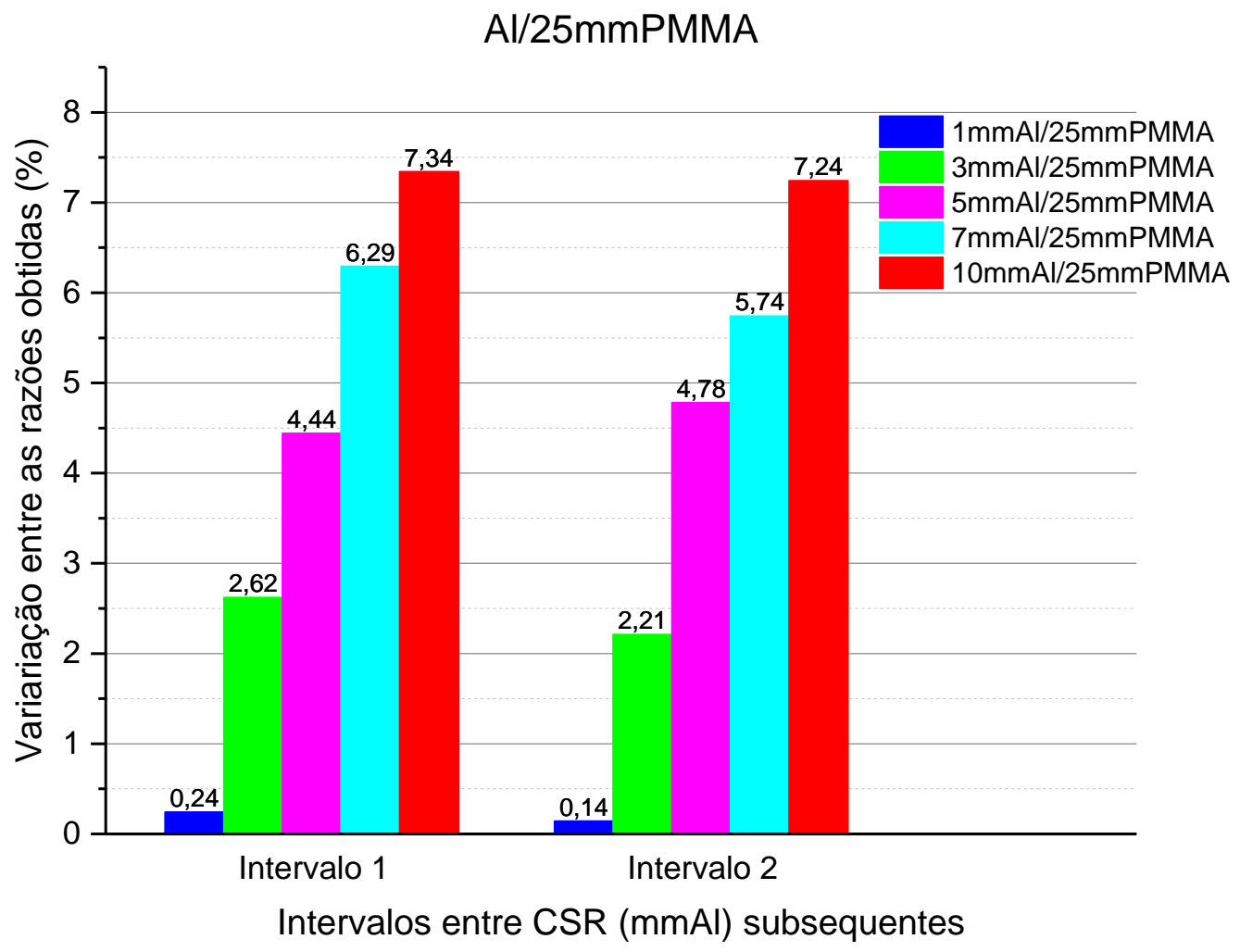

FIGURA 49. Gráfico das diferenças percentuais das razões entre as respostas obtidas pelos conjuntos formados com a câmara de ionização do tipo lápis e as capas absorvedoras cilíndricas de alumínio e a câmara de ionização do tipo lápis com a capa absorvedora cilíndrica 25mmPMMA. 


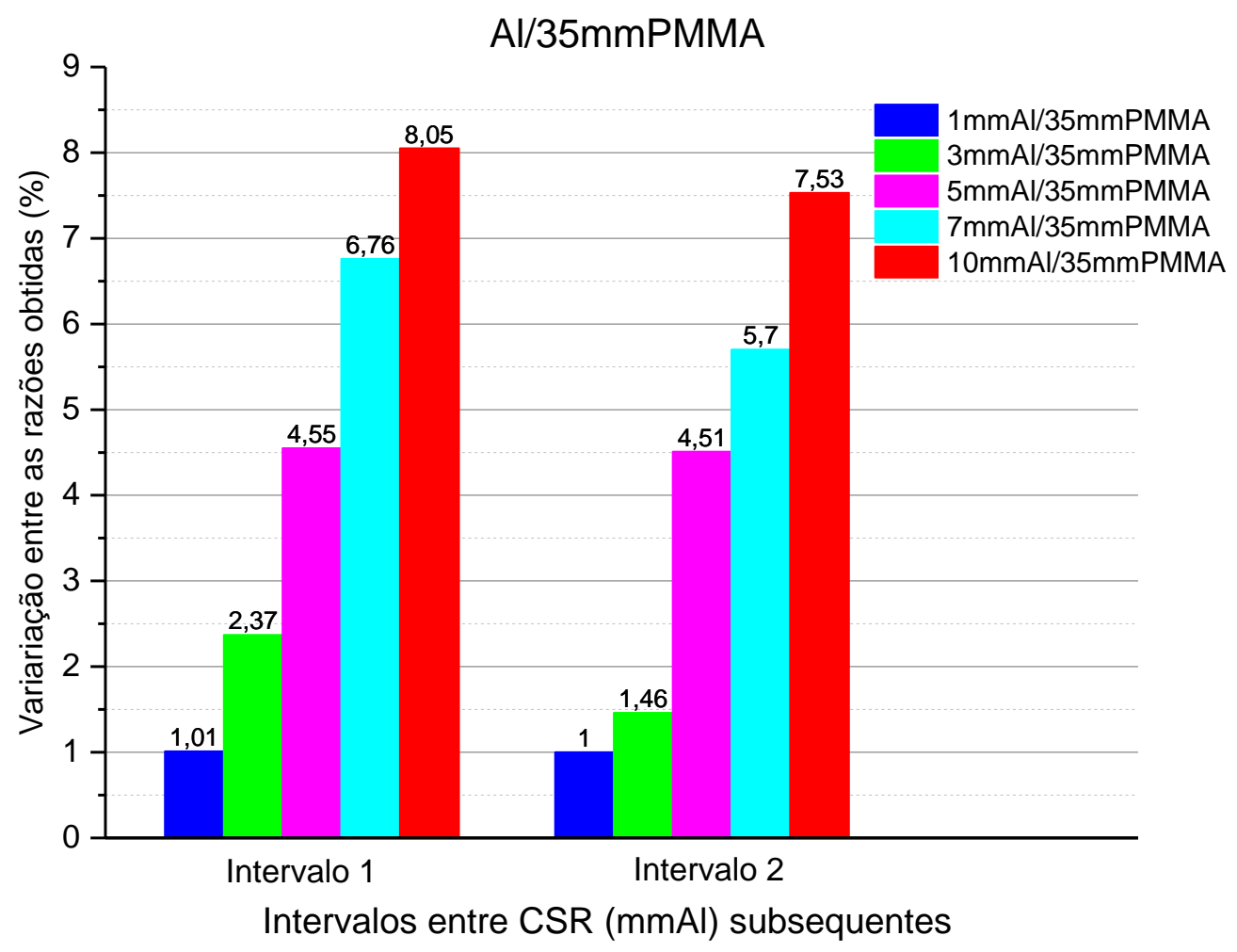

FIGURA 50. Gráfico das diferenças percentuais das razões entre as respostas obtidas pelos conjuntos formados com a câmara de ionização do tipo lápis e as capas absorvedoras cilíndricas de alumínio e a câmara de ionização do tipo lápis com a capa absorvedora cilíndrica 35mmPMMA.

Das variações entre as respostas para as CSR subsequentes das curvas obtidas para os conjuntos formados entre a câmara de ionização do tipo lápis e as capas absorvedoras cilíndricas de alumínio e PMMA e a câmara de ionização no ar representadas no gráfico da FIG.47, a curva que obteve maior variação foi a curva referente ao conjunto formado com a câmara de ionização do tipo lápis e a capa absorvedora cilíndrica de $10 \mathrm{mmAl}$ e a câmara de ionização no ar. Como nos testes realizados no hospital A, não foi possível utilizar as capas absorvedoras cilíndricas de acrílico (PMMA), foi necessário utilizar a curva Tandem formada através da razão entre as respostas obtida entre as capas absorvedoras cilíndricas de alumínio e com câmara de ionização no ar. 
No caso dos conjuntos formados pela câmara de ionização do tipo lápis com as capas absorvedoras cilíndricas de alumínio e pela câmara de ionização do tipo lápis com as capas absorvedoras cilíndricas de 15mmPMMA (FIG.48), 25mmPMMA (FIG.49), e 35mmPMMA(FIG.50) a curva que obteve maior variação é referente ao conjunto formado pela câmara de ionização do tipo lápis com a capa absorvedora cilíndrica de $10 \mathrm{mmAl}$ e a câmara de ionização do tipo lápis com a capa absorvedora cilíndrica de 35mmPMMA.

O gráfico da FIG.51, mostra as duas curvas Tandem utilizadas para avaliar a CSR nos feixes clínicos de tomografia computadorizada durante a realização deste trabalho. Através das curvas Tandem é possível estimar os valores de CSR e posteriormente o fator de correção para qualidade $\left(K_{q}\right)$ adequado ao feixe.

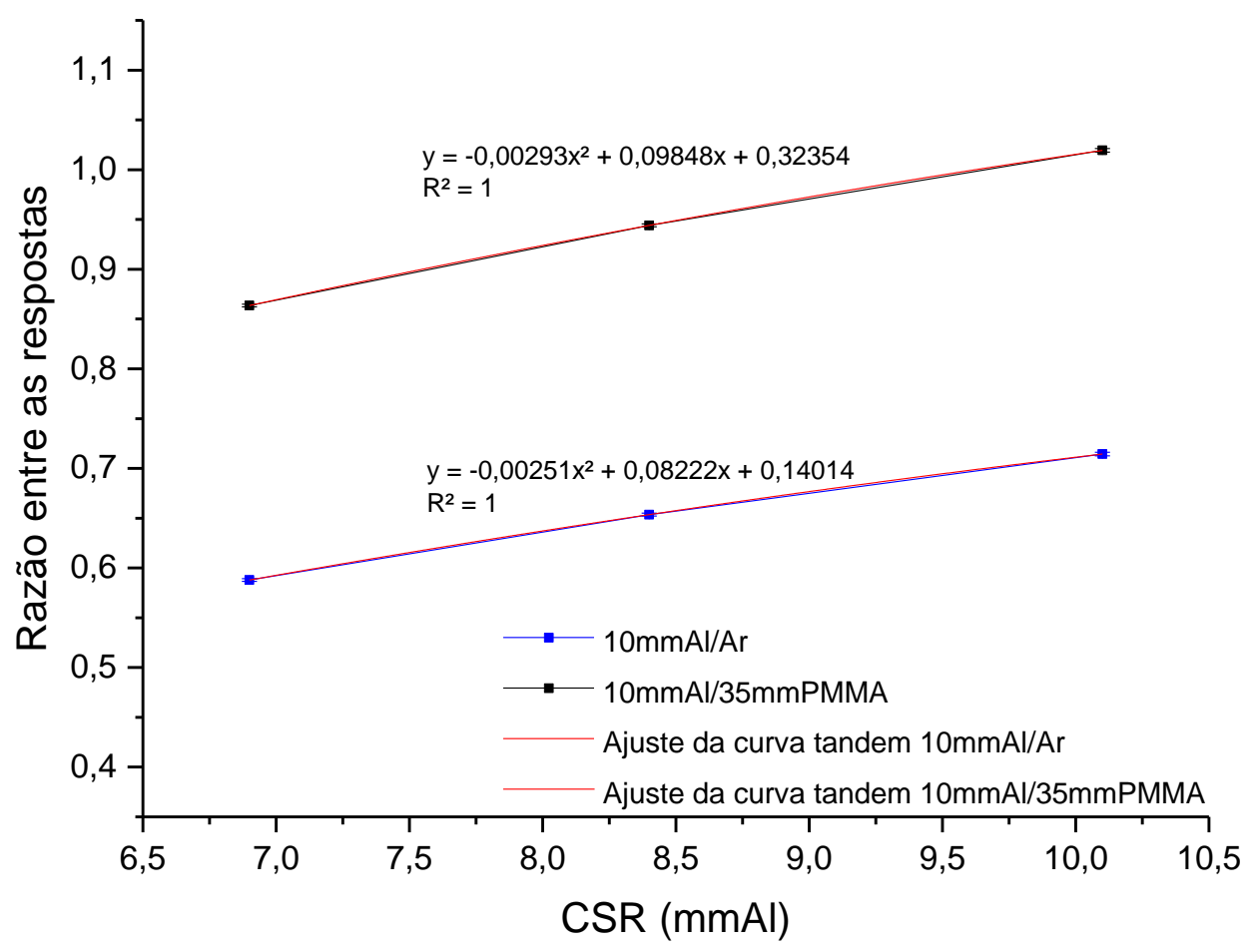

FIGURA 51. Curvas Tandem que apresentaram maiores variações percentuais entre as respostas obtidas para CSR subsequentes e consequentemente maior inclinação. 


\subsection{Testes Realizados com o Sistema Tandem no Hospital A}

O sistema Tandem utilizado para avaliar a CSR do feixe do tomógrafo no hospital $A$, foi o sistema formado com a câmara de ionização do tipo lápis e a capa absorvedora cilíndrica de $10 \mathrm{mmAl}$ e a câmara de ionização no ar

Na TAB.16, estão relacianados os parâmetros utilizados e a razão entre as respostas obtida para o feixe do tomógrafo do hospital $\mathrm{A}$.

TABELA 16. Parâmetros do feixe e razão obtida entre as médias das leituras feitas com o conjunto formado pela câmara de ionização do tipo lápis e a capa absorvedora cilíndrica de $10 \mathrm{mmAl}$ e a média das leituras com a câmara de ionização no ar.

\begin{tabular}{c|c|c|c|c}
\hline $\begin{array}{c}\text { Espessura } \\
\text { nominal de } \\
\text { corte }\end{array}$ & $\begin{array}{c}\text { Número de } \\
\text { Slices }\end{array}$ & Pit (mA.s) & kV nominal & $\begin{array}{c}\text { Razão entre as } \\
\text { respostas }\end{array}$ \\
\hline $12 \mathrm{~mm}$ & 1 & 100 & 120 & $0,705 \pm 0,005$ \\
\hline
\end{tabular}

Utilizando a equação da curva Tandem do conjunto utilizado no hospital A, o valor estimado para CSR no feixe do tomógrafo foi o de $9,8 \mathrm{mmAl}$ e o valor do $K_{q}$ encontrado foi 0,995 . O valor estimado de CSR, mostrou considerável variação em relação ao valor esperado que é o valor correspondente a qualidade RQT9, que é 8,4 mmAl. A incerteza envolvida na medição realizada, foi estimada atráves da incerteza expandida, com $v=2$ graus de liberdade, $\mathrm{k}=2,92^{(39)}$ e nível de confiança de $95 \%$.

\subsection{Testes Realizados com o Sistema Tandem no Hospital B}

O sistema Tandem utilizado para avaliar a CSR do feixe do tomógrafo no hospital $B$, foi o sistema formado com a câmara de ionização do tipo lápis e a capa absorvedora cilíndrica de $10 \mathrm{mmAl}$ e a câmara de ionização do tipo lápis com a capa absorvedora cilíndrica de 35 mmPMMA.

Na TAB.17, estão relacianados os parâmetros utilizados e a razão entre as respostas obtida para o feixe do tomógrafo do hospital B. 
TABELA 17. Parâmetros do feixe e razão obtida entre as médias das leituras feitas com o conjunto formado pela câmara de ionização do tipo lápis e a capa absorvedora cilíndrica de $10 \mathrm{mmAl}$ e a média das leituras com o conjunto formado pela câmara de ionização do tipo lápis e a capa absorvedora cilíndrica de 35mmPMMA.

\begin{tabular}{c|c|c|c|c}
\hline $\begin{array}{c}\text { Espessura } \\
\text { Nominal de } \\
\text { Corte }\end{array}$ & $\begin{array}{c}\text { Número de } \\
\text { Slices }\end{array}$ & Pit (mA.s) & kV & $\begin{array}{c}\text { Razão entre as } \\
\text { respostas }\end{array}$ \\
\hline $2 \mathrm{~mm}$ & 1 & 170 & 130 & $0,996 \pm 0,003$ \\
\hline
\end{tabular}

Utilizando a equação da curva Tandem do conjunto utilizado no hospital B, o valor estimado para CSR no feixe do tomógrafo foi o de $8,6 \mathrm{mmAl}$ e o valor do $K_{q}$ encontrado foi 1,00 . O valor estimado de CSR encontrado foi próximo do valor esperado para qualidade RQT9, que é $8,4 \mathrm{mmAl}$. A incerteza envolvida na medição realizada, foi estimada atráves da incerteza expandida, com $v=4$ graus de liberdade, $k=2,13^{(39)}$ e nível de confiança de $95 \%$.

\subsection{Guia Orientativo para Dosimetria em Tomografia Computadorizada}

O Guia Orientativo proposto neste trabalho se encontra detalhado no Apendice. Foram considerados os resultados obtidos nos itens anteriores associados às recomendações do TRS 457. Estão inclusos desde a interpretação do certificado de calibração até a sugestão de diferentes metodologias de avaliação da CSR em um feixe clínico, destacando que cada sistema de medição possui características específicas que devem ser consideradas.

Pretende-se fornecer o guia, para os usuários das câmaras de ionização calibradas nos feixes padrões do LCl. 


\section{CONCLUSÃo}

As câmaras de ionização do tipo lápis utilizadas na dosimetria de feixes clínicos de tomografia computadorizada analisadas neste trabalho, apresentaram comportamentos diferentes em relação a dependência energética. Embora sejam de mesmo modelo e fabricante, algumas apontaram considerável variação, considerando os intervalos das qualidades RQT. A construção da curva de calibração em função da CSR para as câmaras de ionização do tipo lápis é importante para relacionar com mais precisão e confiabilidade as grandezas específicas para TC. O Guia orientativo para dosimetria em tomografia computadorizada traz um modelo de curva de calibração, construída a partir dos fatores de correção para qualidade $K_{q}$ e um exemplo da aplicação desses fatores que foi feito durante a realização deste trabalho.

Embora a determinação da CSR em feixes de tomografia computadorizada não seja uma tarefa fácil, existem algumas metodologias disponíveis no guia para que o usuário tenha conhecimento das diferentes maneiras de estimar os valores de CSR do feixe clínico em seus sistemas de TC e aplicar o $K_{q}$ adequado.a esse feixe. Essas metodologias podem ser implementadas de acordo com a viabilidade para cada usuário, visando o aprimoramento do controle de qualidade nos equipamentos de tomografia computadorizada. A utilização do sistema Tandem proposto neste trabalho para estimar valores de CSR é viável. Os conjuntos que apresentaram melhor resposta foram os conjuntos formados pela câmara de ionização do tipo lápis e a capa de $10 \mathrm{mmAl}$, com a câmara de ionazação do tipo lápis no ar; e o conjunto formado pela câmara de ionização do tipo lápis com a capa absorvedora cilíndrica de $10 \mathrm{mmAl}$ e a câmara de ionização do tipo lápis com a capa absorvedora cilíndrica de $35 \mathrm{mmAl}$. Apesar dos resultados obtidos para o valor estimado de CSR no hospital " $A$ " terem apresentado significante variação quando comparado ao valor esperado, não se pode descartar a 
possibilidade de que o valor encontrado esteja próximo do real, se considerarmos que também houve influência da radiação espalhada pelos absorvedores nos resultados obtidos nos feixes padrões do $\mathrm{LCl}$. O comportamento do sistema Tandem no hospital "B" foi satisfatório, uma vez que apresentou coerência no resultado e na validação da baixa dependência energética da câmara de ionização do tipo lápis utilizada no conjunto dois, indicada pelos fatores de correção para qualidade $K_{q}$ obtidos durante a sua calibração, diferente da câmara de ionização do tipo lápis utilizada no conjunto um que apresentou maior dependência energética. Deve-se ressaltar que o sistema Tandem não é válido para a determinação de doses absorvidas, e sim um método alternativo de estimar valores de CSR. 


\section{APÊNDICE}

\section{Guia Orientativo Para Dosimetria Computadorizada}

\section{Introdução}

O Guia orientativo para dosimetria em tomografia computadorizada foi desenvolvido para auxiliar os usuários das câmaras de ionização do tipo lápis calibrado nos feixes padrões do LCl, na aplicação dos fatores indicados nos certificados de calibração fornecidos.

De maneira geral, o certificado de calibração é um documento emitido por laboratórios de calibração, quando é realizada a calibração do instrumento ou sistema de medição. Nos certificados são registrados os resultados obtidos, bem como as suas incertezas, além das condições ambientais durante a calibração.

A NBR ISO/IEC $17025^{36}$ determina o conteúdo mínimo que os certificados de calibração e relatórios devem possuir.

- Título

- Nome e endereço do laboratório

- Identificação única do certificado de calibração.

- Nome e endereço do cliente.

- Identificação do método utilizado.

- Identificação do instrumento calibrado.

- Data da realização da calibração

- Resultado da calibração com as unidades de medida. As unidades de medida devem estar relacionadas ao sistema internacional de unidades (SI). Caso o resultado seja declarado em unidade de medida que não pertença ao SI, um fator de conversão ou tabela correspondente deve estar contido no certificado ${ }^{36}$.

- Nome, função e assinatura ou identificação equivalente da pessoa autorizada para emissão do certificado de calibração. 
- Declaração de que os resultados se referem somente aos itens calibrados.

- Condições ambientais em que foi executada a calibração.

- Declaração da incerteza da medição

\section{Construção da curva de calibração}

As câmaras de ionização do tipo lápis possuem características de uso e geometria peculiares e por isso o método de calibração dessas câmaras é também diferenciado. Levando em consideração as peculiaridades da câmara lápis, no código de prática da Agência Internacional de Energia Atômica (AIEA) TRS $457^{7}$ foi estabelecida a metodologia para calibração em SSDL's onde a câmara é irradiada parcialmente.

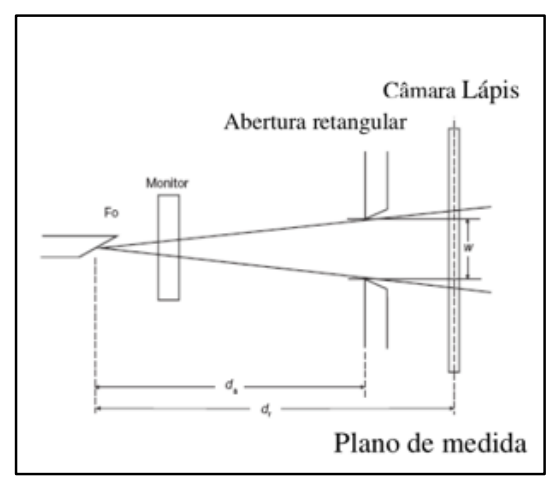

Exemplo de arranjo experimental utilizado para calibração de câmaras de ionização do tipo lápis, segundo a TRS $457\left(d_{\mathrm{a}}\right.$ : distância foco-colimador e $d_{r}$ : distância foco-medida).

Para a determinação do coeficiente de calibração $\left(N_{k, 1}\right)$, utiliza-se o método estabelecido no TRS 457, da irradiação parcial da câmara de ionização. Para encontrar os valores do produto Kerma no Ar - Comprimento $\left(P_{k, l}\right.$, dado em Gy.cm, e do Kerma no ar $\left(K_{a r}\right)$ em Gy, utiliza-se as equações a seguir:

$$
\begin{gathered}
P_{k, l}=M \cdot N_{k, l} \cdot K_{q} \\
K_{a r}=P_{k, l} / w
\end{gathered}
$$


Onde, M é a média das leituras; w é o comprimento irradiado da câmara; $K_{q}$ é o fator de correção para qualidade de radiação.

Os resultados no certificado de calibração são mostrados conforme o exemplo tabela a seguir:

\begin{tabular}{|c|c|c|c|c|c|c|}
\hline Qualidade & $\begin{array}{c}\text { Tensão } \\
(k V)\end{array}$ & $\begin{array}{c}\text { Camada } \\
\text { semirredutora } \\
\text { (mmAl) }\end{array}$ & $\begin{array}{c}\text { Unidade da } \\
\text { escala do } \\
\text { instrumento }\end{array}$ & $\begin{array}{c}\quad P_{k, l} \\
(G y . c m / m i n)\end{array}$ & $K_{q}$ & $\begin{array}{c}\text { Incerteza } \\
\text { (\%) }\end{array}$ \\
\hline RQT8 & 100 & 6,90 & & $x, x x x$ & 0,995 & \\
\hline RQT9 & 120 & 8,40 & $\mu G y / s e g$ & $x, x x x$ & 1,00 & $x$ \\
\hline RQT10 & 150 & 10,1 & & $x, x x x$ & 1,00 & \\
\hline
\end{tabular}

Com os fatores de calibração fornecidos no certificado, o usuário deve construir a curva de calibração de sua câmara com o $K_{q}$ função da CSR.

O gráfico abaixo é um exemplo de curva de calibração, construida com os fatores de correção para qualidade, mostrados na tabela acima.

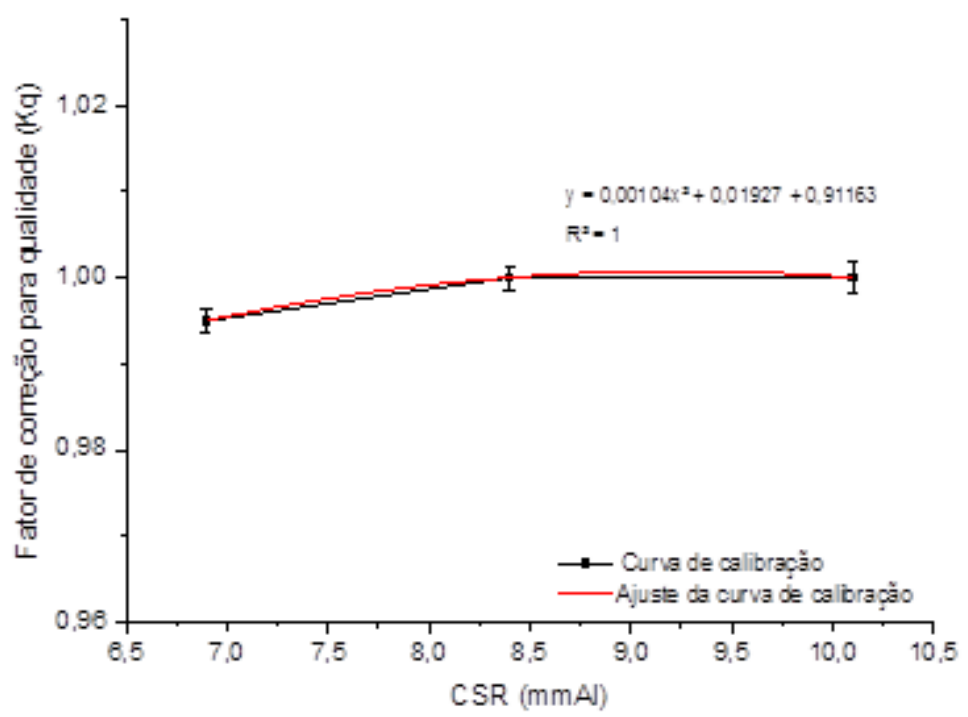

Para encontrar o fator de correção para qualidade adquado ao feixe, é necessário conhecimento prévio da CSR. Algumas metodologias para estimar os valores de CSR podem ser vistas na seção a seguir. 


\section{Metodologias para determinação de CSR}

\section{Metodologia de localização}

A metodologia de localização ${ }^{37}$ consiste em utilizar a técnica scout ou prescan para calcular o valor de CSR. Nessa Técnica o tubo de raios $X$ permanece parado enquanto a mesa realiza um movimento de translação.

É necessário desconsiderar a movimentação da mesa durante os testes. A geometria utilizada para o teste é parecida com a geometria utilizada para o cálculo em radiologia convencional. Utiliza-se de placas de alumínio de espessuras diferentes fixadas no gantry na direção do eixo do tubo de raios $\mathrm{X}$, como mostra a figura abaixo. A partir das médias do Kerma no ar obtidas sem filtração e com a adição dos filtros calcula-se a CSR pela Equação $(A)$.

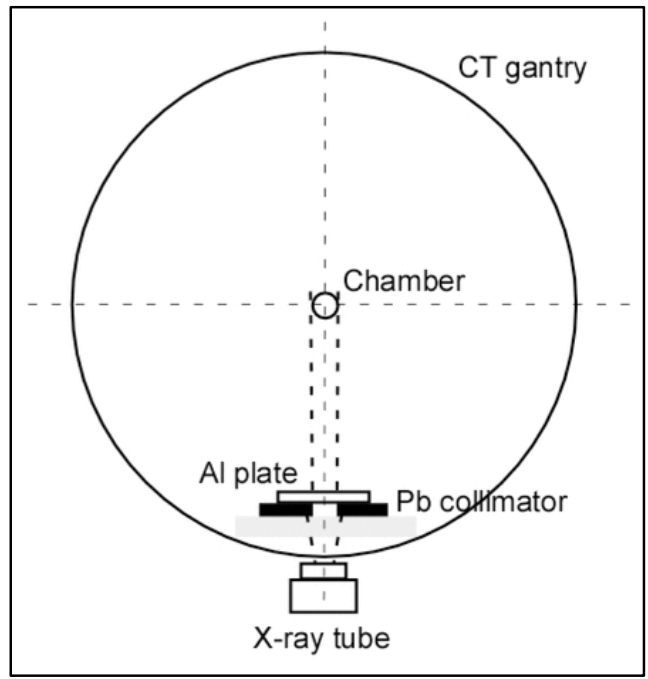

Esquema de arranjo montado para testes da metodologia de posicionamento para cálculo de CSR em tomógrafos. 


$$
C S R=\frac{x_{b} \cdot \ln \left(\frac{2 L_{a}}{L_{0}}\right)-x_{a} \cdot \ln \left(\frac{2 L_{b}}{L_{0}}\right)}{\ln \left(\frac{L_{a}}{L_{b}}\right)}
$$

Onde:

Lo: É a média dos valores de Kerma no ar medidos sem filtro.

La: É a leitura imediatamente superior a Lo.

Lь: É a leitura imediatamente inferior a Lo/2.

$X_{a}$ : É a espessura de alumínio correspondente a leitura $L_{a}$.

xb: É a espessura de alumínio correspondente a leitura $L b$.

\section{Metodologia do anel}

Diferente da metodologia de localização, nessa utiliza-se a técnica corte a corte de aquisição de imagens para realização dos testes ${ }^{37}$. Neste modo, seleciona-se o incremento da mesa ou pitch zero, para que não se movimente no interior do gantry durante a rotação do tubo de raios $\mathrm{X}$ e é feita apenas uma aquisição de imagem em modo axial. A mesa também serve de apoio para a câmara de ionização. Os anéis de alumínio são posicionados na abertura do gantry como pode ser visto na figura abaixo. A partir das médias do Kerma no ar obtidas sem filtração e com a adição dos filtros calcula-se a CSR pela Equação (A) mostrada na seção anterior. 


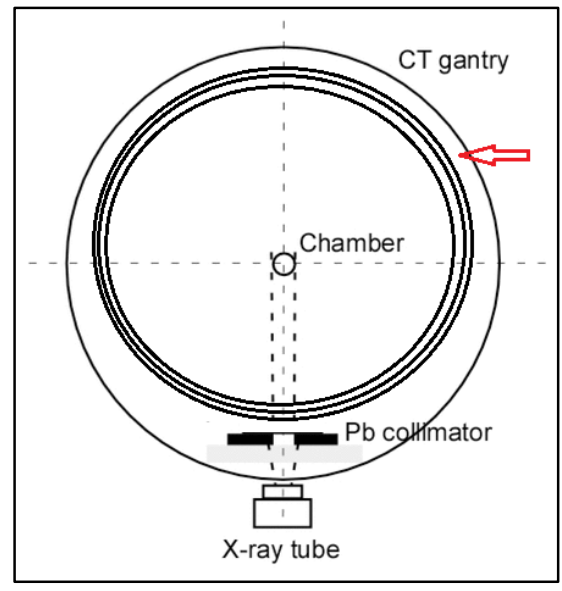

Esquema de arranjo montado para testes da metodologia do anel para cálculo de CSR em tomógrafos.

\section{Sistema Tandem}

Sistema composto por capas absorvedoras cilíndricas com dependências energéticas diferentes (AI e PMMA), utilizadas em conjunto com a câmara de ionização do tipo lápis. As figuiras abaixo, mostram as capas absorvedoras cilíndricas de Al e PMMA, utilizadas para compor 0 sistema Tandem.

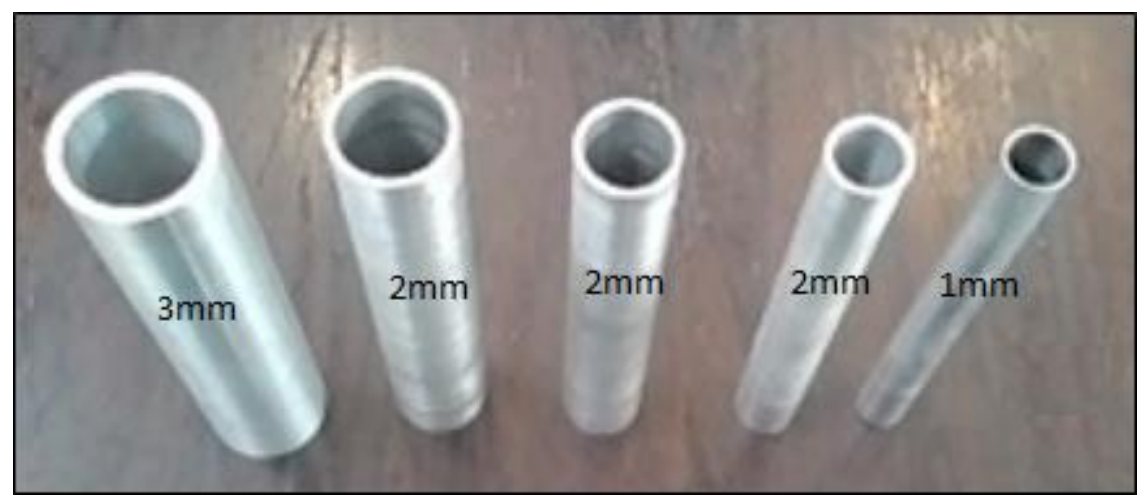

Capas absorvedoras cilíndricas de alumínio. Da esquerda para a direita: uma capa de $3 \mathrm{~mm}$, três de $2 \mathrm{~mm}$ e uma de $1 \mathrm{~mm}$. O comprimento das capas é de $150 \mathrm{~mm}$. 


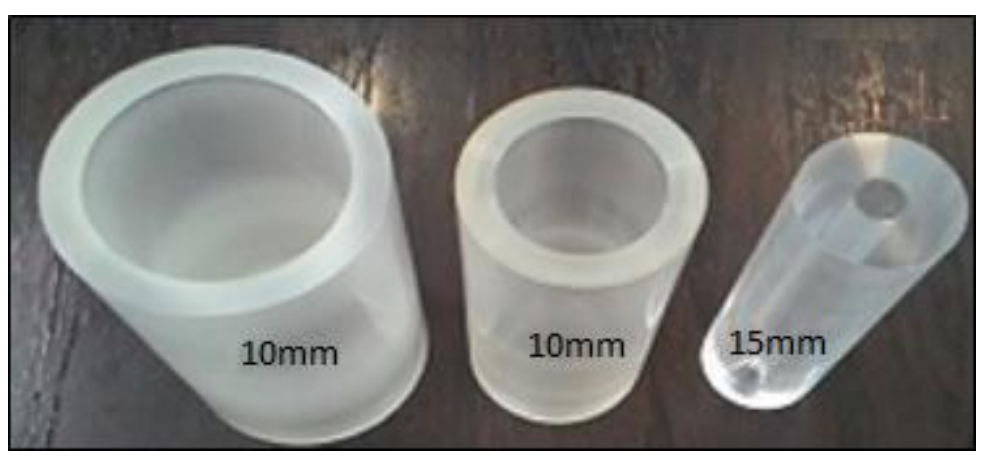

Capas absorvedoras de acrílico (PMMA). Da esquerda para direita: duas capas de $10 \mathrm{~mm}$ e uma de $15 \mathrm{~mm}$. O comprimento das capas é de $150 \mathrm{~mm}$.

Para formar um bom sistema Tandem, deve-se usar os conjuntos formados pela câmara de ionização do tipo lápis e a capa de $10 \mathrm{mmAl}$, com a câmara de ionazação do tipo lápis no ar; ou o conjunto formado pela câmara de ionização do tipo lápis com a capa absorvedora cilíndrica de $10 \mathrm{mmAl}$ e a câmara de ionização do tipo lápis com a capa absorvedora cilíndrica de 35mmPMMA.

As curvas Tandem relacionadas aos conjuntos citados podem ser vistas no gráfico abaixo:

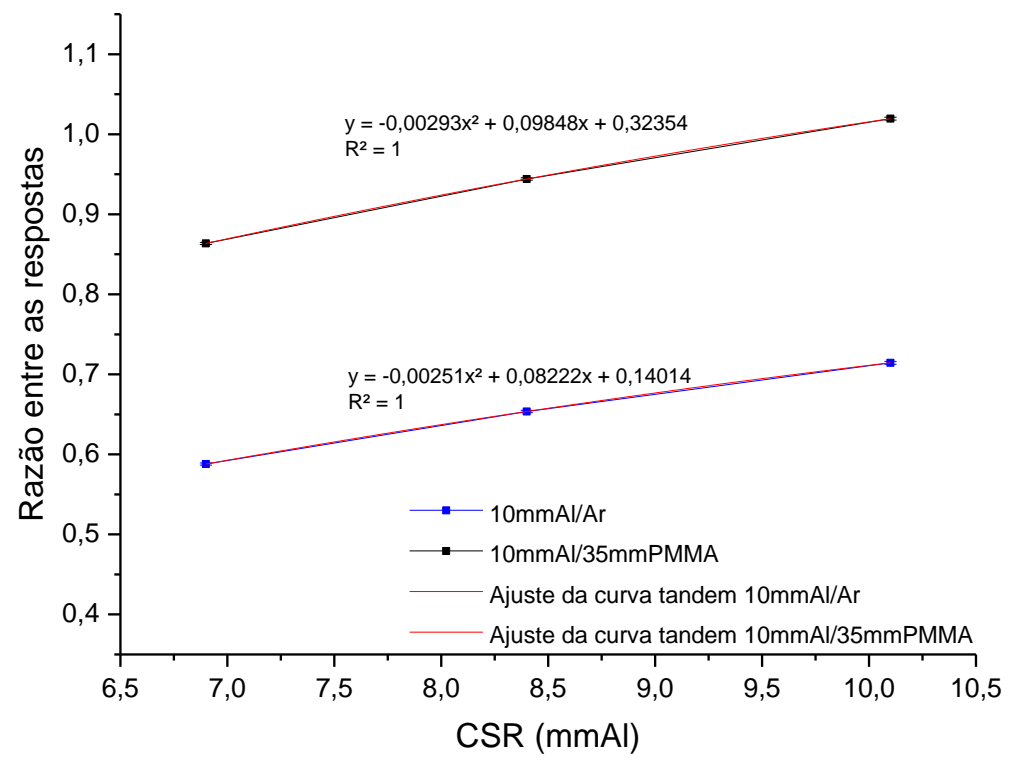

Curvas Tandem formadas pelos conjuntos $10 \mathrm{mmAl} / \mathrm{Ar}$ (em azul) e 10mmAl/35mmPMMA (em preto). 
Com a curva Tandem fornecida pelo laboratório de calibração, determina-se o valor estimado de CSR seguindo os passos abaixo.

1ํ Passo: Realizar leituras com as capas que compõem o sistema.

No exemplo que segue, foi escolhido o sistema formado pela câmara de ionização do tipo lápis com a capa absorvedora cilíndrica de $10 \mathrm{mmAl}$ e a câmara de ionização do tipo lápis com a capa absorvedora cilíndrica de 35mmPMMA.

Com o sistema posicionado conforme figura abaixo, deve-se obter a média das leituras corrigidas para as condições ambientais, com o primeiro conjunto que compõe o sistema Tandem, que no caso é o conjunto formado pela câmara de ionização do tipo lápis com a capa absorvedora cilíndrica de $10 \mathrm{mmAl}$.

O posicionamento do conjunto pode ser visto na figura abaixo.

Conjunto formado pela câmara de ionização e a capa absorvedora cilíndrica de $10 \mathrm{mmAl}$.

Em seguida, obter a média das leituras corrigidas para as condições ambientais com o segundo conjunto que compõe o sistema Tandem que no caso, é o sistema formado pela câmara de ionização do tipo lápis com a capa 
absorvedora cilíndrica de 35mmPMMA. Como as capas de PMMA são pesadas, deve-se utilizar um suporte de material radiotransparente para evitar peso e inclinação na câmara de ionização.

$\mathrm{Na}$ figura abaixo, pode ser visto o posicionamento do conjunto.foram utilizadas placas de isopor como suporte para o conjunto com a capa de 35mmPMMA.

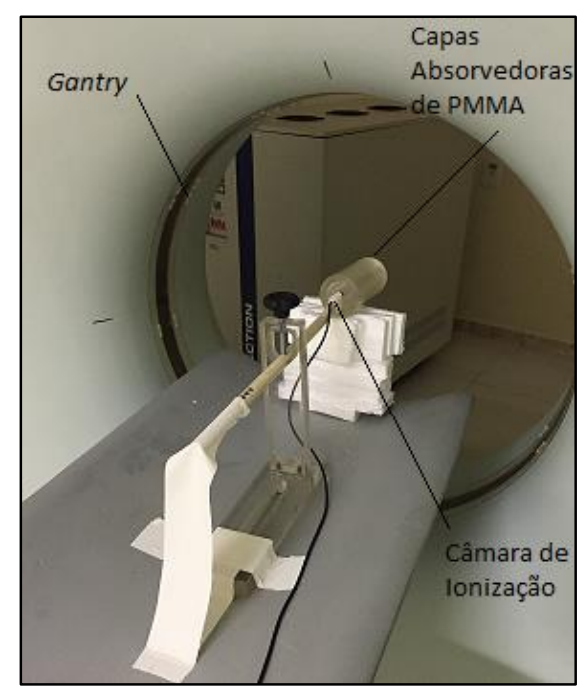

\section{2ำ passo: Calcular a razão entre as respostas dos conjuntos}

Com a média das leituras obtidas para os dois conjuntos, calcula-se a razão entre as respostas dos conjuntos que compõe o sistema Tandem, para o feixe clínico em seu sistema de TC. Conforme equação abaixo.

$$
\text { Razão entre as respostas }=\frac{M \text { do conjunto } C I-10 \mathrm{mAl}}{M \text { do conjunto } C I-35 \mathrm{mmPMMA}}
$$

Onde:

M é a média das leituras corrigida para as condções ambientais.

Com o valor encontrado, utiliza-se a equação da curva Tandem:

$$
y=-0,00251 x^{2}+0,08222 x+0,14014
$$


Para estimar o valor de CSR.

Ex: Para razão entre as respostas igual a 0,9965 o valor de CSR encontrado é de $8,6 \mathrm{mmAl}$.

3 Passo: Encontrar o $K_{q}$ adequado ao feixe

Para encontrar o $K_{q}$, utiliza-se a equação da curva de calibração da câmara de ionização do tipo lápis.

EX: Para a equação da curva igual a:

$$
y=0,00104 x^{2}+0,01927+0,91163
$$

O valor do $K_{q}$ para CSR igual a 8,6 é 1 .

Aplicando o fator de correção para qualidade $\left(K_{q}\right)$ nas medições:

Para determinar a taxa de kerma no ar $\left(K_{a r}\right)$, utiliza-se os fatores de correção para qualidade $\left(K_{q}\right)$ e coeficientes de calibração $(\mathrm{Nk}, \mathrm{l})$ fornecidos pelo laboratório, e multiplicados pelas leituras obtidas com a câmara de ionização como mostra a equação abaixo:

$$
K_{a r}=\mathrm{Nk}, \mathrm{l} \times K_{q} \times M
$$

Onde M é a leitura com a câmara de ionização. 


\section{REFERÊNCIAS}

1. GRONLUND, E. Calibration and clinical measurements in computed tomography - An evaluation of different dosimetric methods. Dissertação de Mestrado - University of Gothenburg, Gotenburg, 2013.

2. SAVI, M.B.M.B. Estudo do níveis de referência de diagnóstico para procedimentos de tomografia computadorizada no estado de Santa Catarina. Dissertação de Mestrado - Universidade Federal de Santa Catarina, Florianópolis, 2014.

3. SILVA, R.C.F. Tomografia computadorizada e risco de câncer. Inca, Rio de Janeiro. Disponível em < http://www2.inca.gov.br/wps/wcm/connect/740a09004f9218968a1bae81a5313a 21/12 artigo.pdf?MOD=AJPERES > Acesso em: outubro de 2015.

4. BRASIL, MINISTÉRIO DA SAÚDE. Diretrizes de proteção radiológica em radiodiagnóstico médico e odontológico. Portaria $\mathrm{n}^{\circ}$ 453. Agência Nacional de Vigilância Sanitária - Brasília. 1998.

5. BRASIL, MINISTÉRIO DA SAÚDE. Agência Nacional de Vigilância Sanitária. Radiodiagnóstico médico: mesempenho de equipamentos e segurança / ministério da saúde, Agência Nacional de Vigilância Sanitária. - Brasília: Ministério da Saúde, 2005.

6. POTIENS, M.P.A. Metodologia dosimétrica e sistema de referênciapara radiação x nível diagnóstico. Tese de Doutorado - Universidade de São Paulo. Instituto de Pesquisas Energéticas e Nucleares, São Paulo, 1999.

7. INTERNATIONAL ATOMIC ENERGY AGENCY. Dosimetry in diagnostic radiology: an international code of practice. Technical Reports Series $\mathbf{N}^{\circ}$ 457, IAEA, Vienna, 2007.

8. DIAS, D. M. Estabelecimento de um novo método de calibração de câmaras de ionização tipo lápis para dosimetria em feixes de tomografia computadorizada. Dissertação de Mestrado - Universidade de São Paulo. Instituto de Pesquisas Energéticas e Nucleares. São Paulo, 2010.

9. INTERNATIONAL ELECTROTECHNICAL COMMISSION. Medical diagnostic X-ray equipment - Radiation conditions for use in determination of characteristics. Revisão 2005. Genève, 2005. 
10. KENNEY, G.N. ; CAMERON, J.R. $X$ ray beam quality measurement utilizing TL dosimeters Progress Report, AEC contact no AT 11-1-1105-TID$19112,1963$.

11. GORBICS, S.G.; ATTIX, F.H. LiF and CaF2:Mn thermoluminescent dosimeters in Tandem. Int.J.Appl.Radiat. Isot., v.19, n.1, p.81-89, 1968.

12. GALHARDO, E.P. Caracterização de sistema Tandem de câmaras de ionização comerciais para dosimetria de feixes re raios $X$ (nível radioterapia) Dissertação de Mestrado - Universidade de São Paulo. Instituto de Pesquisas Energéticas e Nucleares, São Paulo, 1998.

13. MAIA, A.F. Padronização de feixes e metodologia dosimétrica em tomografia computadorizada. Tese de Doutorado- Universidade de São Paulo. Instituto de Pesquisas Energéticas e Nucleares, São Paulo, 2005.

14. RIO, P.B. Estudo de metodologia para a obtenção de camada semirredutora em tomografia computadorizada. Trabalho de Conclusão de Curso - Universidade de São Paulo, São Paulo, 2006.

15. FONTES, L. P.; POTIENS, M.P.A. Avaliação da dependência energética de câmaras de ionização do tipo lápis calibradas em feixes padrões de tomografia. In: CONGRESSO BRASILEIRO DE METROLOGIA, 8, 2015, Bento Gonçalves. Anais eletrônicos, Bento Gonçalves: Metrologia, 2015. Disponível em: www.metrologia2015.org.br/anais/. Acesso em 20 de abril de. 2016.

16. GRANDINETTI, H. As primeiras radiografias. Revista Imagem, v. 30(2), p. 61-69, 2008.

17. SEERAM. Computer tomography physical principles, clinical applications, and quality control. 2.ed. Philadelphia: W. B. Saunders, 2001. $1270 p$

18. BRENNER, D. J.; HALL, E. J. Computed Tomography - An Increasing Source of Radiation Exposure. The new England Journal of Medicine. England, April, 2011.

19. GARIB, D. G. JR. R. R.; RAYMUNDO, M. V.; RAYMUNDO, D. V.; FERREIRA, S. N. Tomografia computadorizada de feixe cônico (Cone beam): entendendo este novo método de diagnóstico por imagem com promissora aplicabilidade na Ortodontia. R. Dental Press Ortodon Facial, Maringá, v. 12, n. 2, p.139-156, 2007.

20. DA NÓBREGA, A. I. Manual de tomografia computadorizada. São Paulo.

Ed. Atheneu, p. 4-8, 2005. 
21. BUSHONG, S. C. Ciência Radiológica para tecnólogos Física, Biologia e Proteção. 9.ed., [tradução Sandro Martins Dolghi... et al.] Rio de Janeiro: Elsevier, 2010. 709 p. cap. 23, p. 374.

22. Boletim Brasileiro de Avaliação de Tecnologia em Saúde - BRATS. A tomografia computadorizada de múltiplos detectores no diagnóstico da doença arterial coronariana. Ano III, n. 4, p. 1-9, 2008.

23. HEIKEN, J. P.; PETERSON C.M.; MENIAS C.O. Virtual colonoscopy for colorectal cancer screening: current status. International Cancer Imaging Society, v. 5, p. 133-139, 2005.

24. WOLBARST, A. B., Physics of Radiology, Appleton \& Lange, Connecticut, EUA, 1993.

25. ROTHENBERG, L. N.; PENTLOW, K. S. Radiation Dose in CT. Radiographic. v.12, n. 6, p.1225-1246, 1992.

26. ZOETELIEF, J., PERNICKA, F., CARLSSON, G. A., DANCE, D.R., DeWERD, L.A., DREXLER, G., JÄRVINEN, H., KRAMER, H.-M., NG, K.-H. Dosimetry in diagnostic and interventional radiology: International Commission on Radiation Units and Measurements an IAEA Activities. Standards and Code of Practice in Medical Radiation Dosimetry. Proceedings of an International Symposium, Vienna, 25-28 November, 2002.

27. INTERNATIONAL COMMISSION ON RADIOLOGICAL PROTECTION. Recommendations of the Internacional commission on Radiological protection, Publicaton 103, Oxforf, Pergamon, 2007.

28. THE INTERNATIONAL COMISSION ON RADIATION UNITS AND MEASUREMENTS. Fundamental quantities and units for ionizing radiation. Report 85, Oxford University Press, 2011.

29. KNOLL, G.F. Radiation detection and measurements. $1^{\underline{a}}$ Ed. New York. John Wiley e Sons. 754p, 1989.

30. OLIVEIRA, M.L. Desenvolvimento de um sistema de referência e de uma metodologia para calibração de aplicadores oftálmicos utilizados em braquiterapia. São Paulo : 2005. Tese (Doutoramento) - Instituto de Pesquisas Energéticas e Nucleares/Univ. de São Paulo. 
32.

INMETRO

disponível

em

<http://www.inmetro.gov.br/metcientifica/index.asp > acesso em março de 2016.

33. RODRIGUES, L.N. Metrologia das Radiações lonizantes, Revista Brasileira de Física Médica.;3(1):69-75, 2009.

34

\section{INMETRO}

disponível

em

<http://www.inmetro.gov.br/inovacao/publicacoes/vim 2012.pdf> acesso em março de 2016.

35. OKUNO, E.; YOSHIMURA, E. M. Física das radiações. São Paulo, SP.: Oficina de textos, 2010.

36.

UFPR

http://www.metrologia.ufpr.br/pdfs/MetroNot/Conteudo.Minimo.dos.Certifica dos.de.Calibracao.pdf acesso em maio 2016.

37. RIO, P.B. Estudo de metodologia para a obtenção de camada semirredutora em tomografia computadorizada. Trabalho de Conclusão de Curso - Universidade de São Paulo, São Paulo, 2006.

38. INSTITUTO NACIONAL DE METROLOGIA, NORMALIZAÇÃO E QUALIDADE INDUSTRIAL (INMETRO) Vocabulário internacional de termos fundamentais e gerais de metrologia. 3rd Ed. Rio de janeiro: INMETRO, 2003.

39. INSTITUTO NACIOMAL DE METROLOGIA, NORMALIZAÇÃO E QUALIDADE INDUSTRIAL (INMETRO), Guia para expressão da incerteza de medição, Rio de Janeiro, 2003. 